\title{
Facing China's Coal Future
}

\author{
Prospects and Challenges \\ for Carbon Capture and Storage
}


The International Energy Agency (IEA), an autonomous agency, was established in November 1974. Its primary mandate was - and is - two-fold: to promote energy security amongst its member countries through collective response to physical disruptions in oil supply, and provide authoritative research and analysis on ways to ensure reliable, affordable and clean energy for its 28 member countries and beyond. The IEA carries out a comprehensive programme of energy co-operation among its member countries, each of which is obliged to hold oil stocks equivalent to 90 days of its net imports. The Agency's aims include the following objectives:

- Secure member countries' access to reliable and ample supplies of all forms of energy; in particular, through maintaining effective emergency response capabilities in case of oil supply disruptions.

- Promote sustainable energy policies that spur economic growth and environmental protection in a global context - particularly in terms of reducing greenhouse-gas emissions that contribute to climate change.

- Improve transparency of international markets through collection and analysis of energy data.

- Support global collaboration on energy technology to secure future energy supplies and mitigate their environmental impact, including through improved energy

efficiency and development and deployment of low-carbon technologies.

- Find solutions to global energy challenges through engagement and dialogue with non-member countries, industry, international organisations and other stakeholders.

IEA member countries:

(C) OECD/IEA, 2012

\section{International Energy Agency}

9 rue de la Fédération 75739 Paris Cedex 15, France

www.iea.org

\section{Spain}

Sweden

\section{Switzerland}

Turkey

\section{United Kingdom}

United States 


\section{Table of Contents}

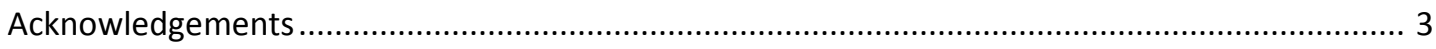

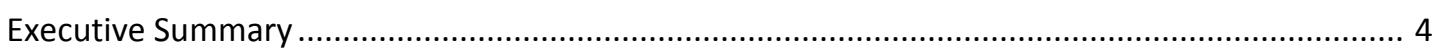

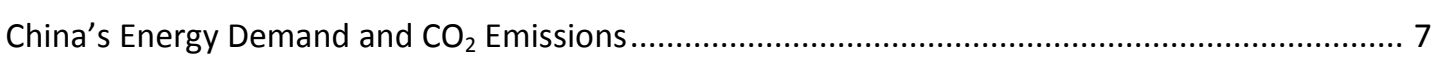

Energy demand and continued reliance on coal .................................................................. 7

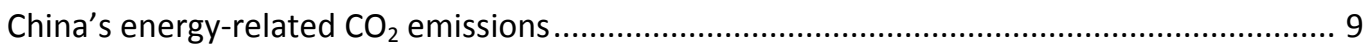

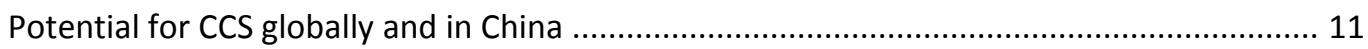

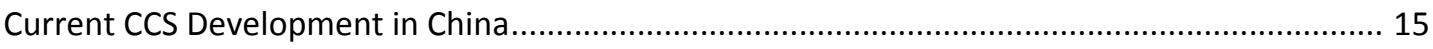

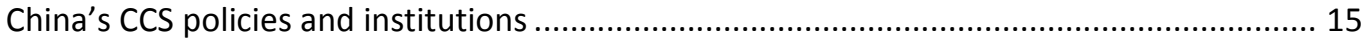

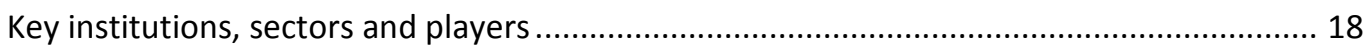

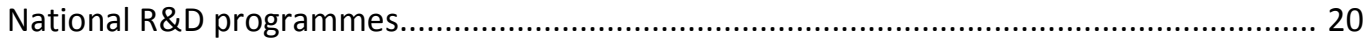

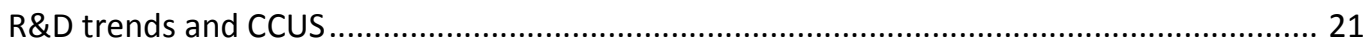

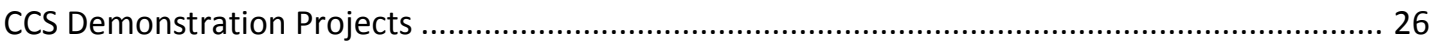

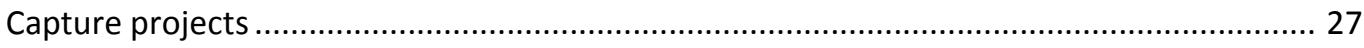

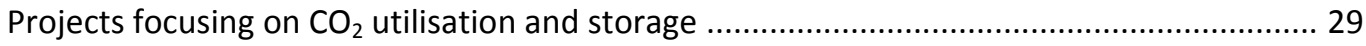

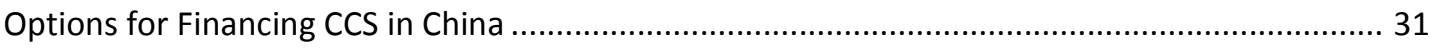

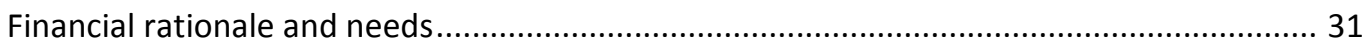

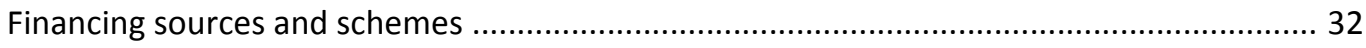

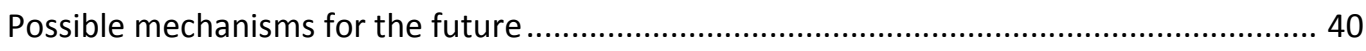

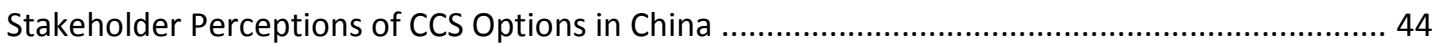

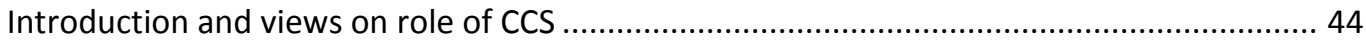

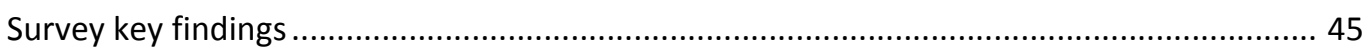

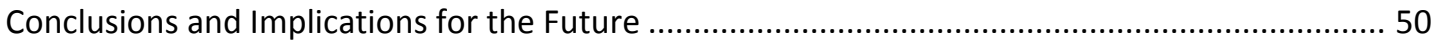

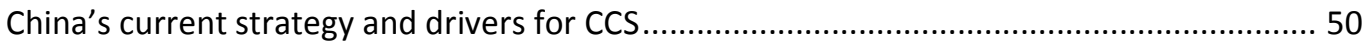

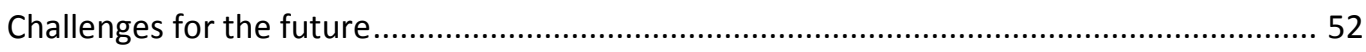

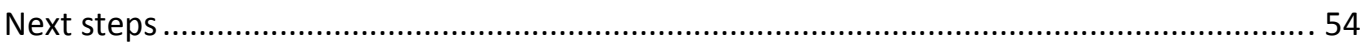

Abbreviations, acronyms and units of measure

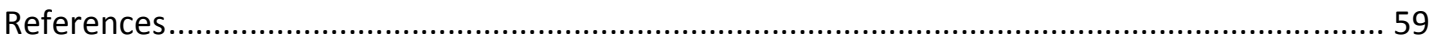

List of figures

Figure 1 World Energy Outlook New Policies Scenario primary energy demand until 2035 ............ 7

Figure 2 New Policies Scenario, Coal demand in China by sector, 2000-35 ................................... 8

Figure 3 Energy-related $\mathrm{CO}_{2}$ emissions by region, 2008-2010 .................................................... 9

Figure 4 Regional distributions of $\mathrm{CO}_{2}$ emissions and sources from coal combustion 2009 .......... 10

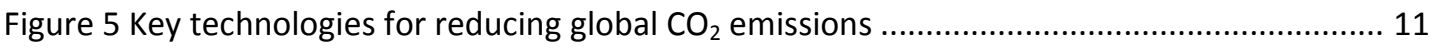

Figure 6 CCS deployment pathway as estimated in 2009 IEA Technology Roadmap ...................... 12

Figure 7 Chinese government institutions involved in energy policy and administration.............. 17 
Figure 8 Typical process flowsheet of standard coal chemical industry in China .......................... 22

Figure $9 \mathrm{CO}_{2}$ emissions of fuels including coal chemical products $\mathrm{w} /$ and w/out CCS ................... 23

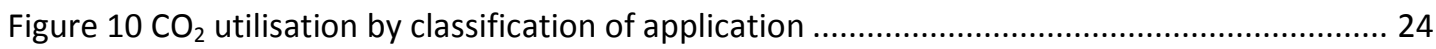

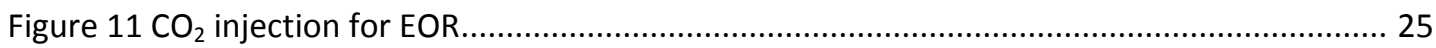

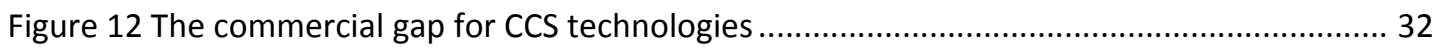

Page | 2 Figure 13 Stakeholder ranking of key factors for CCS development in China.............................. 45

Figure 14 Stakeholder ranking on priorities for capture technology ............................................. 46

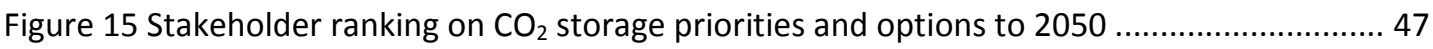

Figure 16 Stakeholder views on industry readiness for CCS in China ......................................... 48

Figure 17 Stakeholder ranking on China's near-term CCS technical development priorities......... 48

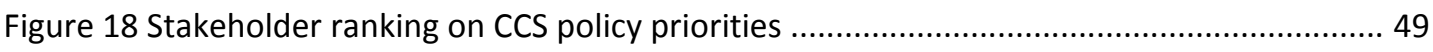

Figure 19 Stakeholder views on barriers to cross-sector co-operation ....................................... 49

\section{List of tables}

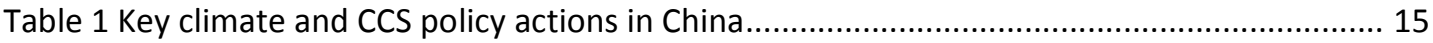

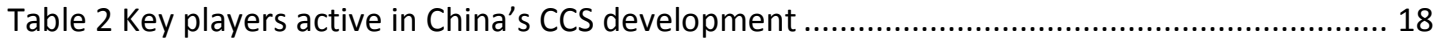

Table 3863 Programme planned IGCC and CTL demonstration plants ........................................... 20

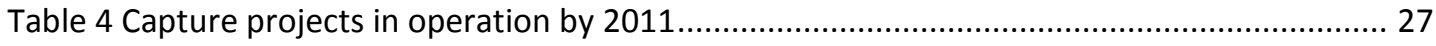

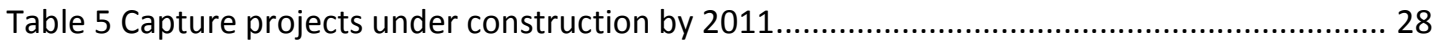

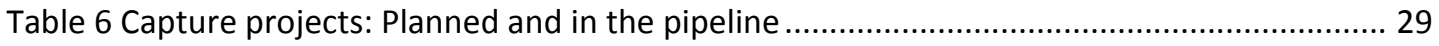

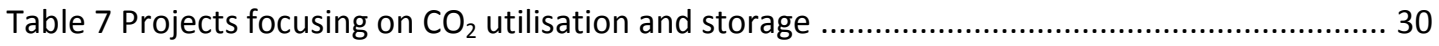

Table 8 Financial scenarios for IGCC and supercritical power plus CCS in China ............................. 34

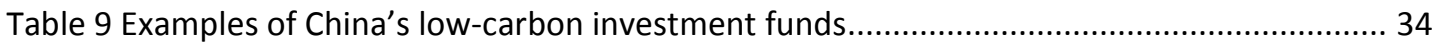

Table 10 Examples of sources of financing for key CCS demonstration projects ........................... 36

List of boxes

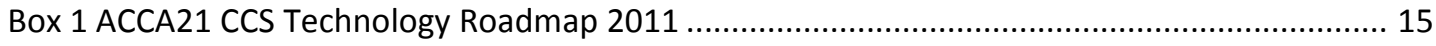

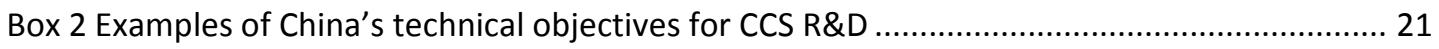

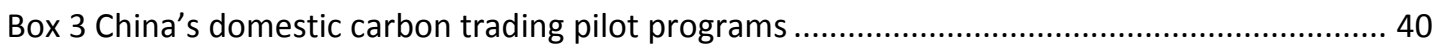

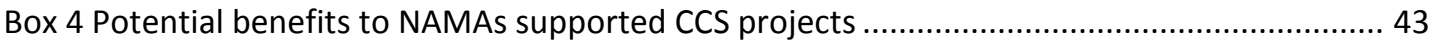

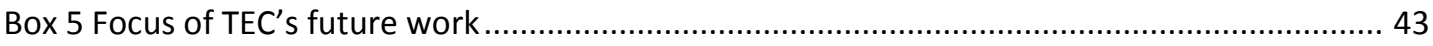

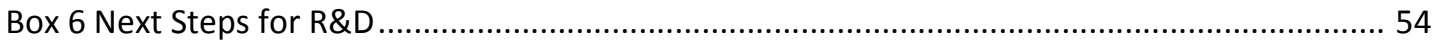




\section{Acknowledgements}

This paper is the first IEA analysis that focuses on country-specific trends, opportunities and challenges for carbon capture and storage (CCS). It follows previous IEA publications on CCS and studies of cleaner coal and advanced coal technologies. The paper benefitted from significant contributions and support from the China Coal Information Institute (CCII) of the State Administration of Work Safety (SAWS) and The Climate Group China.

In October 2010, the IEA, CCII and The Climate Group China jointly organised a meeting in Beijing to identify the status of CCS technology development in China and explore stakeholder views on CCS development and future options for CCS deployment. Based on that workshop and follow-up interviews and dialogue with key stakeholders in China, the IEA developed this information paper with input and collaboration from CCII, The Climate Group China and several independent reviewers. The process and consultation for the report included interviews, questionnaires, desktop research and a review of information from authorities, publications and conference materials. Questionnaires were distributed to government, research institutions, enterprise and international organisations. Both questionnaires and interviews asked about stakeholder viewpoints and attitudes towards CCS; current issues and understanding of CCS technology, technical feasibility and R\&D initiatives; options for financing and commercialisation of CCS technologies; and related policy and regulatory considerations.

The IEA thanks its collaborator, the China Coal Information Institute, under the leadership of President Huang Shengchu, for the considerable input that CCII staff provided for this report. CCII staff members Liu Wenge and Sun Xin managed this collaboration, with the capable assistance of Han Jiaye, Wu Jinyan, Zhao Yingchun and Zhang Yan. Wu Changhua and Lorraine Yin from The Climate Group China also provided important input and collaboration on this project. Consultants Pamela Tomski and Craig Hart contributed to the sections on financing options for CCS in China. Dr. Peng Sizhen, Administrative Center for China's Agenda 21, Dr. Andrew Minchener, Clean Coal Centre, Dr. Lei Zhu, Center for Energy and Environmental Policy, Chinese Academy of Sciences also provided expert review and comment on this work.

The authors would also like to thank IEA contributors Bo Diczfalusy, Director of the Sustainable Energy Policy Directorate, Ulrich Benterbusch, Head of the Office of Global Energy Policy and Juho Lipponen, Head of the IEA CCS unit and Jonathan Sinton, China Programme Manager for their guidance. IEA staff, Keith Burnard, Dennis Volk, and Julian Smith provided valuable comments, information and suggestions in the development of this paper. Julie Jiang, Tom Kerr, Brendan Beck, and Brian Ricketts, and the Office of Legal Counsel also played an instrumental role in the development of this work, and particular thanks go to the Communications Information Office and the publications team. 


\section{Executive Summary}

According to IEA analysis, if there are no major policy changes, carbon-intensive coal and other fossil fuels will continue to play a significant role in meeting future energy needs, in China and globally. Carbon capture and storage (CCS) is one of the technology options available to reduce

Page $\mid 4$ carbon dioxide $\left(\mathrm{CO}_{2}\right)$ emissions from the use of fossil fuels. CCS offers the opportunity to meet climate change objectives while providing energy security, as part of a portfolio of options including energy efficiency, renewable energy, nuclear energy, more efficient coal technologies and fuel switching from coal to gas. To meet the energy challenges of associated $\mathrm{CO}_{2}$ emissions, global deployment of all these technologies will be necessary to achieve a more sustainable future.

China's recent rapid economic development has been accompanied by significant environmental challenges, and in the future the country will need to continue to consider various options for mitigating the climate change impacts of energy use. Based on IEA analysis, CCS can provide large-scale abatement in China, which continues to depend heavily on fossil fuels both in the power sector and across industry sectors including cement, iron and steel, chemicals, biomass and fuel transformation, and gas processing. In many industries, such as iron and steel, cement, gas processing or the refining sector, CCS is the only realistic technology apart from energy efficiency improvements which will be available to achieve deep emissions cuts.

This paper discusses the status of CCS in China, providing updates on past activities in R\&D and on current projects, and an overview of potential and challenges for CCS development in China. It explores China's energy and emission trends and pathways and the potential role for CCS, and analyses China's current CCS-related activities and policies and options for financing of CCS. The paper also provides perspectives on CCS from various Chinese stakeholders, examples of key CCS activities with details on specific projects, and information on the regulatory and policy environment and international co-operation related to CCS in China. Globally, CCS for facilities using natural gas must be considered, but this report is concerned mainly with technologies using coal, which will remain China's dominant fuel for some years to come.

As with other countries evaluating large-scale deployment of CCS technologies, China must consider many complex issues, including significant investment needs for demonstration projects, regional development priorities, coal-sector employment, the coal-development chain, political concerns, centralisation of power generation, security of supply, and long-term trade and commodities markets. Another set of issues relates to the technical sophistication and human resource capacity required to build the CCS industry, as well as the competitive advantages of various related technologies and limitations in understanding storage potential. A strategy that considers accurate local costs of CCS development, potential for retrofits and the time horizon for the large deployment of new coal-fired power generation will be an important factor in assessing a nationally appropriate deployment strategy for CCS. Another driving factor for CCS development is China's potential to become a significant supplier of $\mathrm{CO}_{2}$ capture technology alongside initiatives to export advanced supercritical coal-fired boilers abroad, given China's cost advantages compared to suppliers in OECD member countries.

Activities on CCS in China have evolved from an initial focus on research and development and exploration of technical potential of CCS towards the demonstration of CCS technologies on various scales with initial planning of larger-scale pilot projects. While large-scale demonstration $\left(>1 \mathrm{Mt} \mathrm{CO}_{2}\right.$ annually) of integrated CCS projects is still at an early and/or planning stage, China has acquired significant knowledge and technical expertise in CCS pilot projects, integrating various mature and developing technologies that may facilitate demonstration and potential deployment 
of CCS. In particular, China is focusing on developing opportunities for utilisation of $\mathrm{CO}_{2}$ to drive and support demonstration of carbon capture utilisation and storage technologies (CCUS). China places emphasis on developing opportunities for utilisation of $\mathrm{CO}_{2}$ to drive and support further deployment of CCS. Note that throughout this paper we will use the term "CCS" in general, and will refer to "CCUS" when the activity in question has an emphasis on $\mathrm{CO}_{2}$ utilisation.

\section{Key findings and conclusions:}

- The pace of China's economic growth and the resulting increase of emissions over the next ten years, together with China's commitment to addressing the problem of global climate change, is likely to bring CCS technologies into focus with crucial actions for deployment necessary between 2020 and 2030. The pace of CCS development and deployment in China will have a significant impact on the overall global potential of CCS to play its role in mitigating $\mathrm{CO}_{2}$ emissions. The IEA BLUE Map Scenario, which seeks to limit greenhouse-gas (GHG) emissions to 450 parts per million ( $\mathrm{ppm}$ ), points to including CCS in a portfolio of mitigation options and technologies as part of a low-cost option in which CCS provides $19 \%$ of total $\mathrm{CO}_{2}$ emissions reductions by 2050. The role of China and other emerging and developing countries is fundamental to meeting the challenges identified in this scenario.

- China has several technology demonstration projects with aspects of CCS, either in operation, under construction or planned, and the national government continues to support technical development and research into feasibility of CCS on a larger scale. However, at top levels of China's policy-making process, co-ordination among agencies, regulatory bodies and steering groups will be essential to further develop this area and determine the most efficient path for CCS technology development. Evaluating alternative and appropriate actions for China's context, understanding the importance of timely action and assessing the lock-in effects of technology choices are critical in responding to rapidly accelerating $\mathrm{CO}_{2}$ emissions in China and to the global effort to deploy climate change mitigation tools.

- In addition to energy security and the desire to develop technology, China's actions on CCS are driven by global climate policy considerations and the Chinese government's national climate policy and sustainable development objectives. Given limited economic incentives for CCS projects in China, as in most parts of the world, additional international mechanisms are likely to be required for early deployment of CCS. An emissions trading system may constitute a major financing platform for GHG emissions reductions in the long term. However, the future of the Clean Development Mechanism (CDM) framework and of CCS within that structure requires further analysis, although, as the largest beneficiary of CDM projects and source of credits, China stands to gain from its inclusion. International climate financing through the Green Climate Fund (USD 100 billion per year, currently being negotiated under the UNFCCC) could potentially facilitate the development of CCS in China and other developing countries during the learning-curve phase.

- China's move towards CCUS is underpinned by early experiences with enhanced oil recovery (EOR) and enhanced coalbed methane (ECBM) projects. However, safety, storage permanence and long-term monitoring will be critical, and doubts remain whether all such utilisation projects can meet the inherent objectives of CCS as a climate change mitigation tool. The economics, capacity and technology development pathway appropriate for China's CCUS objectives merit more analysis. They must be clarified in the context of a larger lowcarbon energy strategy that references CCS and takes into account co-benefits, environmental 
impacts and other externalities across technologies, and the life cycle of the coal development process.

- Clarification on cost estimates and comparative capture routes relevant to China's case, along with advanced coal technology and cleaner pathways, such as efficiency improvements, retrofits and plant upgrades, will help to clarify strategic priorities towards CCS research, development and demonstration. China's development and progress on other coal technologies in the next 10 to 20 years (including coal-to-liquids, coal-to-chemicals, and integrated gasification combined cycle [IGCC]) will be important to determine policy direction for related CCS applications, primarily with regard to safety, security and environmental impact across the coal development chain, and long-term demand impact on domestic resources and markets.

- Survey results point to the key focus and challenge of further demonstrating economic feasibility and clarifying industrial and support policies to address cost concerns if CCS pilot projects and further demonstration will be deployed. Current R\&D projects in China focus on post-combustion capture and IGCC with initial plans for future storage, though, however these projects tend to explore $\mathrm{CO}_{2}$ utilisation applications. Stakeholders indicate that, until 2020 , project demonstration may likely focus on post-combustion processes and limited to those projects that provide a reference for government decision-making on future CCUS policy emphasising aspects of utilisation. However, China's comparatively low labour and construction costs suggest that it may be well suited for early commercial demonstration across technologies through joint international programmes in advanced technologies that can be deployed in OECD countries.

- China is already engaged in an ambitious effort on CCS research, development and demonstration. It has the right conditions and political will to enhance these efforts provided that international support and global climate policy also expand. Several international co-operative initiatives, development banks and international institutions have sought to develop capacity-building and knowledge-sharing initiatives, including networks, fora, workshops, joint research programmes and collaborative technology-development programmes. For example, the CERC, NZEC and related research programmes have made significant inroads in clarifying and developing best practices in these areas, and future multilateral and bilateral projects should consider the importance of these agreements from the outset. 


\section{China's Energy Demand and $\mathrm{CO}_{2}$ Emissions}

\section{Energy demand and continued reliance on coal}

In the past decade, China has experienced accelerated industrial and urban development, with strong growth of gross domestic product (GDP). This has led to an unprecedented demand for energy in concentrated population and industrial centres, resulting in a doubling of China's primary energy demand from 1108 million tonnes of oil equivalent (Mtoe) in 2000 to over 2271 Mtoe in 2009 (IEA, 2011a). China is the largest energy consumer in the world, ahead of the United States, which consumed some 2160 Mtoe in 2009.

China's economic growth is projected to continue and to drive increasing energy consumption for several decades (Figure 1). By 2035, China is likely to see a large increase in demand for primary energy, perhaps up by nearly $70 \%$ from the present levels (IEA, 2011a). This demand is likely to be met by increasing use of fossil fuels along with other sources, such as nuclear and renewable.

Figure 1 World Energy Outlook New Policies Scenario primary energy demand until 2035

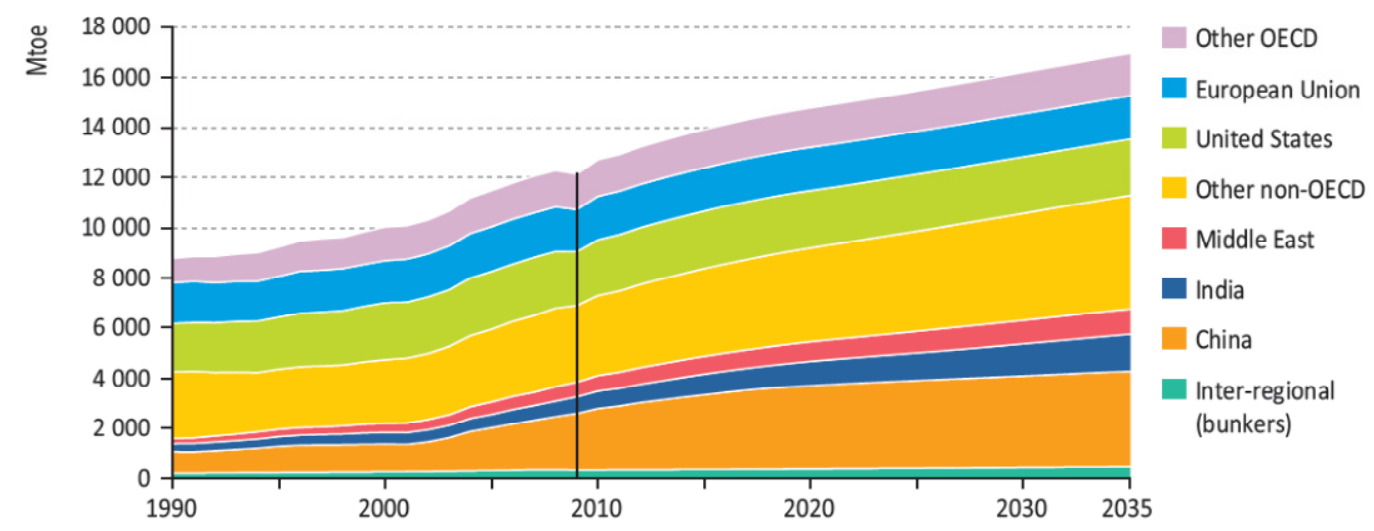

Source: IEA, 2011a.

As a result of this rapid economic development, China faces significant environmental challenges. In its development planning, the Chinese government is placing greater emphasis on scientific development and consideration for environment and sustainability as noted in the December 2011, National 12th Five-Year Plan for Environmental Protection (2011-2015). China's five-year plans and related industrial and energy policies increasingly focus on developing a low-carbon economy and set out relevant targets. In practice, this has led to significant investment across a range of clean technologies and resource efficiency measures. Related policy development and planning has demonstrated that future development objectives and technology considerations will take into account climate change mitigation efforts and other environmental impacts and, critically, will acknowledge China's stressed resources.

The challenge is complex, as use of coal has been a cornerstone of China's unprecedented economic growth. China's energy supply has been based on increased use of coal, both domestic and, to some extent, imported. Over the last decade, more than $80 \%$ of the global increase in coal demand came from China alone. Its share of global coal demand rose from $27 \%$ in 2000 to $47 \%$ by 2010 , with coal use more than doubling to 2350 Mtoe. Based on preliminary estimates for 2010, China accounted for nearly half of global coal use (IEA, 2011a). 
In 2009, China consumed more coal than the next 16 biggest consumers combined (Australia, Canada, Germany, India, Indonesia, Japan, Kazakhstan, Korea, Poland, Russia, South Africa, Taiwan, Turkey, Ukraine, the United Kingdom and United States). In 2010, coal supplied nearly $67.1 \%$ of China's total primary energy supply. It is utilised across key sectors including power generation, chemicals and transportation fuels. In the power sector, $78.7 \%$ of China's electricity was produced from coal in 2009. As for coal production, China's proven recoverable domestic reserves represent $19 \%$ of world coal reserves, behind the United States $(23 \%)$, but not Russia (16\%) (IEA, 2011b).

Coal is also expected to remain the dominant fuel source in China for the coming two or three decades, driven largely by demand in the power sector. It is, however, projected that the demand for coal in both industry and power will stabilise after 2020 (Figure 2).

Figure 2 New Policies Scenario, Coal demand in China by sector, 2000-35

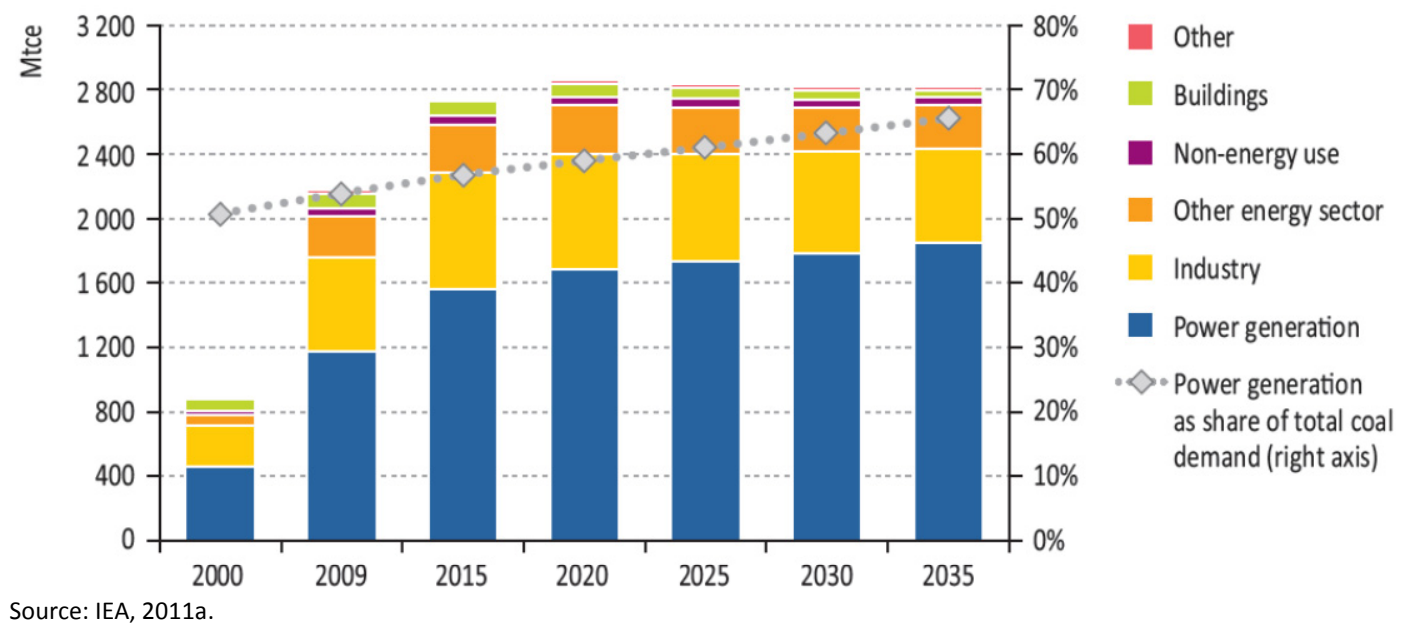

According to the World Energy Outlook 2011 (IEA, 2011a), coal is likely to remain the cornerstone of the electricity mix, although the share of power generation from coal is projected to drop from $79 \%$ in 2009 to $56 \%$ in 2035, with expected increases in the use of renewable energy, nuclear and hydropower. However, under the BLUE Map $450 \mathrm{ppm}$ of $\mathrm{CO}_{2}$ case scenario, which sets the goal of halving global energy-related $\mathrm{CO}_{2}$ emissions by 2050 (compared to 2005 levels) and limits global temperature rise to $2-3^{\circ} \mathrm{C}$ by 2050 , coal demand would need to decrease by more than half by 2035.

The Chinese government's strategic goal to reduce dependence on expensive imported natural gas and petroleum has been a major factor driving this reliance on coal. This strategy has been central to China's economic growth, energy security and macroeconomic stability (Morse, Rai and $\mathrm{He}, 2009)$. China's energy security concerns have accelerated coal power plant expansion, with large investments in more efficient, centralised new-generation coal power plants. China is also investing heavily in renewable energy, including the world's fastest growing wind energy sector (ERI, October 2011). Given the increase in alternatives to fossil fuels, increased energy efficiency, investment in new nuclear facilities and the switch to lower-emissions fossil fuels (such as coalbed methane [CBM] and natural gas), China may significantly reduce its energy intensity and emissions over time. However, according to the WEO New Policies Scenario, the overall growth in demand will still lead to a significant increase in emissions (IEA, 2011a). 


\section{China's energy-related $\mathrm{CO}_{2}$ emissions}

In 2010, China had the highest $\mathrm{CO}_{2}$ emissions from energy of all countries (Figure 3 ). With its growing population, now over 1.3 billion people, and energy-intensive, export-oriented economy, China is set to dominate global energy and $\mathrm{CO}_{2}$ emissions growth to 2035 and beyond.

Figure 3 Energy-related $\mathrm{CO}_{2}$ emissions by region, 2008-2010

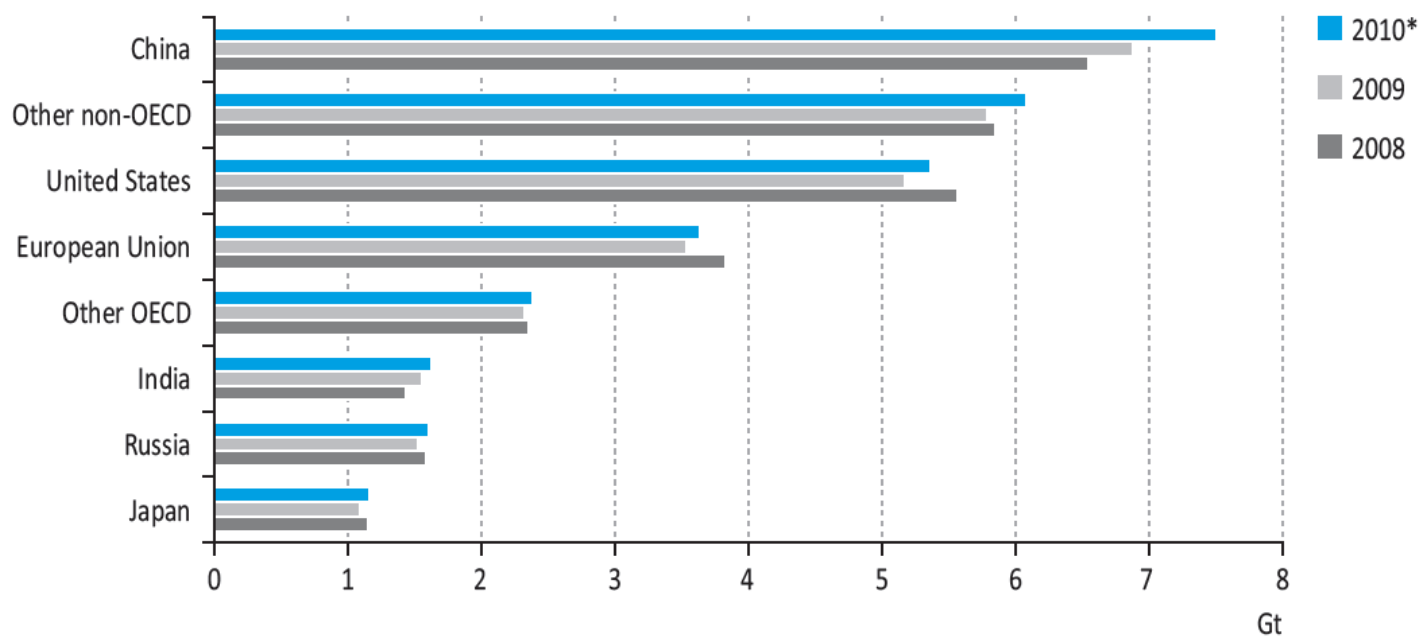

*estimated

Source: IEA, 2011a.

China's per-capita energy use is still just one-third of the OECD average. As per-capita energy demand continues to rise, this gap is expected to shrink rapidly, placing China's $\mathrm{CO}_{2}$ emissions on a steep upward path that will dominate global emissions. China's energy-related $\mathrm{CO}_{2}$ emissions may increase from the current 7.5 gigatonnes per year (Gt/yr) to over $10 \mathrm{Gt} / \mathrm{yr}$ by 2035, an increase of over 35\% (IEA, 2011a).

In 2009, by USD amount, China was first in the world in terms of clean energy investment, with investment totalling USD 34.6 billion, nearly double the United States total of USD 18.6 billion (Pew Charitable Trusts, 2010). However, heavy reliance on coal is projected to continue, and deployment of CCS may be necessary to mitigate growing $\mathrm{CO}_{2}$ emissions from coal consumption (ERI-NDRC, 2009). Heavy reliance on coal combustion in both power generation and industry demonstrates a trend towards continued increase in emissions from coal combustion which totalled $12849 \mathrm{MtCO}_{2}$ globally in 2009, with China accounting for $5881 \mathrm{MtCO}_{2}$ (Figure 4). Nonetheless, efforts to increase the share of new alternative fuels and develop low-carbon energy technologies may continue to drive down costs of reducing emissions and improve technology learning rates in relation to reducing emissions from fossil fuels. 
Figure 4 Regional distributions of CO2 emissions and sources from coal combustion 2009

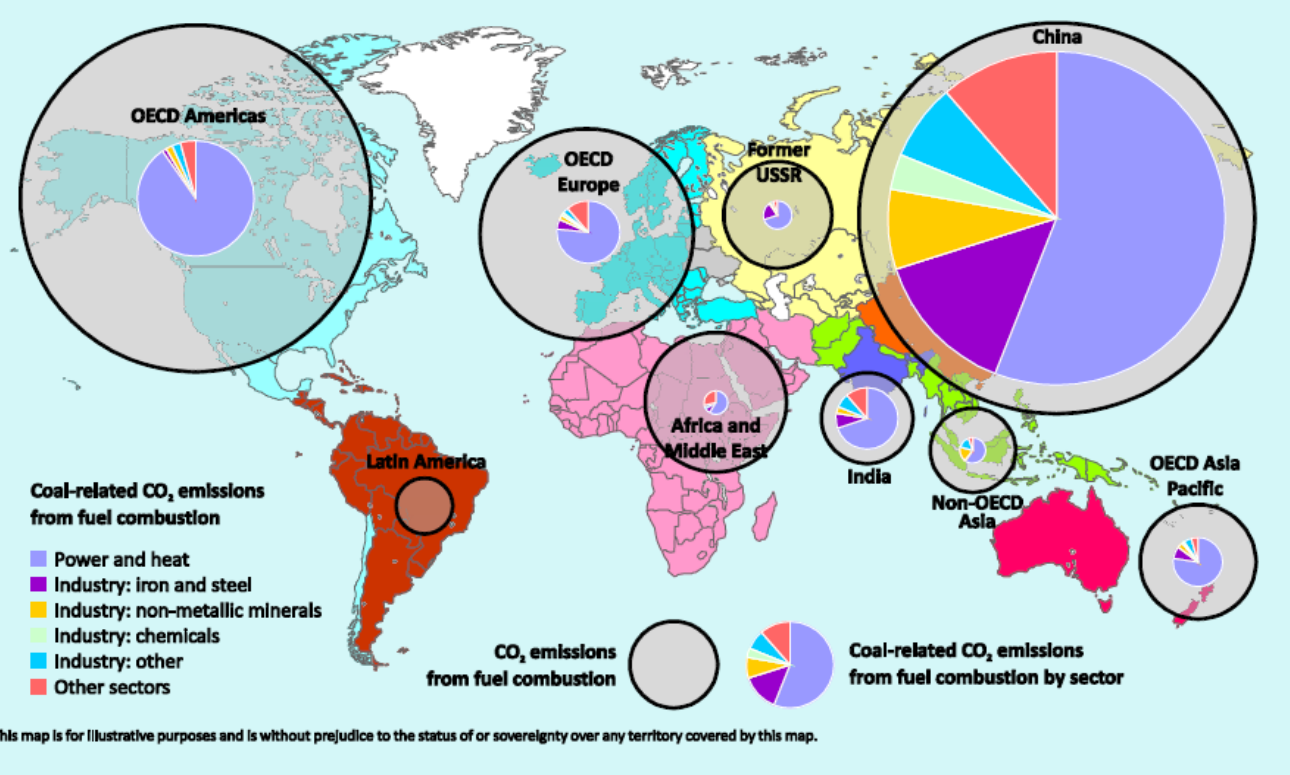

Source: IEA, 2011c.

Although China has not committed to any internationally binding $\mathrm{CO}_{2}$ or $\mathrm{GHG}$ emissions reduction targets, its national objective is to cut $\mathrm{CO}_{2}$ emissions per unit of gross GDP by $40 \%$ to $45 \%$ from 2005 levels by 2020. China has taken strong action to improve energy efficiency and reduce carbon intensity, has enacted progressive policies to promote renewable and nuclear energy, and has replaced the biggest share of its ageing, less efficient coal-fired power plants. The country continues to make significant progress in reducing its energy intensity. ${ }^{1}$ In 2009, China consumed about one-quarter of the energy per unit of economic output that it did in 1980. China has also become a world leader in renewable energy, and aims to boost its share of renewable energy to $15 \%$ of total consumption by 2020 .

During the $11^{\text {th }}$ Five-Year Plan (2006-10), the Chinese government planned to reduce energy use per unit of GDP (energy intensity) by $20 \%$. Though the target was not fully reached, China's Premier Wen Jiabao has announced that during that period a reduction of $19.1 \%$ was reached, based on successes with several wide scale energy efficiency, enterprise energy saving and conservation programs and the shutting down of China's most polluting small-scale coal-fired power plants. The $12^{\text {th }}$ Five-Year Plan (2011-15), released in March 2011, announced a further planned reduction of $16 \%$. The plan aims to improve sustainability targets and pace for growth, including a new carbon intensity target for reducing emissions growth relative to GDP by $17 \%$.The $17 \%$ target is part of the larger goal of reducing emissions by $40 \%$ to $45 \%$ by 2020 (WRI, 2010).

\footnotetext{
${ }^{1}$ Energy intensity is a measure of total primary energy use per unit of gross domestic product.
} 


\section{Potential for CCS globally and in China}

\section{Global role of CCS}

Many governments and organisations now recognise the potential contribution of CCS to global climate change mitigation efforts. But, as highlighted in this report, key questions remain. The Intergovernmental Panel on Climate Change (IPCC) estimates that CCS could help reduce global GHG stabilisation costs by $30 \%$ or more during this century, in a portfolio of technologies including renewable energy, nuclear energy, energy conservation and energy efficiency (IPCC, 2005) (Figure 5). Under the IEA BLUE Map Scenario, which calls for $\mathrm{CO}_{2}$ emissions from the energy sector to be reduced by 50\% from 2005 levels by 2050, it is anticipated that CCS could contribute about $19 \%$ of total emissions reduction or $9.1 \mathrm{GtCO}_{2}$ in 2050 (IEA, 2010b). CCS may have the potential to achieve significant emissions reductions because, other than efficiency improvements, it is the only near-commercial technology solution that can address $\mathrm{CO}_{2}$ emissions from large-scale fossil-fuel power plants and other industrial facilities.

Figure 5 Key technologies for reducing global $\mathrm{CO}_{2}$ emissions

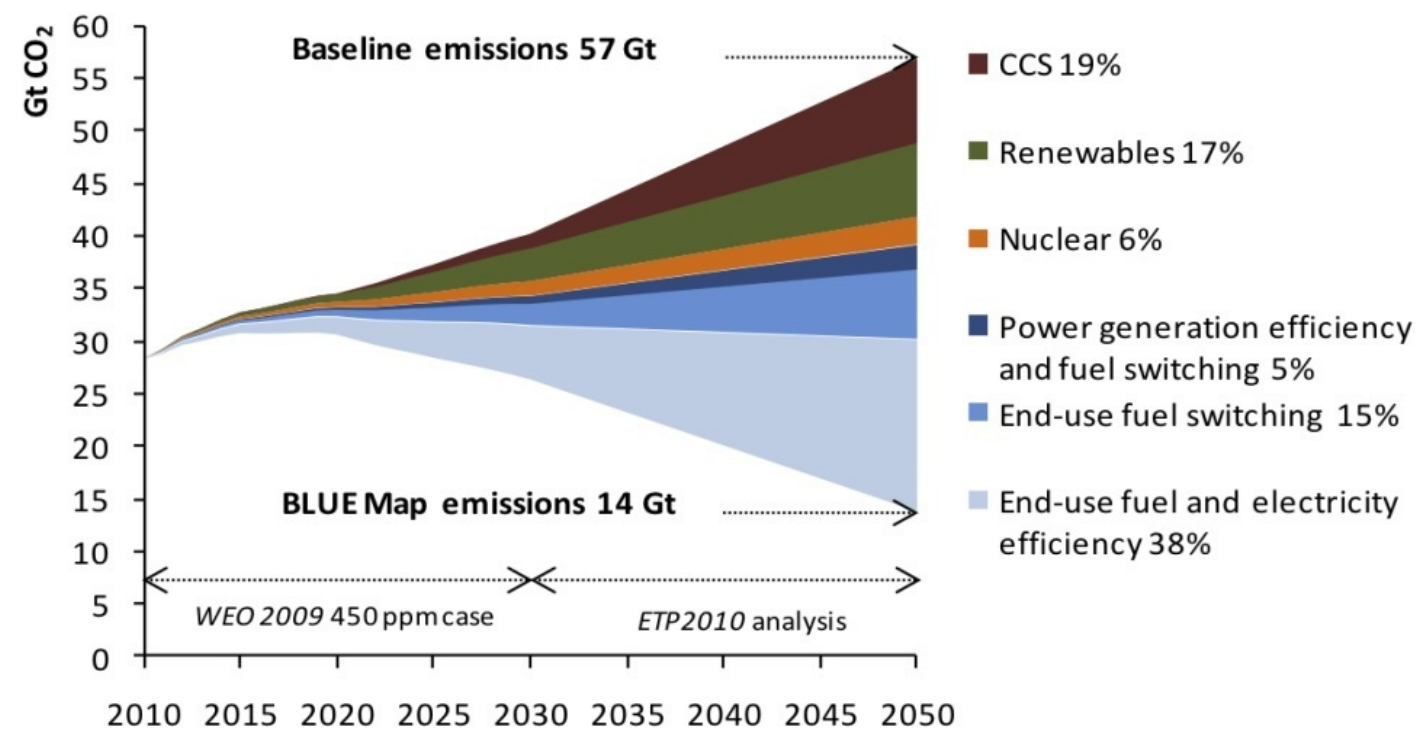

Source: IEA, 2010b.

The contribution of CCS to emissions reduction would increase from $3 \%$ of total reduced volume in 2020 to $10 \%$ in 2030 and $19 \%$ in 2050 . In this scenario, CCS would thus become the technology providing the single biggest share of emissions reduction. If China continues on a course to high fossil-fuel usage, CCS must play an important role in the total emissions mitigation effort.

In recognition of the important contribution $\mathrm{CCS}$ may make to global $\mathrm{CO}_{2}$ mitigation and energy security, the Group of Eight (G8) committed in 2008 to launching 20 large-scale (>1 MtCO $/ \mathrm{yr}$ ) integrated CCS demonstration projects by 2010, with broad deployment by 2020. In 2009, the Major Economies Forum on Energy and Climate (MEF) issued its Technology Action Plan: Carbon Capture, Use and Storage in support of a similar commitment (MEF, 2009). While the 2010 target has been missed, considerable project activity is underway globally. Large-scale CCS deployment 
from 2020 onwards is still possible, but it will require substantial efforts, including large publicand private-sector investments, policy actions and international co-operation.

In order to meet CCS deployment targets under the IEA BLUE Map Scenario, the IEA estimated in 2009 that over 3000 CCS facilities, each averaging $3 \mathrm{mt} \mathrm{CO} \mathrm{CO}_{2}$ captured annually (roughly evenly divided between fossil-fuel power and industrial sectors) must be built around the world by 2050

Page I 12 (Figure 6). Under this scenario, China would need to build 10 to 12 large-scale projects by 2020 and ramp up to 600 projects by 2050 . This provides a snapshot of what would be needed to meet the outline of such a scenario. In reality, current policies and regional CCS development are not on track to meet these milestones either in OECD and Non-OECD countries. It is therefore necessary to continue to update any such future visions and adjust milestones, scenario analysis and policies accordingly. ${ }^{2}$

Figure 6 CCS deployment pathway as estimated in 2009 IEA Technology Roadmap

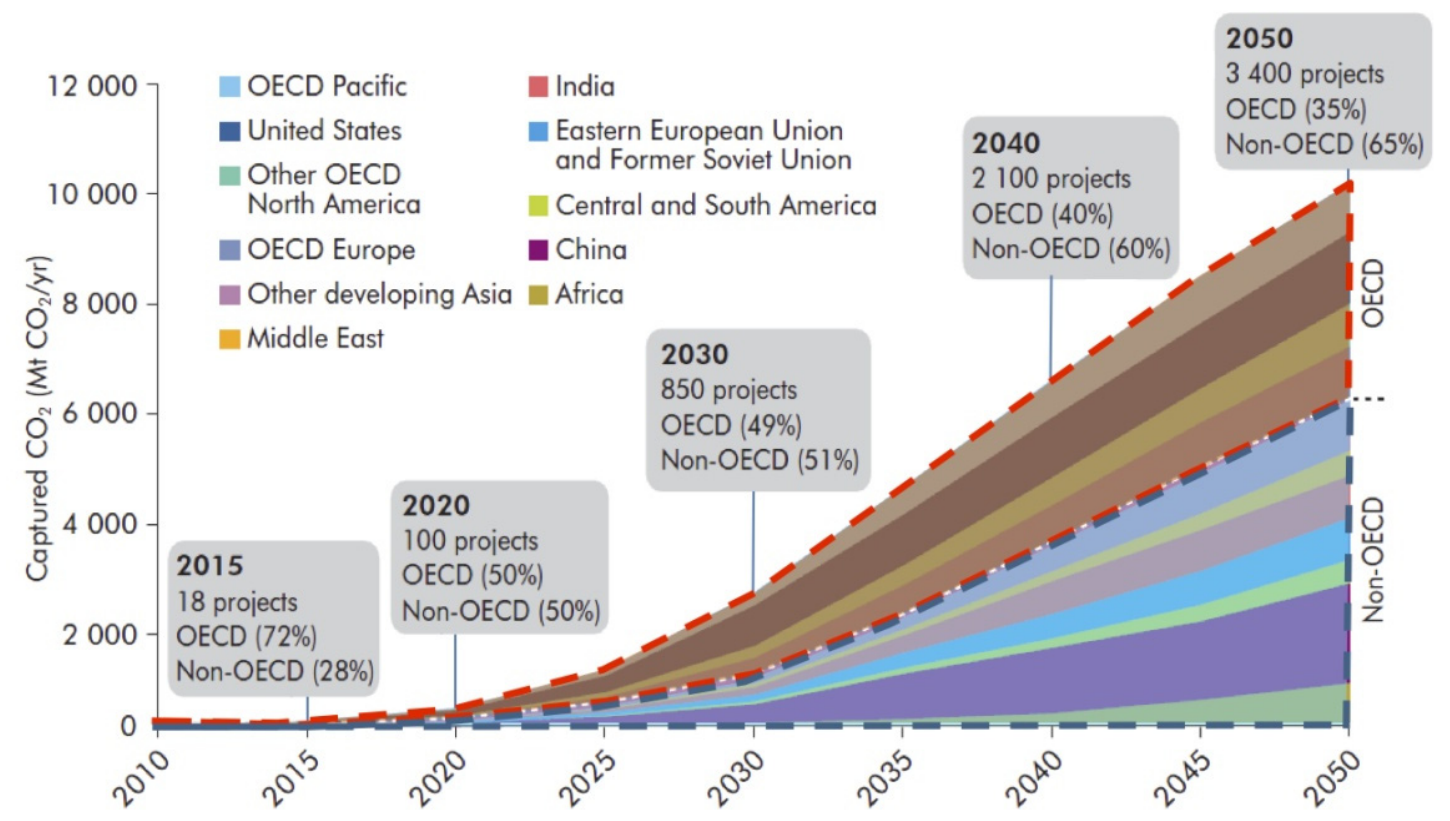

Source: IEA, 2009b.

The annual average investment required for this deployment scenario from 2010 to 2020 is estimated at USD 3.5 billion to USD 4 billion in OECD countries and USD 1.5 billion to USD 2.5 billion for projects in developing countries (IEA, 2009b). Globally, recent government commitments for CCS demonstration projects have totalled USD 25 billion, but progress of allocating funds to projects has been slow. Currently, about 70 large-scale integrated CCS projects globally are in various stages of development, including early planning and pre-feasibility stages. ${ }^{3}$ These projects may also be subject to continued approval and funding challenges, with some high-profile projects cancelled in 2011, while new project plans have also been announced.

\footnotetext{
${ }^{2}$ The numbers of projects presented here should not be considered targets, but simply results of scenario analysis by the IEA. The IEA employs several methods in its energy scenario work, either projecting current developments into the future, or plotting a cost-effective pathway to a politically agreed goal. Both approaches can be useful for policy-makers and industries in testing the impact of policy decisions. As in other countries, it will be up to Chinese authorities to set goals for technology deployment in China, as appropriate.

${ }^{3}$ For a recent stock-take of global CCS project activity, see the report Global Status of CCS: 2011 by Global CCS Institute, www.globalccsinstitute.com/publications/global-status-ccs-2011.
} 
Additionally, the limited number of projects in operation today reflects a very challenging environment for CCS, with global financial uncertainty affecting investment by both private and public sectors.

\section{Role of CCS in China's GHG mitigation effort}

As indicated in the discussion of China's energy and $\mathrm{CO}_{2}$ emission trends in the previous section of this report, fossil fuel use is likely to continue, with a related increase in $\mathrm{CO}_{2}$ emissions. CCS technologies may therefore be an important option in China's energy future. However, it must be noted that there is currently no official quantification of the role of CCS in China. External organisations have done calculations within energy scenario work, but these can only be taken as illustrative of developments in a possible best-case scenario for tackling climate change.

China's Low-Carbon Development Pathway by 2050: Scenario Analysis of Energy Demand and Carbon Emissions, completed in 2009 by the Energy Research Institute (ERI) of the National Development and Reform Commission (NDRC), found that, without enhanced policies on energy conservation and emissions reduction, energy demand would increase from 1.57 billion tonnes of oil equivalent (btoe) in 2005 to 4.69 btoe in 2050 and that GHG emissions would reach $12.2 \mathrm{GtCO}_{2}$ (ERI-NDRC, 2009). This large energy demand and increasing $\mathrm{CO}_{2}$ emissions pose severe challenges to China's sustainable development, environmental protection and energy security and have a major impact on the global energy market and global climate policies. Given this high consumption of fossil fuels, CCS will be an important component of China's GHG mitigation strategy. However, it will be necessary to address many economic and site-specific cost considerations, as well as technical and policy issues (including appropriate incentives, clearer estimation of storage capacity and issues regarding safety and permanence).

As the world's largest consumer of fossil fuels and producer of $\mathrm{CO}_{2}$ emissions, China presents a critical yet challenging market for large-scale deployment of CCS. In the face of competing economic, development, energy security and low-carbon energy priorities, China has shown cautious, but increasing interest in CCS. CCS is compatible with an existing and developing fossilfuel infrastructure. With its distinct comparative advantages and unique opportunities to host large-scale demonstrations, China has the potential to become a leading global provider of CCS technologies and engineering services.

Senior Chinese leaders have highlighted the importance of looking more closely at CCS as a technology with potential for large-scale deployment in China, and there is significant activity in both government and industry R\&D programmes to explore options for CCS. China's current RD\&D efforts emphasise various carbon capture technologies, with an increasing focus on utilisation opportunities. China's early commercial demonstration projects, GreenGen and the Shenhua Direct Coal Liquefaction CCS Project, feature important technologies (coal gasification and coal liquefaction) with key learning on concentrated $\mathrm{CO}_{2}$ streams for hydrogen production, EOR and storage that will likely have strategic implications for China's long-term energy supply and strategy.

In 2005, China integrated CCS into its national medium- to long-term science and technology development plan, as a cutting-edge technology to achieve fossil-energy development of nearzero emissions. In 2006, the Ministry of Science and Technology (MOST) launched China's National Basic Research Programme (973 Programme) for the utilisation of greenhouse gasses as a resource in enhanced oil recovery and underground storage. In 2007, CCS was mentioned by NDRC as a key research area for GHG emissions reduction in the National Climate Change 
Programme. In 2008, MOST launched a CCS technology research programme under the National High-tech Programme 863 (MOST, 2008).

Along with government research programmes, development of the commercial integrated gasification combined cycle (IGCC) project, as well as supercritical and ultra-supercritical projects, demonstrates China's advancing engineering expertise in power generation and coal gasification.

Page | 14 Industry has acknowledged the role that gasification technologies can play in laying the ground work for near-term and future opportunities to demonstrate CCS technologies. Gasification in refining and other industrial facilities that allow for early separation and pure streams of $\mathrm{CO}_{2}$ could create the near-term opportunities necessary to gain experience and demonstrate specific types of CCS technologies at a more competitive price.

Testing applications of CCS in industrial facilities is either non-existent or at an early stage in key sectors such as the cement industry. But given China's significant cement, steel and chemicals sectors, industrial applications have the potential to comprise a significant portion of CCS-related emissions reductions in the future. Currently, there are only limited projects using industrial-scale gasification paired with geological storage.

With some initial co-operation and preliminary estimates of storage potential, an important step is to develop a detailed map for different types of $\mathrm{CO}_{2}$ storage in China. Projects such as the China Australia Geological Storage of $\mathrm{CO}_{2}$ Project (CAGS) are currently providing resources and information to support this work. It is also important to note that given China's increasing focus on CCUS, storage potential in China's oilfields and coal seams is but a small fraction of the capacity needed.

China's leadership has not mandated CCS implementation as a part of its current $\mathrm{CO}_{2}$ emissions reduction policy. But in China's Scientific \& Technological Actions on Climate Change, a paper issued in 2007 by MOST in conjunction with 13 ministries and departments (MOST et al., 2007), the government identified CCS as a key mitigation technology. China is aggressively advancing RD\&D to overcome technical barriers and get a better indication of economic and financial viability. Initial government policies have been supportive of CCS RD\&D through national science and technology programmes.

Another example of analysis aiming to clarify the role of CCS in China is the CCUS technology roadmap, published in September 2011 by the Administrative Centre for China's Agenda for the $21^{\text {st }}$ Century (ACCA21) of the Ministry of Science and Technology. It is not a deployment roadmap, but rather a roadmap on technical development aspirations (Box 2). 
The ACCA21 roadmap* sets out goals for the development of CCUS technologies and cost levels in the coming decades. It sets out a vision to "provide technically viable and financially affordable technological options to combat climate change and facilitate the socio-economic sustainability" with the following milestones:

By $\mathbf{2 0 1 5}$, key capture technologies with low energy consumption will be realised and the research and development (R\&D) system for storage safety will be established. A full-chain pilot and demonstration at scale over 300000 tonnes/yr will be conducted with an aim of achieving less than $25 \%$ additional energy consumption at the cost of approximately RMB 350/tonne;

By 2020, the storage safety system will be put in place. The Mt full-chain CCUS demonstration will be set up with less than $20 \%$ additional energy consumption at a cost of approximately RMB 300/tonne.

By 2030, the technical and engineering capacity for design, construction and operation of a full-chain CCUS project with scale over $1 \mathrm{Mt} / \mathrm{yr}$ with less than $17 \%$ additional energy consumption and the cost of RMB $240 / t$ or less will be in place.

*The ACCA21 roadmap does not contain a schedule or mandate actions for CCS technology deployment.

Source: ACCA21, 2011

\section{Current CCS Development in China}

\section{China's CCS policies and institutions}

In recent years, policy for CCS in China has focused on research and technology development. The national government has emphasised the need to further explore CCS as an important technology in a mix of energy options to mitigate climate change impacts. China has not yet introduced any specific policies or schemes to stimulate large scale development and deployment of CCS technology, but CCS has been included in a series of special actions and planning for climate change and low-carbon R\&D development (Table 1).

Table 1 Key climate and CCS policy actions in China

\begin{tabular}{|c|c|}
\hline Policy statement & Background/description \\
\hline $\begin{array}{l}\text { Medium- and Long-term } \\
\text { National Plan for Science } \\
\text { and Technology } \\
\text { Development (2006-2020) }\end{array}$ & $\begin{array}{l}\text { In February 2006, the State Council issued a proposal "to develop highly efficient clean } \\
\text { fossil energy and resource exploitation technologies with carbon dioxide zero emissions } \\
\text { technologies, and to list the cleaner and more efficient coal development and utilisation } \\
\text { techniques, as well as coal liquefaction and poly-generation as a top priority". }\end{array}$ \\
\hline $\begin{array}{l}\text { China's National Climate } \\
\text { Change Programme } \\
\text { (NCCP) }\end{array}$ & $\begin{array}{l}\text { On } 4 \text { June 2007, the National Development and Reform Commission, issued China's } \\
\text { first policy document to address climate change (and the first national climate-change } \\
\text { programme among developing countries). The programme set targets, principles, key } \\
\text { areas and policies to address climate change and included CCS development (coal } \\
\text { gasification-based co-production technology, carbon capture, utilisation and storage } \\
\text { technology) in the key area of GHG reduction. The policy states a commitment to } \\
\text { "vigorously develop coal liquefaction, coal gasification, the coal chemical industry, and } \\
\text { poly-generation based on coal gasification, as well as carbon dioxide capture, utilisation } \\
\text { and storage technologies". }\end{array}$ \\
\hline
\end{tabular}




\begin{tabular}{|c|c|}
\hline Climate Change & $\begin{array}{l}\text { promote CCS research, development and demonstration. This was listed as one of the } \\
\text { key tasks of GHG mitigation technology development by advancing capacity building, } \\
\text { and developing a CCS technology roadmap and programmmes for demonstration of } \mathrm{CO}_{2} \\
\text { utilisation and storage. }\end{array}$ \\
\hline $\begin{array}{l}\text { China's Policies and } \\
\text { Actions for Addressing } \\
\text { Climate Change (2008) }\end{array}$ & $\begin{array}{l}\text { On } 29 \text { October 2008, the State Council Information Office published a White Paper } \\
\text { entitled China's Policies and Actions for Addressing Climate Change. It listed "Research } \\
\text { of CCS technology" as one of China's policies and actions to mitigate climate change } \\
\text { and indicated that China will advance the use of cleaner coal and develop efficient and } \\
\text { clean power-generating technology, such as large-scale combined cycle units and poly- } \\
\text { generation, to promote technology for carbon dioxide sequestration. }\end{array}$ \\
\hline $\begin{array}{l}\text { Guide for CCS Science and } \\
\text { Technology Development }\end{array}$ & $\begin{array}{l}\text { An initiative developed by MOST outlines CCS R\&D goals in } 2020 \text { and } 2030 \text {, identifying } \\
\text { major tasks for capture, storage, transportation and utilisation technology development } \\
\text { and determines near-term priority projects under national science and technology } \\
\text { programmes. }\end{array}$ \\
\hline China's 12th Five-Year Plan & $\begin{array}{l}\text { In March } 2011 \text {, China's } 12^{\text {th }} \text { Five-Year Plan (FYP) was released establishing } \mathrm{CO}_{2} \\
\text { emissions reduction targets and further supports the development of advanced fossil fuel } \\
\text { and low carbon technologies and RD\&D as a means to reduce } \mathrm{CO}_{2} \text { emissions. }\end{array}$ \\
\hline $\begin{array}{l}\text { China's Policies and } \\
\text { Actions for Addressing } \\
\text { Climate Change (2011) }\end{array}$ & $\begin{array}{l}\text { On November 2011, the State Council Information Office published an updated White } \\
\text { Paper on China's Policies and Actions for Addressing Climate Change in advance of } \\
\text { COP17. The paper emphasises key climate actions of the 12th FYP and guidance on the } \\
\text { National Plan to Address Climate Change (2011-2020). The paper highlights the } \\
\text { importance China places on expanding key cooperation and R\&D initiatives including } \\
\text { CCS, and development of low carbon technology roadmaps. It also details 12th FYP } \\
\text { commitments to emissions trading markets and low carbon pilot projects. }\end{array}$ \\
\hline
\end{tabular}

Source: PRC Information Office of the State Council and Chinese government publications.

China's first CCS policy efforts began with a series of central government policies led by the National Development and Reform Commission, China's leading policy-making institution along with MOST. These policies focus on supporting CCS R\&D within national science and technology programmes. China's Medium and Long-term National Plan for Science and Technology Development (2006-20) noted that CCS was an important frontier technology. In 2007, China issued its National Climate Change Programme, which aims to strengthen the development and dissemination of advanced technologies. A large portion of this programme focuses on developing coal gasification and systems including CCUS technologies (NDRC, 2007).

As mentioned earlier, in 2007, MOST issued China's Scientific and Technological Actions on Climate Change (MOST et al., 2007), an initiative developed in conjunction with 13 of the many government institutions involved in energy policy and administration (Figure 7). Under this initiative, projects in China of over USD 100 million must go through project approvals. In the case of storage projects, requirements must be approved by the National Development and Reform Comission, the National Energy Administration and the Ministry of Land Resources.

In line with broad policy priorities established in the five-year plan and related energy planning, further development of CCS will require legislative action at top-level bodies, including the State Council, the National People's Congress and ministries with jurisdiction across several industrial sectors and areas. Provincial, local and municipal bodies will also be essential to specific projectapproval processes, as will engaging local stakeholders throughout the planning, feasibility and approval stages, to avoid projects being derailed late in the process.

Municipal and local authorities in China have led significant efforts in developing low-carbon and clean-energy projects within their jurisdictions. Given the complexities of industry sectors and geological and environmental considerations, engagement at the local level will be important for CCS project development in China and globally. 
Figure 7 Chinese government institutions involved in energy policy and administration

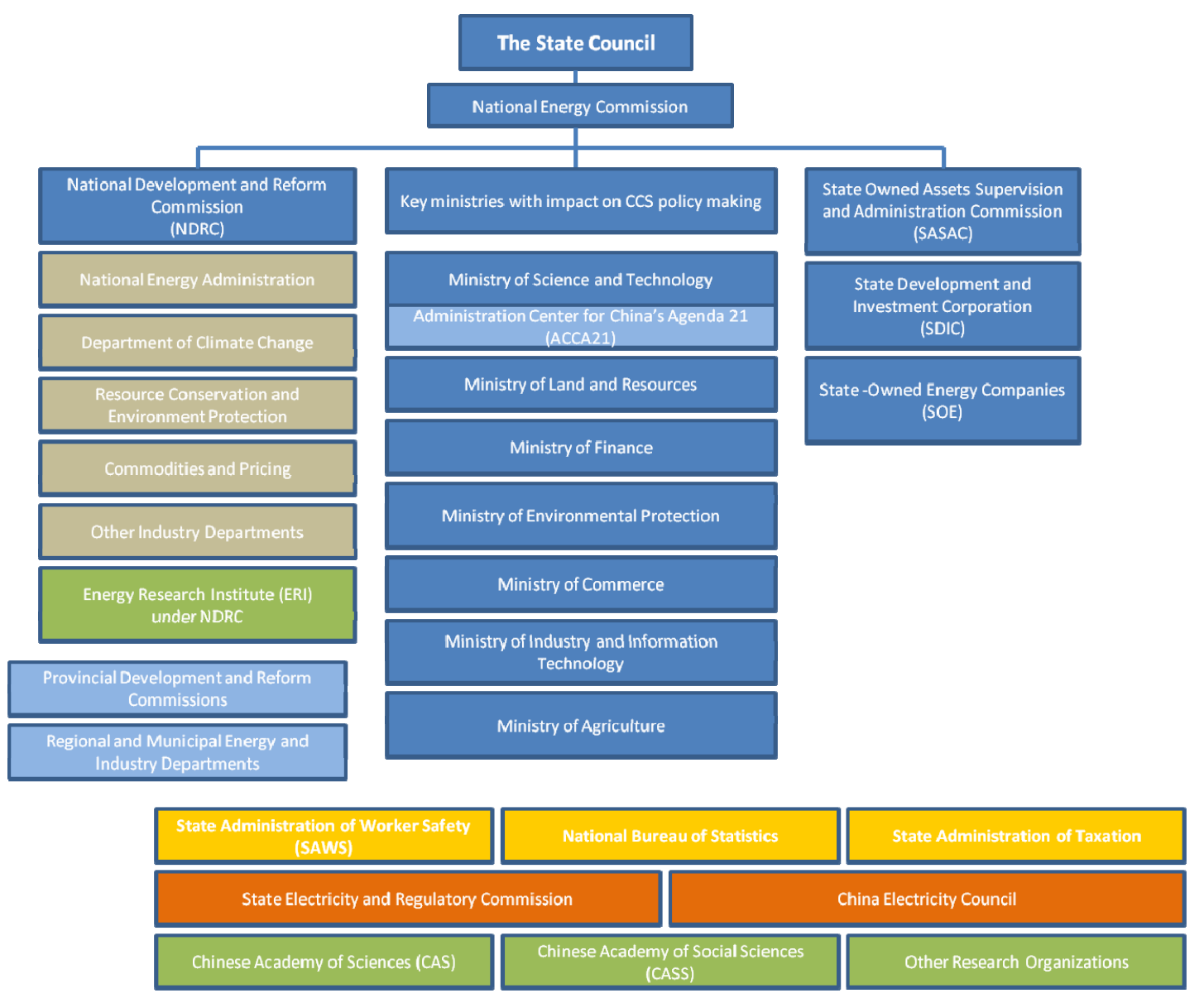

Source: IEA and Chinese government publications.

Several agencies that have oversight and regulatory authority over power generation, power markets and coal development may also have active roles in the development of CCS policy in China. For instance, the State Electricity Regulatory Commission of China (SERC), the agency responsible for regulating China's power sector, is developing a climate change action plan which will include aspects for consideration of the CCS industry with a focus on possible mandates and incentives for improved energy efficiency and renewable energy in the electricity sector. Following higher-level policy development and legal and regulatory frameworks in China, SERC may be in a position to provide further regulation on CCS with a view to integrating CCS in future action plans. This may include a range of actions, from requirements for new plant builds requiring CCS readiness to more aggressive mandates on efficiency and emissions that would provide incentives for CCS.

Given China's rapidly evolving regulatory frameworks for industry, stricter environmental considerations and the unique challenges posed by China's increasing energy demand, regulators will need to identify gaps and work to develop CCS-related regulations that consider examples of relevant regulations adopted in other countries while meeting China's unique situation and development priorities. Regulatory developments in the CCS sector will need to cut across 
various areas and traditional industry sectors. That will likely require co-ordination among government agencies or bundled responsibilities within only a few direct authorities to develop and implement relevant laws to guide development of approvals processes, administration and long-term oversight of projects.

The role of state-owned enterprises in developing voluntary industry guidelines to address developing low-carbon policies will be important in both power generation and the whole energy sector. It will be equally important that relevant industries are engaged in steps to develop CCS with clear objectives and safety considerations, following directives from policy makers. As in other countries, existing guidelines and regulations for oil and gas exploration, coal mines, pipeline regulations and other legislation may be adapted or provide guidance on CCS-related legislation, along with climate specific policies that factor CCS into a suite of climate-change mitigation technologies.

The consideration and incorporation of CCS into scenario modeling, scenario analysis and the framing of key policy questions will also be important to clarify the role CCS may play in China, given specific technology pathways, emissions abatement requirements and deployment time frames. The Energy \& Environment Policy Research Institute of the Chinese Academy of Sciences, among other research institutes is currently modeling future scenarios for energy and climate, and may include costs and benefits of CCS in its analysis.

\section{Key institutions, sectors and players}

Several key state-owned companies, research institutions, non-government organisations and government institutions are involved with CCS RD\&D in China (Table 2). Furthermore, the government is leveraging its CCS investments with a broad array of international co-operative activities on CCS within bilateral and multilateral frameworks. It has encouraged Chinese companies to forge international partnerships and become global leaders in CCS technology and research. Table 2 provides an overview of several key players involved in CCS development in China that are referenced throughout this paper, further descriptions including international government initiatives and demonstration project participants are detailed in the financing and projects sections of this paper. Given the pace of project developments, announcements and activities on CCS, this table is not intended to be exhaustive, but to identify the range of players and examples of work in this area.

Table 2 Key players active in China's CCS development

\begin{tabular}{|c|c|}
\hline Government & Role \\
\hline $\begin{array}{l}\text { National Development and Reform } \\
\text { Commission (NDRC) }\end{array}$ & $\begin{array}{l}\text { Formulates energy and climate policy; approves large energy } \\
\text { demonstration projects. }\end{array}$ \\
\hline Ministry of Science and Technology (MOST) & $\begin{array}{l}\text { Develops technology roadmaps, funds R\&D programmes and } \\
\text { manages technology transfer. }\end{array}$ \\
\hline $\begin{array}{l}\text { Administrative Center for China's Agenda } 21 \\
\text { (ACCA21) }\end{array}$ & $\begin{array}{l}\text { Administration of China's Agenda } 21 \text { and primary co-ordinator for } \\
\text { MOST's international CCS collaboration. }\end{array}$ \\
\hline Ministry of Industry and Information & Provides support for CCS equipment manufacturing industry. \\
\hline Ministry of Land Resources & Manages land usage and permits. \\
\hline Industry & Role \\
\hline China Huaneng Group & $\begin{array}{l}\text { Managing Partner of GreenGen, which constructed China's first } \\
\text { carbon capture demonstration at Beijing Thermal Power Plant (2008), } \\
\text { carbon capture plant at Shidongkou Plant (2010). }\end{array}$ \\
\hline
\end{tabular}




\begin{tabular}{|c|c|}
\hline China Power Investment Co & GreenGen partner. \\
\hline China National Petroleum Corporation & EOR research; partner in the Shenhua DCL / CCS Project in Ordos. \\
\hline Datang Power & GreenGen participant. \\
\hline ENN Group & $\begin{array}{l}\text { Bioenergy (microalgae)/sequestration project in Dalate, Inner } \\
\text { Mongolia; in partnership with Duke Energy. }\end{array}$ \\
\hline Guodian Power & GreenGen Participant. \\
\hline PetroChina & $\begin{array}{l}\text { China's first } \mathrm{CO}_{2}-\mathrm{EOR} / \text { storage project at Jilin Oil Field (2006); } \\
\mathrm{COACH} \text {. }\end{array}$ \\
\hline Shenhua Group & DCL/CCS project in Ordos, Inner Mongolia. \\
\hline SINOPEC & $\begin{array}{l}\text { Carbon capture project at a SINOPEC power plant for } \mathrm{CO}_{2} \mathrm{EOR} \text { at } \\
\text { Shenli Oilfield. }\end{array}$ \\
\hline Thermal Power Research Institute (TPRI) & $\begin{array}{l}\text { Gasification technology developer used at GreenGen; Shidongkou No. } \\
2 \text { Power Plant Project with Carbon capture; COACH; NZEC. }\end{array}$ \\
\hline Academic / Research & Role \\
\hline China Petroleum University & Geologic storage research, $\mathrm{COACH}$. \\
\hline China University of Geosciences at Wuhan & $\begin{array}{l}\text { Geological modelling and simulation, lab experiments for saline } \\
\text { aquifer storage. }\end{array}$ \\
\hline $\begin{array}{l}\text { Chinese Academy of Science, Institute of } \\
\text { Geology and Geophysics }\end{array}$ & Geologic storage research, technology roadmaps, COACH; NZEC. \\
\hline $\begin{array}{l}\text { Center for Energy and Environmental Policy, } \\
\text { Chinese Academy of Sciences (CAS) and } \\
\text { CASS }\end{array}$ & CCS related environment and economic policy analysis. \\
\hline $\begin{array}{l}\text { Energy Research Institute of National } \\
\text { Development and Reform Commission }\end{array}$ & $\begin{array}{l}\text { Engaged in CCS through Center for Energy, Environment and Climate } \\
\text { Change Research and Center for Clean Development Mechanism, } \\
\text { COACH; NZEC. }\end{array}$ \\
\hline North China Electric Power University & Gasifier technology provider; $\mathrm{COACH}$; NZEC. \\
\hline Peking University & $\begin{array}{l}\text { Geological } 19 \text { modelling and simulation, lab experiments for saline } \\
\text { aquifer storage. }\end{array}$ \\
\hline Shanxi University & $\begin{array}{l}\text { Institute of Low-Carbon Development active in a number of CCS } \\
\text { research activities. }\end{array}$ \\
\hline Tsinghua University & $\begin{array}{l}\text { Fundamental research on supercritical } \mathrm{CO}_{2} \text { flow in porous media, } \\
19 \text { modelling and simulation, GeoCapacity, } \mathrm{COACH} \text {; NZEC, Carbon } \\
\text { capture, ECBM, policy. }\end{array}$ \\
\hline Zhejiang University & Oxy-fuel and chemical looping research; $\mathrm{COACH}, \mathrm{NZEC}$. \\
\hline $\begin{array}{l}\text { Huazhong University, National Laboratory of } \\
\text { Coal Combustion }\end{array}$ & $\begin{array}{l}\mathrm{O}_{2} / \mathrm{CO}_{2} \text { combustion/Joint Implementation of } 5 \text {-year US-China CERC } \\
\text { CCUS technical programme }\end{array}$ \\
\hline Financial & Role \\
\hline $\begin{array}{l}\text { China State Development and Investment } \\
\text { Corporation }\end{array}$ & GreenGen participant. \\
\hline China Power Investment Corporation & Planning and development of post combustion and IGCC pilot projects \\
\hline Asian Development Bank & GreenGen project lender and CCS technical capacity development. \\
\hline World Bank & Capacity Building Trust Fund to support planning studies. \\
\hline NGO/International Institutions/Other & Role \\
\hline $\begin{array}{l}\text { Carbon Sequestration Leadership Forum } \\
\text { (CSLF) }\end{array}$ & $\begin{array}{l}\text { An international climate change initiative focused on knowledge } \\
\text { sharing, capacity development and international cooperation on CCS. }\end{array}$ \\
\hline Clean Air Task Force & CCS policy and advocacy. \\
\hline The Climate Group & CCS and climate policy. \\
\hline Energy Foundation & Funding for technical research projects on CCS. \\
\hline Global CCS Institute & CCS project tracking and support for research, pilots and capacity. \\
\hline
\end{tabular}


National Resources Defense Council

World Resources Institute

Sources: Hart and Liu, 2010; IEA.
Identification of policy considerations and CCS opportunities.

CCS regulatory issues and public engagement.

\section{National R\&D programmes}

During China's $10^{\text {th }}$ Five-Year Plan (2001-05), the National Key Technologies R\&D Programme supported strategic CCS studies by Chinese research institutions, with an emphasis on the applicability of CCS in China and its potential impact on energy systems and GHG emissions reductions.

The National High-tech Development Plan (863 Programme), launched in 1986, is a programme funded and administered by the government to stimulate development of advanced technologies in a wide range of fields. The objective of the programme is to reduce China's dependency on foreign technologies. The 863 Program advances a wide range of technologies including space, biotechnology and telecommunications.

Funded by MOST, the 863 Programme supports the development of CCS technology through R\&D on carbon capture (absorption) technologies and storage issues (including geological capacity and viability of saline aquifers) and safety assessments and monitoring. From 2008-10, 300 RMB million (USD 43 million) was allocated to CCS within the 863 Programme, with plans to further support CCS technology development under this programme in the $12^{\text {th }}$ Five-Year Plan (2011-15).

The 863 Programme energy technology projects include high efficiency gasification. The programme has provided seed funding to some 30 gasification research projects, including 5 IGCC demonstrations. Three IGCC demonstrations have been at power plants and two at coal-toliquids (CTL) plants (Hart and Liu, 2010) (Table 3). Although none of the proposed plants supported under the programme have existing plans to store $\mathrm{CO}_{2}$ upon completion (new transport and storage infrastructure would be required and may be prohibitive), these projects may improve capture and other enabling technologies and system integration.

Table 3863 Programme planned IGCC and CTL demonstration plants

\begin{tabular}{|c|c|c|c|}
\hline Company & Capacity & Technology & Location \\
\hline China Huaneng Group* & 250 MW Power & $\begin{array}{l}\text { TPRI Two-Staged Dry-feed } \\
\text { Pressured Coal Gasifier }\end{array}$ & Tianjin, China \\
\hline China Huadian Corp. & 230 MW Power & $\begin{array}{l}\text { ECUST Opposed Multi-nozzle } \\
\text { Water-coal Slurry Gasifier }\end{array}$ & Hangzhou, Zhejiang \\
\hline $\begin{array}{l}\text { Dong Guan Power \& } \\
\text { Chemical }\end{array}$ & $\begin{array}{r}800 \text { MW Power; Stage } \\
1-20 \text { MW by } 2011\end{array}$ & KBR TRIG Gasifier & Dong Guan, Guangdong \\
\hline Yankuang Group & 1 million tonnes/year & CTL & Yulin, Shaanxi Province \\
\hline Lu'an Group & 160000 tonnes/year & CTL & Lu'an, Shanxi Province \\
\hline
\end{tabular}

*This project has been approved by NDRC and is under construction

Source: China Coal Information Institute. 
The National Basic Research Programme (973 Programme), funded by MOST (2006-11) at the level of RMB 35 million, emphasises the basic science of long-term $\mathrm{CO}_{2}$ storage, high efficiency and cost-effective $\mathrm{CO}_{2}$ separation, and new theory and methodologies for $\mathrm{CO}_{2}$ transport. The programme also aims to enhance oil recovery ratios through the use of $\mathrm{CO}_{2}$ by increasing profitability of oil operations while mitigating $\mathrm{CO}_{2}$ emissions.

An important source for CCS research funding is the National Science Foundation of China (NSFC) which supports fundamental research on $\mathrm{CO}_{2}$ storage. This research has involved studies of migration of supercritical $\mathrm{CO}_{2}$ in porous media in saline aquifers. It includes research programmes with Tsinghua University on geologic capacity, laboratory experiments, modelling simulations and joint international research projects such as the China-Australia Geological Storage Project (CAGS), and the Lawrence Berkeley National Labs (Zhang, 2010). The Frontier Programme Project, funded by the Chinese Academy of Science supports pilot tests of impure carbon capture and saline aquifer storage (2009-10). In 2011, the Ministry of Industry and Information also announced plans to support development of a manufacturing industry for CCS and related equipment, which likely supports the potential for commercial deployment and technology drivers down the line. National research initiatives have also funded similar technical programmes such as work on polygeneration, high-efficiency catalytic conversion and thermalto-power conversion for gas turbines, which may also lead to enhanced research on capture technologies (CAS, 2005).

Box 2 Examples of China's technical objectives for CCS R\&D

- $\mathrm{CO}_{2}$ absorption, migration, phase change and related mechanisms in geological structures

- Chemical reactions and solidification conditions of $\mathrm{CO}_{2}$ in the stratum

- Physical and chemical theoretical issues, complicated permeation mechanics and basic numerical simulations for enhanced oil/gas recovery

- Chemical erosion and related mechanisms during long-distance pipeline transportation of $\mathrm{CO}_{2}$.

Source: Zhang, Zhang and Tian; 2009.

\section{R\&D trends and CCUS}

\section{IGCC and gasification technology}

Gasification technology has been used for many years in the chemicals industry in China, and its application to the power sector is advancing rapidly. Chinese companies have purchased licenses from several foreign suppliers in US, and Europe (Clean Coal Centre, 2010; Cai, 2010; Hart and Liu, 2010). Experience gained through the construction and operation of imported gasifiers helped China develop its own large-capacity gasifiers for chemicals and power generation. Chinese gasifiers include the Opposed Multi-burner Coal-water Slurry Gasifier, developed by East China University of Science and Technology (ECUST), based on a GE/Texaco gasifier; the Twostaged Dry-feed Pressurised Coal Gasifier, developed by the Xi'an Thermal Power Research Institute (TPRI) based on a Shell design; and the Two-staged Water-coal Slurry Gasifier, developed by Tsinghua University based on a GE/Texaco gasifier (Liu et al., 2008).

TPRI, part of the Huaneng Group, is a key player in the power sector. TPRI is the co-ordinator for the Greengen Project, funded by a group of power companies led by China Huaneng Group and the Chinese government's 863 Programme. IGCC is a key technology in this three-stage project which costs USD 1 billion. Construction on the first phase began in 2009. TPRI also has access to 
Huaneng's Beijing Gaobeidian Thermal Power Plant, a post-combustion capture facility that annually recovers about 3000 tonnes of $\mathrm{CO}_{2}$ used for food production. TPRI's central role in Huaneng's pilot projects, its own technology development efforts and its research and commercialisation relationships with international technology providers position the institute well to export equipment and engineering services for future CCS projects.

Page 122 Growth of large-scale modern coal gasification plants for non-power applications deployed in China represents a potential early opportunity for the application of CCS and EOR, especially through clustering of various units in specific industrial locations. An inherent characteristic of the coal gasification process of such plants is that large quantities of high concentration $\mathrm{CO}_{2}$ are separated and, at present, vented into the atmosphere. Marginal costs for application of CCS to such plants may be lower than for coal-based power generation processes, since it would only be necessary to provide for compression, transport and injection of $\mathrm{CO}_{2}$ into suitable storage sites (Michener, 2011). This clustering effect - centralising sources of emissions and developing planned industrial parks - may give China another advantage over other locations in developing more cost-competitive CCS projects.

\section{Coal-to-liquids (CTL)}

China's coal chemical technology is basically a diversified gasification technology (Figure 8). Its process begins as coal is converted into carbon monoxide (CO) and hydrogen through a gasification reaction. Then, part of the $\mathrm{CO}$ is converted into hydrogen and $\mathrm{CO}_{2}$ through a transformation reaction, and the ratio of $\mathrm{CO}$ and hydrogen is adjusted to suit the need of the production target (i.e. methanol, olefin, etc). $\mathrm{CO}_{2}$ is separated from syngas by means of acid gas removal. Finally, $\mathrm{CO}$ and hydrogen are reacted together to generate various synthetic products (Ren, 2009).

Figure 8 Typical process flowsheet of standard coal chemical industry in China

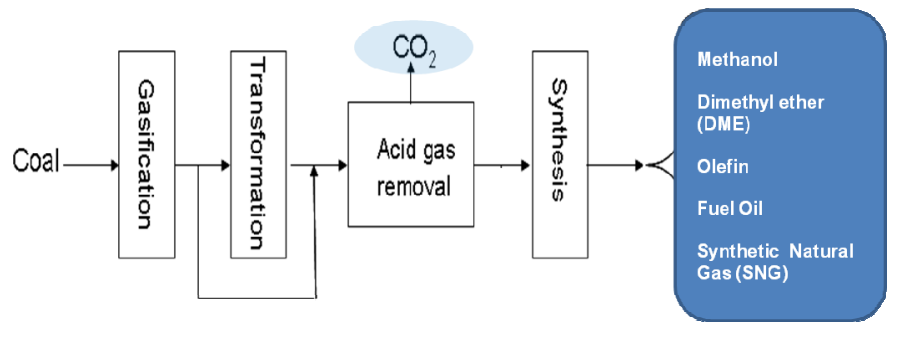

Source: Ren, 2009.

During the process of direct coal liquefaction, large amounts of hydrogen are required. In the conversion reaction of coal-to-hydrogen, $\mathrm{CO}$ needs to be transformed into $\mathrm{CO}_{2}$, and separated by means of an acid gas removal process.

In the coal chemical process flow, the acid gas removal process emits huge amounts of $\mathrm{CO}_{2}$ under high pressure and high concentration, often $80 \%$ to $99 \%$. China's coal chemical industry development will need to consider the opportunity to address high $\mathrm{CO}_{2}$ emissions and potential high concentration streams, which could dramatically increase efficiency of capture and enhance the economic feasibility of CCS projects over coal-fired power generation. 
Figure $9 \mathrm{CO}_{2}$ emissions of fuels including coal chemical products $\mathrm{w} /$ and $\mathrm{w} /$ out CCS

\section{Comparing Fuels}

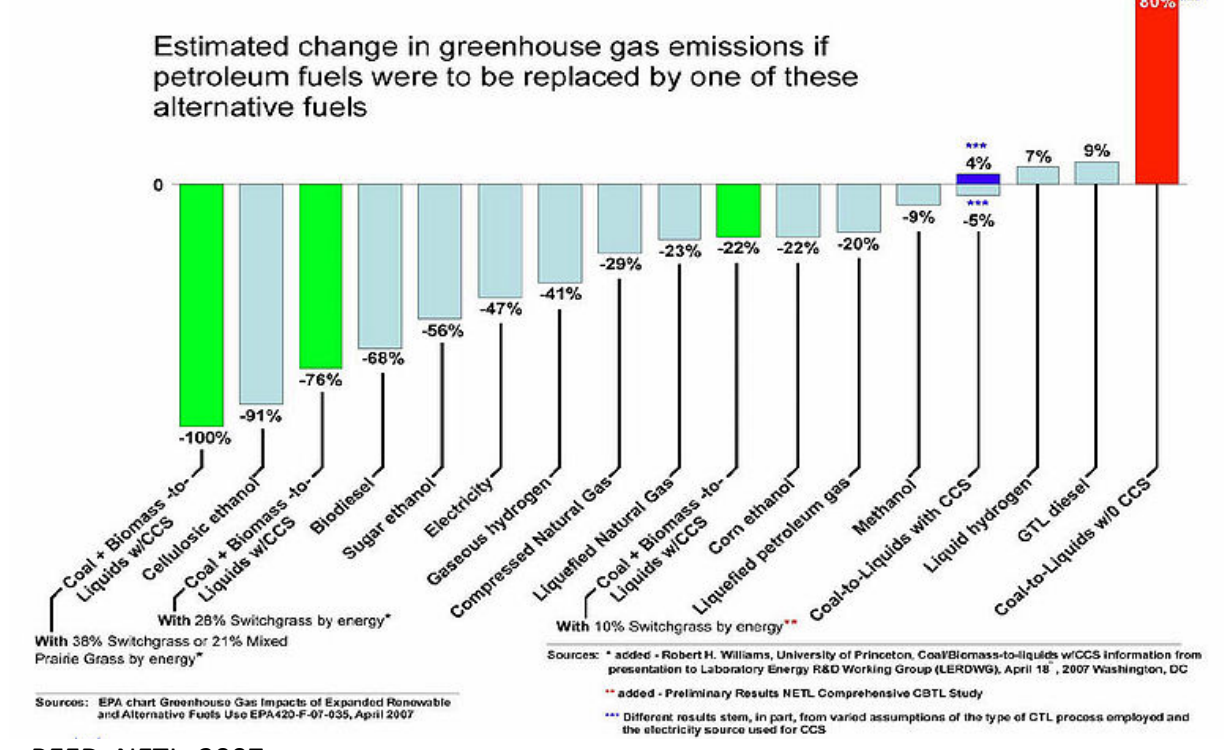

Source: REED, NETL, 2007

China's vast coal reserves and production along with limited domestic oil resources and rising energy demand and oil prices, has focused the country's policy and strategy to developing and modernising a coal-chemical industry. As China builds its advanced coal technology programmes including coal chemicals (coal-to-methanol, coal-to-dimethyl ether, coal-to-olefin, direct and indirect liquefaction of coal, coal-to-hydrogen and coal gasification), there may be opportunities to integrate these R\&D efforts in line with CCS objectives. However, given comparatively high greenhouse gas emissions emitted in various technology processes in both production and combustion, such as coal-to-liquids (Figure 9), it will be necessary to consider development of these technologies in line with both deployment of CCS and the case if CCS is not deployed.

In the petrochemicals sector, Shenhua and China National Petroleum Company (CNPC) are leading Chinese companies developing CCS technology and know-how. CNPC designed the capture unit for the Shenhua coal-to-liquids (CTL) project and is Shenhua's partner in the ongoing test injection into the Ordos Basin of up to 100000 tonnes of $\mathrm{CO}_{2}$ annually. Shenhua and CNPC will be among the few companies in the world with experience operating a fully integrated commercial-scale industrial CCS project.

\section{Carbon capture, utilisation and storage (CCUS)}

In China, there is significant focus on CCUS (the utilisation of carbon dioxide in industrial and other commercial uses) due to the potential to offset costs of CCS projects. While early projects have explored the potential for commercial $\mathrm{CO}_{2}$ to be used in the beverage and food industry, as well as chemicals, welding and ceramics, their scale will be limited compared with required emissions reduction expected from CCS in general. If CCS is to be fully deployed in China, markets for such applications would be overtaken. Although they may offer revenue generating opportunities in the short term, the overall impact will be very limited.

China's heavy industrial, chemicals and related manufaturing sectors may offer China the potential to further develop utilisation processes not possible in other regions. CCS technologies 
are applicable to a range of industrial sectors and applications, with the potential to develop cobenefits and encourage technology crossover for applications in related industries. It will be crucial to identify near-term opportunities that may provide incentives for early demonstration and deployment of CCS technologies without losing sight of climate mitigation objectives. However, officials from NDRC have indicated that the focus is on utilisation of $\mathrm{CO}_{2}$ as a commercial opportunity rather than storage without any economic benefits (NDRC, 2011) (Figure 10 and Table 4).

Figure $10 \mathrm{CO}_{2}$ utilisation by classification of application

\begin{tabular}{|c|c|c|}
\hline & Area of application and process & Key examples \\
\hline & $\begin{array}{l}\text { Physical Usage - Arc welding shield gas, } \\
\text { beverage additives, fire extinguisher, } \\
\text { pressure and leavening agents, oil and } \\
\text { gas displacement, refrigeration and dry } \\
\text { ice production }\end{array}$ & $\begin{array}{l}\text { EOR } \\
\text { ECBM } \\
\text { Food and Beverage }\end{array}$ \\
\hline $\begin{array}{c}\mathrm{CO}_{2} \\
\text { utilation }\end{array}$ & $\begin{array}{l}\text { Chemical Usage - Fine chemicals, high } \\
\text { polymer material and commodity } \\
\text { chemicals, chemical fertilizer and urea, } \\
\text { polymerization with unsaturated } \\
\text { hydrocarbon, amine, epoxy compounds } \\
\text { and high-polymer material }\end{array}$ & $\begin{array}{l}\text { Chemical Synthesis } \\
\text { Fertilizer } \\
\text { Mineralization }\end{array}$ \\
\hline & $\begin{array}{l}\text { Biological Usage - Sterilisation agents, } \\
\text { and gaseous plant fertiliser }\end{array}$ & $\begin{array}{l}\text { Biofuels } \\
\text { Bio-plastics }\end{array}$ \\
\hline
\end{tabular}

Source: Ai Ying Ying, 2010, IEA

China's RD\&D programmes in support of CCUS currently focus on carbon capture from advanced power generation (i.e. IGCC); oxy-fuel combustion and chemical looping, and high-purity industrial $\mathrm{CO}_{2}$ sources (i.e. coal-to-liquids, hydrogen production for refineries, coal-to-chemicals and ammonia production). In terms of $\mathrm{CO}_{2}$ utilisation, EOR and ECBM recovery are current areas of focus for government-funded CCUS research projects.

As funding for R\&D and demonstration in this area grows, it is important to consider the development of a path that will lead to maximised mitigation of $\mathrm{CO}_{2}$ emissions and permanence of $\mathrm{CO}_{2}$ sequestration at a reduced cost. Many existing and potential uses of $\mathrm{CO}_{2}$ do not ensure the permanent removal of $\mathrm{CO}_{2}$ from the atmosphere. While current CCUS activity, both globally and in China, focuses on enhancing the commercial viability of projects, it is important not to lose sight of the ultimate goal to permanently contain the $\mathrm{CO}_{2}$.

\section{$\mathrm{CO}_{2}$ utilisation in chemicals production}

Use of $\mathrm{CO}_{2}$ as a raw material in the chemical industry may also offer utilisation potential in China. By means of catalytic direct synthesis, catalytic hydrogenation and catalytic reforming, $\mathrm{CO}_{2}$ may be transformed into urea, an important product used as a chemical raw material, along with dimethyl carbonate, low-carbon hydrocarbons, aldehydes and derivatives, oxygenated alternative fuels, reformed methane and other chemical products. (Shen Guoliang, 2009). 
China has also launched industrial $\mathrm{CO}_{2}$ utilisation demonstration projects to produce biodegradable plastics. A few operators including China National Offshore Oil Corporation's (CNOOC)'s Oriental Chemical Industry City in Hainan, have developed a 3000 tonne per year (t/yr) project in Hainan, as well as Beijing (3000 t/yr), Inner Mongolia and Jinlong (10 $000 \mathrm{t} / \mathrm{yr}$ ), as well as an application for carbonation in the food and beverage industries in a project linked to Huaneng's Bejing and Shanghai facilities.

\section{Enhanced oil and coalbed methane recovery}

There is considerable interest and activity in China in using $\mathrm{CO}_{2}$ for EOR $\left(\mathrm{CO}_{2}\right.$-EOR) and ECBM recovery $\left(\mathrm{CO}_{2}\right.$-ECBMR). The use of $\mathrm{CO}_{2}$ for enhanced oil (and gas) recovery or enhanced coalbed methane recovery may provide the most significant opportunity for $\mathrm{CO}_{2}$ utilisation. EOR can provide an option to offset costs and support the economics of CCS projects (Fig. 11). However, ensuring permanence of storage must be prioritised to meet the intended purpose of CCS deployment. Some utilisation methods would still allow for $\mathrm{CO}_{2}$ leakage back into the atmosphere. $^{4}$

Figure $11 \mathrm{CO}_{2}$ injection for EOR

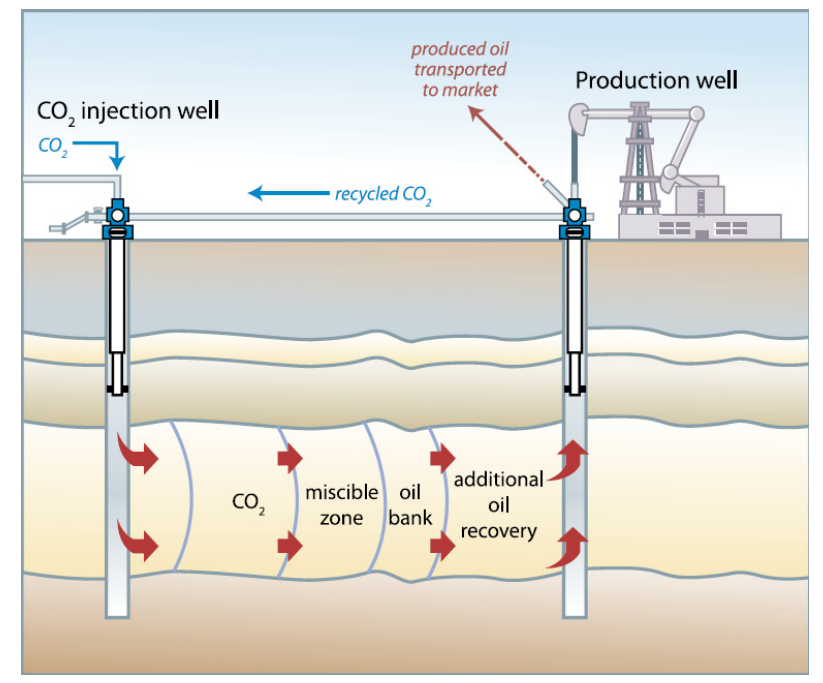

Source: IPCC, 2005.

China's oil and gas industry is dominated by three state-owned holding companies: the CNPC; the China Petroleum and Chemical Corporation (SINOPEC) and CNOOC. PetroChina, an arm of CNPC, is the industry lead in $\mathrm{CO}_{2}$-EOR and has conducted $\mathrm{CO}_{2}$ injections in its oilfields and worked in cooperation with MOST and several research universities. Experimentation with EOR has been conducted in the fields of Jiangsu, Jilin, Changun and Zhongyuan, as well as in the Ordos Basin, Inner Mongolia, and the northern Tarim Basin, Xinjiang Province, (Liu, et al., 2008; Friedmann, 2009). PetroChina has also experimented with $\mathrm{CO}_{2}$ injection for enhanced coalbed methane recovery (Friedmann, 2009).

\footnotetext{
${ }^{4}$ Note. Petrochina's research arm in the Research Institute for Petroleum Exploration and Development (RIPED) has conducted research in this field.
} 
There are a handful of projects exploring EOR potential, including at sites in Shengli, Shandong Province, Zhongyuan, Henan Province, Daqing, Heilongjiang Province and Dagang, Tianjin Province. The Sinopec Shengli Oil Field project, co-operating with the Shengli Power Plant, is making use of chemical absorption methods to capture $\mathrm{CO}_{2}$ to then purify and use for EOR. Further, to these efforts there has been consideration of the potential for ECBM and injection into coal seams for permanent storage. There is early research in this area including co-operation between China and Canada in developing a project in Qinshui Basin, Shanxi Province, managed by China United Coalbed Methane Corporation (Ye Jianping, 2007).

The $\mathrm{CO}_{2}$ Injection/Sequestration project in deep coal seams for CBM exploitation was divided into two phases over five years. The first two years include test injection of $\mathrm{CO}_{2}$ in one $\mathrm{CBM}$ well to study how $\mathrm{CO}_{2}$ injection in deep and unmineable coal seams can increase output of $\mathrm{CBM}$ and sequester GHG. Early test results suggest that recovery of CBM wells may be increased by as much as $80 \%$ by employing $\mathrm{CO}_{2}$ injection.

In 2009, the Canadian government invested CAD 500000 in the programme (China Energy Net, 2010). The role that enhanced coalbed methane (ECBM) recovery may be able to play in China will depend upon further geological assessments of possible coalbed methane seams and proximity to $\mathrm{CO}_{2}$ sources. To date, capacity and potential of $\mathrm{CBM}$ and related potential for economic and wide-scale development of the resource are still unclear. However, with existing targets for an increased domestic CBM production (10 million tonnes of CBM in the $11^{\text {th }}$ Five Year Plan), there may be opportunities for companies developing ECBM. However, delayed production

of domestic CBM in general and limited experience in related ECBM technology applications and the need for continued research and integrated market development will remain challenges.

In China, projects led by PetroChina and Shell in Jilin province involve an investment of RMB 205 million. PetroChina, the largest national oil company, began building China's first $\mathrm{CO}_{2}$ EOR project in Jilin Province in 2006. The Shenhua CTL plant and the Huaneng Greengen plant, with plans for storage, will potentially offer additional learning and demonstration of components of CCS technologies and applications for EOR. To expand projects for EOR using $\mathrm{CO}_{2}$ to meet climate change mitigation goals, these projects will need to monitor and limit potential leakage to ensure permanent storage at these sites, which tend to have greater risk of geological fractures than unused sites.

In 2006, MOST approved the national key basic research development programme of the Utilisation of GHG for the Enhancement of Oil Recovery and Underground Storage and launched systematic research on enrichment of $\mathrm{CO}_{2}$ from oxy-combustion using enriched $\mathrm{CO}_{2}$ for EOR. Oil recovery rates may increase by $8 \%$ to $10 \%$ in China, with some initial estimates of an increase in oil production as high as 5 billion to 6 billion tonnes, and storage estimates of 13 billion to 15 billion tonnes $\mathrm{CO}_{2}$. However, early studies estimate that the EOR storage potential in China may be limited. In any case, $\mathrm{CO}_{2}$ injection projects for enhanced oil recovery (EOR) have limited significance for long-term, large-scale $\mathrm{CO}_{2}$ sequestration (MIT, 2007).

\section{CCS Pilot and Demonstration Projects}

Advanced technology programmes including MOST's 973 and 863 programmes and those of the National Science Foundation of China have provided support for CCS demonstration projects. In addition to universities and scientific research institutes, a number of large state-owned 
enterprises such as CNPC, the Shenhua Group, and the Huaneng Group also lead relevant work in the field of CCS technology development.

Many of these activities are currently focused on small pilot projects to develop learning and technical knowledge in advance of large CCS demonstration. For example, the Huaneng Group is running two CCS projects, in Beijing and Tianjin, to pilot IGCC capture and utilisation technologies, along with hydrogen production and hydrogen power generation. The Greengen project in Tianjin is under construction. When completed in 2016 through a three-phase development, it will include a $250 \mathrm{MW}$ IGCC power plant and a $400 \mathrm{MW}$ demonstration plant. The project is seeking to adapt and optimise a gasifier developed by TPRI to work towards a nearzero emissions power plant, working closely with its partners, including international representation (Chen and $\mathrm{Xu}, 2010$ ). China Power Investment Corporation (CPI) is currently developing four IGCC projects to possibly pilot a commercial-size CCS project in Chongqing. For this project, $\mathrm{CPI}$ has discussed using $\mathrm{CO}_{2}$ produced for injection via EOR in oil fields in Jiangsu Province.

\section{Capture projects}

China has a number of $\mathrm{CO}_{2}$ capture technology projects currently in operation, under construction or in the planning stages

\section{Capture projects in operation}

Currently, three pilot projects in power generation have been developed and are now in operation: Huaneng Group's 3000 t/yr capture pilot on its Gaobeidian plant in Beijing (China's first capture pilot, launched in 2008); China Power Investment Corporation's 10000 t/yr capture pilot in Chongqing; and Huaneng Group's 100000 t/yr Shidongkou plant in Shanghai (China's largest capture pilot).

Table 4 Capture projects in operation by 2011

\begin{tabular}{|c|c|}
\hline \multicolumn{2}{|l|}{ A. China Huaneng Group's Gaobeidian Thermal Power Plant w/carbon capture } \\
\hline $\begin{array}{l}\text { Description: The Huaneng Gaobeidian Power Plant was the first coal-fired } \\
\text { power plant with } \mathrm{CO}_{2} \text { capture in China. The project was developed by } \\
\text { Huaneng Group and Xi'an Thermal Power Research Institute Co., Ltd. The } \\
\text { total investment was RMB } 30 \text { million and since its commissioning in } 2008 \text { it } \\
\text { has captured } 3000 \text { tonnes of } \mathrm{CO}_{2} \text { per year. The } \mathrm{CO}_{2} \text { recovery rate has been } \\
\text { reported at greater than } 85 \% \text { with a } \mathrm{CO}_{2} \text { purity reaching } 99.997 \% \text {. The } \mathrm{CO}_{2} \text { is } \\
\text { sold to a local beverage producer. The pilot has capacity for maximum daily } \\
\text { carbon capture of } 12 \text { tonnes from a total of approximately } 4 \text { million tonnes of } \\
\mathrm{CO}_{2} \text { discharged from the Gaobeidian Plant. The estimated cost of production } \\
\text { of every tonne of food grade } \mathrm{CO}_{2} \text { is reported as RMB } 400 \text {. }\end{array}$ & $\begin{array}{l}\text { Project objective: } 3000 \text { t/yr flue gas } \\
\text { carbon capture pilot } \\
\text { Status: Operating current } \\
\text { demonstration since July } 2008 \\
\text { Location: Gaobeidian, Chaoyang } \\
\text { District, Beijing } \\
\text { Technology: Post-combustion } \\
\text { capture + reuse in beverage industry } \\
\text { Capture specifications: Rate }>85 \% \text {; } \\
\mathrm{CO}_{2} \text { purity }>99.9 \%\end{array}$ \\
\hline \multicolumn{2}{|c|}{ B. China Power Investment Corporation (CPIC), Chongqing Hechuan Shuanghuai Power Plant Pilot } \\
\hline $\begin{array}{l}\text { Description: The CPIC Chongqing Shuanghuai Thermal Power Plant has a } \\
\text { carbon-capture pilot based on two } 300 \mathrm{MW} \text { units. Located at Shuanghuai } \\
\text { Town, Hechuan District, in Chongqing Municipality, this project was built in } \\
\text { September } 2008 \text { and put into operation in January } 2010 \text {. It has an annual } \\
\text { capacity of treating } 50 \text { million standard cubic metres of flue gas and annual } \\
\text { production of } 10000 \text { tonnes of industrial-grade } \mathrm{CO}_{2} \text {. With the investment of } \\
\text { RMB } 12.35 \text { million, the carbon capture rate was greater than } 95 \% \text { with a } \mathrm{CO}_{2} \\
\text { concentration over } 99.5 \% \text {. The process requires } 3.5 \mathrm{GJ} \text { of low-pressure steam } \\
\text { and approximately } 90 \mathrm{kWh} \text { of electricity consumed for every tonne of carbon } \\
\text { captured. The cost of liquid } \mathrm{CO}_{2} \text { obtained from the pilot Shuanghuai Plant is } \\
\text { approximately RMB } 400 \text { per tonne. The volume of flue is less than } 1 \% \text { of the } \\
\text { total volume of emissions discharged from the Shuanghuai Power Plant. }\end{array}$ & $\begin{array}{l}\text { Project objective: Industrial pilot } \\
\text { capture } 10000 \text { t/yr of } \mathrm{CO}_{2} \\
\text { Status: Operating demonstration } \\
\text { since January } 2010 \\
\text { Location: Hechuan, Chongqing } \\
\text { Technology: Post-combustion } \\
\text { capture } \\
\text { Capture specifications: Rate }>95 \% \\
\mathrm{CO}_{2} \text { purity }>99.5 \%\end{array}$ \\
\hline
\end{tabular}


C. China Huaneng Group's Shanghai Shidongkou No. 2 Power Plant

Description: Huaneng operates a $\mathrm{CO}_{2}$ capture demonstration from flue gas from two $660 \mathrm{MW}$ ultra-supercritical boiler units at the Huaneng Shanghai Shidongkou No. 2 Power Plant. The plant is currently capturing 100000 tonnes of $\mathrm{CO}_{2}$ per year with post-combustion technology developed in China. Operating since 2009, the capture project has the capacity to treat 66000 standard cubic metres per hour, accounting for approximately $4 \%$ of the total flue gas emissions from these two units. The plant is designed to capture and produce 100000 tonnes of food grade $\mathrm{CO}_{2}$ annually, which is sold to local industries. Approximately $75 \mathrm{kWh}$ of electricity is consumed for the capture of every tonne of $\mathrm{CO}_{2}$. The investment of RMB 150 million in the demonstration site has enabled China to have one of the world's largest capture facilities on a coal-fired power plant.
Project objective: $120,000 \mathrm{t} / \mathrm{yr}$ flue gas carbon capture, demonstration carbon capture

Status: Operating demonstration since 2009

Location: Baoshan District, Shanghai

Technology: Post-combustion

capture + reuse in the beverage industry

Capture specifications: $\mathrm{CO}_{2}$ purity > $99.5 \%$

Source: ACCA21, 2011, IEA Research

\section{Capture projects under construction}

China also has two advanced capture projects under construction: Huaneng Group's IGCC Greengen project in Tianjin; and an oxy-fuel pilot being developed by Huazhong University of Science and Technology (HUST) in Hubei Province.

Table 5 Capture projects under construction by 2011

\begin{abstract}
D. Huaneng Tianjin GreenGen Project carbon capture and sequestration projec
Description: Located in the Binhai New District, the Huaneng Tianjin GreenGen Project is designed as an R\&D project and demonstration of coalbased energy systems based on IGCC and focused on gasification-based hydrogen production. The project's hydrogen turbine, IGCC and fuel-cell power generation, enables $\mathrm{CO}_{2}$ separation and treatment. The project is designed to enhance efficiency of coal power generation to enable near-zero emissions of pollutants and $\mathrm{CO}_{2}$ in three phases. The first phase, 2006-11, aims at a $250 \mathrm{MW}$ IGCC demonstration plant and laboratory. The second phase, planned for 2010-12, seeks to conduct R\&D and demonstration and optimisation of technologies such as gasification, hydrogen production, hydrogen turbines, and fuel cells, and to prepare for construction of a $400 \mathrm{MW}$ near-zero emissions power station. The third phase, 2013-15, includes completion of construction of the $400 \mathrm{MW}$ gasification-based hydrogen, hydrogen and fuel cell generation near-zero emissions power station. In February 2010, the Asia Development Bank (ADB) provisioned USD 135 million in loans ADB and provided USD 1.25 million technical assistance grant to study potential application of CCS technologies.
\end{abstract}

Project objective: IGCC and focused on gasification-based hydrogen production

Status: Phase 1, 250 MW IGCC plant

with capture potential is under construction

Location: Binhai New Area, Tianjin Technology: IGCC, pre-combustion capture, EOR

E. Huazhong University of Science and Technology $35 \mathrm{MW}$ oxyfuel industrial pilot

Description: HUST has built an existing $400 \mathrm{KW}$ oxy-fuel pilot facility. This facility uses staged combustion and fires pulverised coal and/or oil under air with $\mathrm{O}_{2} / \mathrm{CO}_{2}$ flue gas recycling and a calcium-based absorbent inside the furnace for desulphurisation. A $3 \mathrm{MW}$ oxy-fuel pilot plant is planned for an early stage with a capture ability of 1 tonne of $\mathrm{CO}_{2}$ per hour.

Project Objective: 35 MW oxy-fuel combustion boiler with plans for full demonstration plant with 100000 t/yr $\mathrm{CO}_{2}$ storage

Location: Yingcheng, Hubei Province Technology: Oxy-fuel combustion + storage in salt mines

Status: Small pilot built/planning next Capture specifications: Capture rate $>90 \%$

Source: ACCA21, 2011, IEA Research

\section{Capture projects: planned and in the pipeline}

Several other projects have been announced or planned, though the development of these projects and related approvals are still unclear. Three plants are currently planned but awaiting further preparation and approval: the China Guodian 20000 t/yr capture pilot; an IGCC clean- 
energy technology demonstration, project in Lianyungang City; and an IGCC project in Guangdong, led by the Dongguan Taiyangzhou Power Corporation.

Table 6 Capture projects: Planned and in the pipeline

F. China Guodian carbon capture and utilisation project, Tianjin Beitang Power Plant

Description: China Guodian Corporation plans to construct a 20000 tonne per year CCUS project . The project, located at Tianjin's Beitang Power Plant, will use a chemical absorption technique to capture and process liquid $\mathrm{CO}_{2}$ that will be treated for food-grade application.

Project Objective: $10000 \mathrm{t} / \mathrm{yr}$ carbon capture; 20000 tonnes per year

Location: Tianjin

Technology: Post-combustion capture for utilisation in the food industry

Status: Planned

Capture specifications: Rate > $95 \% ; \mathrm{CO}_{2}$ purity $>99.5 \%$

\section{G. Clean energy technology demonstration system in Lianyungang}

Description: The Energy Power Research Center of the Chinese Academy of Sciences is implementing this demonstration project, planned to include an advanced $1200 \mathrm{MW}$ IGCC ultra-clean power generation plant, two $1300 \mathrm{MW}$ ultra-supercritical generation systems and co-production of chemical raw materials and fuels. The capture and storage demonstration will plan to capture 1 million tonnes per year to store in a saline layer. Planning and approval is aimed by end of 2011; with construction to begin in 2012 and expected completion in three years.
Project Objective: Capture and future storage demonstration of 1 million tonnes of $\mathrm{CO}_{2}$ per year Status: Planned for 2012-15; seeking approval

Location: Lianyungang, Jiangsu Province

Technology: IGCC + aquifer storage Capture specifications:

Future Plans: Planning and approval by end 2011; construction planned to begin in 2012

H. Dongguan Taiyangzhou Power Corporation, Xinxing Group, Nanjing Harbin Turbine Co Ltd.

Description: A planned new-build $750 \mathrm{MW}$ (net) IGCC power plant is expected to capture up to 1 million tonnes of $\mathrm{CO}_{2}$ per year. $\mathrm{CO}_{2}$ would be transported in a pipeline and stored in near-depleted offshore oil and gas reservoirs. At present, the proposed storage site would be $100 \mathrm{~km}$ from the power plant. Once feasibility studies receive approval from China's National Energy Administration, construction is expected to take three years. Dongguan Taiyangzhou Power Corporation is in an early phase of planning construction of a $750 \mathrm{MW}$ (net) IGCC plant with CCS. The project is regarded as one measure to implement the Reform and Development Plan for the Pearl River Delta endorsed by China's State Council.
Project objective: Capture of 1 million tonnes of $\mathrm{CO}_{2}$ per year Location: Dongguan, Guangdong Technology: IGCC with CCS Status: Planned for 2012-15; seeking approval

Source : ACCA 21 2011, IEA Research.

\section{Projects focusing on $\mathrm{CO}_{2}$ utilisation and storage}

While the Government of China attaches increasing importance to climate change mitigation, the country's early CCS demonstration projects, GreenGen and Shenhua's Direct Coal Liquefaction / CCS Project, have progressed rapidly through their application of coal gasification and coal liquefaction, which are key technologies that will eventually be coupled with $\mathrm{CO}_{2}$ EOR projects that have strategic implications for China's long-term energy supply. The current stage of development, overall capacity and the requirements for permanence of $\mathrm{CO}_{2}$ storage through EOR and ECBM processes are still, however unclear and need to be further assessed as the projects develop.

Five $\mathrm{CO}_{2}$ utilisation and storage projects are currently in development: the Shenhua Group's coalto-liquids CCS demonstration project in Erdos, Inner Mongolia; SINOPEC's carbon capture and EOR demonstration project, in Shengli Town, Dongying City, Shandong Province; China United Coalbed Methane's $\mathrm{CO}_{2}$ sequestration and enhanced coalbed methane recovery project in 
Qinshui Basin, Shanxi Province; PetroChina's $\mathrm{CO}_{2}$ EOR research and pilot project, Jilin Oilfield, Jilin Province; and ENN Group's Micro algae bio-fuel project in Dalate, Inner Mongolia.

Table 7 Projects focusing on $\mathrm{CO}_{2}$ utilisation and storage

I. Shenhua Group Erdos coal-to-liquids CCS demonstration project (Storage)

Page | 30 Description: Shenhua Group's Erdos CTL capture and sequestration industrial demonstration project was designed to capture $\mathrm{CO}_{2}$ discharged from the Shenhua gasification-based hydrogen production device, a part of the direct coal-liquefaction technology. The $\mathrm{CO}_{2}$ will be transported by tank truck to a storage site within $17 \mathrm{~km}$ and injected $1000 \mathrm{~m}$ to $3000 \mathrm{~m}$ underground for storage in a saline aquifer. In the gasification-based hydrogen production, a $\mathrm{CO}_{2}$-rich gas mixture with concentration of $87 \%$ would be generated, far higher in concentration than emissions discharged from a power plant, greatly reducing the cost of carbon capture. In the first phase, the project aims to capture 100000 tonnes of $\mathrm{CO}_{2}$ per year. An additional investment of RMB 210 million would contribute to the development for a staged process planned to store 1 million tones to 3 million tonnes of $\mathrm{CO}_{2}$. This CCS project is one of the first planned to sequester $\mathrm{CO}_{2}$ in deep saline aquifers. The site was identified through 3D seismic exploration and preliminary analysis of geological conditions in the area.

J. $\mathrm{CO}_{2}$ capture and EOR demonstration China SINOPEC Shengli Oil Field

Description: The Shengli Power Plant Capture project is part of SINOPEC's science and technology pilot test project. The project uses a compound amine method to recover $\mathrm{CO}_{2}$, by which $\mathrm{CO}_{2}$ from flue gas of a coal-fired power plant was captured, purified and compressed for truck transport, to be used for enhanced oil recovery in a low permeability oil reservoir in the Shengli Oilfield. In March 2010, this project was producing liquid $\mathrm{CO}_{2}$ with $99.5 \%$ concentration. Since 2008, the plant has operated a 100 tonnes per day pilot for CCS and EOR, capturing a $14 \%$ slipstream from the flue gas of the Shengli Power Plant and Oilfield. Sinopec has plans to develop an 800000 tons - 1 million t/yr carbon capture and purification project, EOR and storage demonstration from 2013-14.

Project objective: Shenhua Group aims to develop a CTL capture plant to sequester 100000 tonnes of $\mathrm{CO}_{2}$ per year in the first phase of the project Status: Starting operation Location: Erdos, Inner Mongolia Technology: $\mathrm{CO}_{2}$ chemical source capture + saline aquifer storage

Capture specifications: N/A Storage: Deep saline aquifer, one injection well and one monitoring well

Project objective: $20000 \mathrm{t} / \mathrm{yr}$ to $40000 \mathrm{t} / \mathrm{yr}$ of captured $\mathrm{CO}_{2}$ from flue gas of coal-fired power plant with planned injection into oil reservoir for EOR

Status: With pilot injection started this project produces liquid $\mathrm{CO}_{2}$, operating a CCS and EOR pilot of 100 tonnes per day.

Location: Shengli Town, Dongying City, Shandong Province

Technology: Post combustion + EOR Capture specifications: Rate $>14 \%$ of flue gas from power plant and oil field; $\mathrm{CO}_{2}$ purity $>99.5 \%$

Future Plans: $1 \mathrm{Mt} / \mathrm{y}$ demonstration plant 2013-14

K. China United Coalbed Methane ECBM Project

Description: China United Coalbed Methane, with the support of MOST, has developed a $\mathrm{CO}_{2}$ sequestration and enhanced coalbed methane recovery project in an unmineable deep coal seam. The research project for deep coalseam injection with $\mathrm{CO}_{2}$ for enhanced coalbed methane and mining technologies is in partnership with China United CBM Company, Prata Man, and Enviro Energy International Holdings Limited. Technical support for the project was obtained from Canada-based ARC. The project, commenced in 2008 , identified the site for the injection area and surveyed potential $\mathrm{CO}_{2}$ sources. Subsequently, China United CBM Company conducted well drilling, well completion, fracture, emission and extraction at the test location to obtain geological and engineering parameters. In May 2010, the first field $\mathrm{CO}_{2}$ injection was completed, with 234 tonnes of $\mathrm{CO}_{2}$ injected to deep coal seams. L. CNPC/PetroChina $\mathrm{CO}_{2}$ EOR research and pilot project, Jilin Oilfield

Description: With support from MOST, PetroChina has established a pilot programme in Jilin oilfield in Northeast China. PetroChina started China's first project on $\mathrm{CO}_{2}$ storage and utilisation (EOR), which has been in operation since 2006. The company has invested RMB 200 million, and $\mathrm{CO}_{2}$ has been injected into ten wells to enhance oil recovery. The $\mathrm{CO}_{2}$ mainly comes from natural gas sourced at the Changchun gas field. By May 2010, 122000 tonnes of liquid $\mathrm{CO}_{2}$ had been injected into EOR and storage pilot test sites. A reported 80000 tonnes has been stored. A plant has also been constructed to separate and capture $200000 \mathrm{t} / \mathrm{yr}$ of $\mathrm{CO}_{2}$ from the oilfield. By 2015, expectations are that the site will enable $\mathrm{CO}_{2}$ storage capacity of 0.8 million tonnes to 1 million tonnes and output of $500000 \mathrm{t} / \mathrm{yr}$ of oil.
Project objective: $\mathrm{CO}_{2}$ sequestration and enhanced coalbed methane recovery project

Status: Early test injections have been completed

Location: Qinshui Basin, Shanxi Province

Technology: R\&D on enhanced coalbed methane technologies

Project Objective: Research and develop EOR and storage technologies, enhance oil recovery from low-permeability oil reservoirs for 1 million t/yr by 2015

Status: Phase I completed; Phase II in progress

Location: Jilin Oilfield, Jilin Province Technology: Separation of $\mathrm{CO}_{2}$ from natural gas + EOR

Capture specifications: $\mathrm{CO}_{2}$ source from highly-carbonated natural gas projected $\mathrm{CO}_{2}$ storage of $\mathrm{O} .8$ million to 
M. ENN Group's Micro algae biofuel project

Description: The project aims to use microalgae to absorb $320000 \mathrm{t} / \mathrm{yr} \mathrm{CO}_{2}$ emitted from the flue gas of coal-derived methanol and coal-derived dimethylether production equipment and to produce bio-diesel and feeds.
Project Objective: ENN is planning to construct a facility that absorbs $320000 \mathrm{t} / \mathrm{yr}$ of $\mathrm{CO}_{2}$ Location: Dalate, Inner Mongolia

Status: Under construction

Technology: Third-generation bio-fuel technology

Capture specifications: Capture from coal-derived methanol and

dimethylether production

\section{Options for Financing CCS in China}

\section{Financial rationale and needs}

While CCS still faces considerable technological, regulatory and public acceptance hurdles, a central barrier to deployment is the ability of project developers to overcome project risks and secure adequate financing to address the additional or incremental cost of projects with CCS, often referred to as the commercial gap. Based on several reports and IEA estimates, a typical coal-fired power plant in OECD member countries will likely incur additional costs of around USD 1.5 billion (for capture technologies without storage costs, with $90 \%$ capture efficiency).

In China those figures for capture costs are likely to be lower, roughly USD 1 billion, based on 2009 cost analysis by the UK-China Near Zero Coal initiative (NZEC). Operating costs for power plants with CCS are also higher, largely because of the energy penalty or extra energy required to run the capture and compression system (15\% to 30\%). With today's technology, coal-fired power plants with CCS could see an increase in the cost of electricity of as much as $80 \%$ or would need carbon prices at levels as high as USD 70/ton (USD 40/ton in China) to become financially viable. More specific cost analysis for China can be referenced from the 2009 NZEC studies and other domestic cost analysis. However more in-depth analysis of costs related to the whole chain of CCS and site-specific costs would help further clarify costs for specific technology pathways that are likely to differ in China from those of other countries engaging in CCS demonstration.

According to IEA CCS cost analysis, considering uncertainties of current cost performance data, from a global perspective, no single technology for carbon capture from coal-fired power generation clearly outperforms the available alternative capture routes. In particular, this applies to average overnight costs and levelised cost of electricity, but also includes cost of $\mathrm{CO}_{2}$ emissions avoided, provided the same plant without capture is chosen as a reference (Finkenrath, 2011).

China's position towards funding CCS on a wide scale is similar to that of most developing countries. Some concerns reflect the belief that CCS is too expensive, reluctance to accept responsibility for funding it solely themselves, considering China's stated $\mathrm{CO} 2$ emissions per capita compared with OECD figures. However, given China's rising energy consumption and correlated carbon emissions per capita, further consideration for rapid mitigations efforts even at higher costs may be needed, for China's efforts to achieve a balance between enhancing and sustaining energy security - while providing affordable energy - also limit progress in this area. 
CCS demonstration projects and early commercial projects are expected to be more expensive than later projects, and costs are expected to decline as experience is gained and the technology moves along its learning curve (Riahi et al., 2004) (Figure 5.1). Public-private partnerships (PPP) and targeted incentives need to be further explored at this stage in order to address the commercial gap, accelerate deployment and drive down both costs and risks. Substantial public funding support is needed to mitigate high costs and risks, but governmental support levels should decline with experience, technology improvements and market development.

Figure 12 The commercial gap for CCS technologies

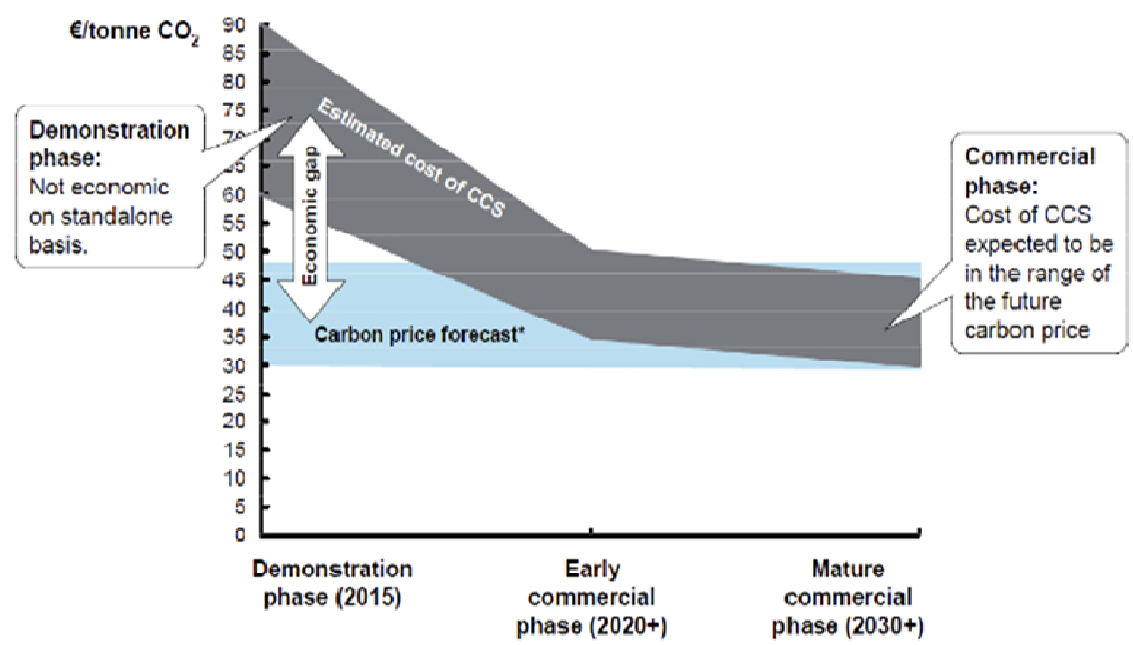

*The commercial gap (additional cost of technologies compared to conventional technology) is a major barrier to large-scale demonstration projects and early commercial deployment. Current CCS financing and risk-sharing mechanisms are insufficient in both OECD and non-OECD countries. The extent to which CCS is deployed largely depends on the provision of stronger incentives, industry developments and international cooperation.

Source: McKinsey, 2008.

A number of CCS financing mechanisms and incentives are available, but none are sufficient to fully address the magnitude of the commercial gap. There is a strong consensus among experts in the CCS community that governments must offer a more robust suite of incentive policies and financing tools to help mobilise large volumes of private capital. There is also an assumption that OECD member countries must support CCS demonstration projects in developing countries, but issues related to broad climate policy uncertainties make commitments uncertain. Despite a number of proposals and discussions on these critical financing issues, there have been limited policy actions. CCS funding models and financing options remain insufficient in OECD countries and are just beginning to emerge in developing countries and China. Given the magnitude of CCS deployment needs both globally and in China, it is crucial to develop financing mechanisms matched to the scale of the challenge.

\section{Financing sources and schemes}

To respond to the large CCS investment challenge for China, there are a number of existing and potential domestic and international financing options that might be used to advance large-scale CCS implementation in China. 


\section{Domestic financing options in China}

China's energy and industrial companies and capital markets, like those in the rest of the world, to date are unable to fully support the additional costs and risks of large-scale CCS demonstrations. The Chinese government has made modest CCS RD\&D commitments and has considerable financial resources to support clean energy investments. However, in the context of current economic, strategic and developmental priorities, China is taking a cautious approach. At the same time, the Chinese government has made it clear that potential domestic financing sources (described below) will need to be highly leveraged with international collaboration and financing mechanisms, (Wan Gang, CSLF Ministerial). International know-how and technology transfer are also critically important and should accompany any financial support.

\section{The state budget and related measures}

The energy sector is a strategic priority in China, and the government has set ambitious targets to improve efficiency of its coal fleet, further develop nuclear and renewable energy, and enhance energy efficiency. In 2009, China was first in the world in clean energy investment with USD 34.6 billion, nearly double the US total of USD 18.9 billion (Pew Charitable Trusts, 2010).

Because most of China's energy and large industrial companies are state-owned enterprises, the government is able to significantly influence the adoption of certain technologies through its central planning, policies and state budgets. Clean energy policies are largely driven by the central government and enacted through various national, provincial and local government programmes.

In addition to state budget support for CCUS RD\&D, incentives or subsidies offered for renewable energy (i.e. subsidies, tax incentives, low-interest or interest-free loans, pricing mechanisms such as power purchase agreements or feed-in tariffs, etc.) could be tailored for CCUS. There is no official indication that the Chinese government has considered using incentive tools available for renewable energy, for example, to promote CCS; however, it is worthwhile to highlight key elements of their approach to renewables.

The Renewable Energy Law of 2005 was the key piece of recent legislation that mandated minimum deployment levels (i.e. gigawatts of capacity by a target date). It supported these goals with the establishment of a renewable energy subsidy raised by charging a fee to all electricity users in China of about USD 0.029 per kilowatt-hour (kWh). The fee, originally based on the incremental difference between coal and renewable energy (USD 0.044 to USD 0.059 per kWh), goes to electricity grid operators that must buy renewable power from project developers. Thus, the cost of renewable energy development and deployment in excess of conventional coal-fired power is passed on to all customers as a surcharge to retail power prices. In 2009, the Renewable Energy Law was amended to require electricity grid companies to buy all the electricity produced by renewable energy generators. The national government provides incentives for grid companies to connect to renewable energy projects, and those who do not comply face significant fines (Campbell, 2010).

To further highlight the opportunity for CCUS under a similar renewable energy policy, a $400 \mathrm{MW}$ IGCC facility with CCUS would require a tariff of USD $0.112 / \mathrm{kWh}$ to achieve a market financial return. (ADB, 2011) (Table 5). The required tariff is $23 \%$ higher than tariffs currently available for wind power in China (approximately USD 0.09/kWh). 
Table 8 Financial scenarios for IGCC and supercritical power plus CCS in China

\begin{tabular}{|c|c|c|c|c|}
\hline \multirow{2}{*}{ Scenarios } & \multicolumn{2}{|c|}{ Tariff USD/MWh } & \multirow{2}{*}{$\begin{array}{l}400 \text { MW IGCC } \\
\text { with CCS }\end{array}$} & \multirow{2}{*}{$\begin{array}{c}650 \mathrm{MW} \\
\text { supercritical } \\
\text { with CCS }\end{array}$} \\
\hline & IGCC & Supercritical & & \\
\hline $\begin{array}{l}\text { Base Case (No } \\
\text { subsidy) }\end{array}$ & 112 & 90 & No subsidy & No subsidy \\
\hline \multicolumn{5}{|c|}{ "What if" assessments to provide targeted financing incentives } \\
\hline $\begin{array}{l}\text { Carbon revenues } \\
\text { only }\end{array}$ & 83 & 56 & USD 37/tonne $\mathrm{CO}_{2}$ & $\begin{array}{r}\text { USD 70/tonne } \\
\mathrm{CO}_{2}\end{array}$ \\
\hline Capital subsidy only & 99 & 73 & USD 135 & USD 350 \\
\hline $\begin{array}{l}\text { Capital subsidy and } \\
\text { energy penalty offset }\end{array}$ & 88 & 61 & USD 135 million + USD 24 million per/a & $\begin{array}{l}\text { USD } 350 \text { million + } \\
\text { USD } 50 \text { million/a }\end{array}$ \\
\hline $\begin{array}{l}\text { Identical capital } \\
\text { subsidy and carbon } \\
\text { offset revenue at } \\
\text { USD20/ton }\end{array}$ & 75 & 67 & USD 226 million & USD 226 million \\
\hline
\end{tabular}

Source: ADB, 2010.

The Chinese government has also established a number of funds (some in co-operation with nonprofit organisations or jointly with provincial governments) to accelerate low-carbon project development and reduce GHG emissions. These may be broadened to include CCS (Table 9) (International Emissions Trading Association, 2010).

Table 9 Examples of China's low-carbon investment funds

\begin{tabular}{|c|c|c|}
\hline Fund & Organisation & Purpose \\
\hline $\begin{array}{l}\text { China Clean Development } \\
\text { Mechanism Fund }\end{array}$ & Chinese Ministry of Finance & $\begin{array}{l}\text { Use revenue from CDM projects to } \\
\text { promote and support low-carbon } \\
\text { projects. }\end{array}$ \\
\hline China Green Carbon Fund & China Green Foundation & $\begin{array}{l}\text { Support forestation and other forest } \\
\text { management and conservation } \\
\text { measures. }\end{array}$ \\
\hline Green Energy Technology Fund & $\begin{array}{l}\text { Chinese State-owned Assets } \\
\text { Supervision and Administration } \\
\text { Commission }\end{array}$ & $\begin{array}{l}\text { Support clean energy industries in } \\
\text { Tianjin's Binhai High-Tech Industry } \\
\text { Park. }\end{array}$ \\
\hline Venture Capital Funds & Private and state funds & $\begin{array}{l}\text { Invest in the country's high-tech } \\
\text { sector, with new energy and energy } \\
\text { efficiency as a prime focus. }\end{array}$ \\
\hline
\end{tabular}

Source: Bloomberg New Energy Finance, 2010.

It is worthwhile to point out that China's RMB 4 trillion (USD 586 billion) stimulus package (2008-09) included state budget expenditures across ten industries and sectors, with the bulk of the funds directed towards infrastructure. Approximately, RMB 210 billion (USD 31 billion) $-5.3 \%$ of its entire stimulus package - was used for energy conservation and environmental engineering, although none directly stipulating CCS (EON, 2009).

\section{Provincial and local governments}

As noted, policies for encouraging the adoption of energy technologies are largely driven by China's central government and enacted through national, provincial and local government programmes. Both provincial and local governments provide incentives for renewable energy development. China has established economic development zones or industrial clusters to stimulate technology manufacturing and provide resources to energy and infrastructure projects, 
including IGCC, a key CCS application. Relevant projects that have received financial support from local government include GreenGen in Tianjin Municipality, the Shenyang IGCC project in the Shenyang High Tech Industrial Development Zone and the Dong Guan IGCC project in Dong Guan (Hart and Liu, 2010).

\section{Domestic bank loans}

Like many sectors in China, the banking sector is under transition from centrally planned to market-oriented, and banks range from publicly owned to hybrids. China Development Bank (CDB), a wholly state-owned bank with a mandate to advance China's national interest, plays an important role in the energy sector (Downs, 2010). In 2010, CDB, with double the assets of the World Bank, provided over USD 35.5 billion in low-interest loans to Chinese companies for clean energy projects, which constitute about $28 \%$ of all CDB lending. Many of the loans were in support of expanding China's manufacturing and production base, which will help push down technology costs for domestic use and enable more competitive exports.

Given financing for demonstration projects to date, China's state-owned banking system has demonstrated willingness to lend to CCUS projects, which is significant, particularly, as few banks globally have been willing to lend to CCS-related projects. For example, domestic banks provided USD 195.5 million (representing 47\% of project costs) to finance GreenGen's Phase I and are expected to participate in the second and third phases, which include CCUS. Future CCUS projects supported by the central government are likely to be viewed favourably by state-owned domestic banks for financing support, as they actively promote Chinese government policy.

\section{Domestic carbon markets}

In 2013, China plans to launch a domestic carbon market to help meet its 2020 carbon intensity targets: - $40 \%$ to - $45 \%$ by 2020 compared with 2005 levels and a $17 \%$ reduction over the $2011-15$ period. Targets for individual provinces have been allocated and the government has been exploring sectoral cap-and-trade schemes to help meet these goals, but there is still debate among experts and industry regarding their design (World Bank, 2011). Domestic trading platforms will be included in three major exchanges, in Beijing, Shanghai and Tianjin, and seven pilot carbon market regions have been chosen: the provinces of Guangdong and Hubei and the cities of Shenzhen, Beijing, Chongqing, Shanghai and Tianjin (Stanway, 2011) Possible sectors for pilot projects are likely to include coal-fired power generation (for which CCUS could be eligible) (Jing, 2010). Demand for domestically generated carbon credits could open significant CCUS project opportunities.

\section{China's state-owned enterprises and international private capital}

China's industrial sector uses about $70 \%$ of total energy, with much of it concentrated among about 1000 state-owned enterprises. Therefore government sustainability directives for clean energy and carbon-capture technologies can be relatively quickly deployed. Moving beyond R\&D investments, large CCS projects would require larger additional pools and funds for CCS directed by state-owned enterprises (SOEs). As costs for deploying CCS in China are still unclear, and may vary from low-cost early opportunity industrial projects to more expensive projects in power and industry, select SOEs may be directed by agencies with authority over these sectors to stimulate development and deployment in specific CCS applications. As SOEs develop their plans for strategic investments in line with government policy, costs related to deployment of CCS must 
examined along with other mitigation options in terms of the cost of inaction as well as potential cost increases in later CCS retrofits if plans are not put in place early on.

International collaborators and international joint venture partners on both RD\&D projects have generally supported their own efforts in China by contributing knowledge, expertise or funding to the projects. Given China's comparative CCS advantages, discussed earlier, international equity investors may be attracted to some projects as an opportunity to develop projects and technologies at a lower cost than that of deploying projects in OECD or other developed countries. Given potential market opportunities and the expected development of operational and technical expertise in China, building early partnerships with Chinese firms also provides a strategic business case for funding and investing in projects in China. Examples of companies that have invested in RD\&D in China include Peabody Energy, with a 6\% equity stake in GreenGen, and Duke Energy's broad research alliance with ENN Group that includes CCS (Duke Energy News, 2011) and project co-operation on ENNa low 2 algae utilisation pilot project.

Table 10 Examples of sources of financing for key CCS demonstration projects

\begin{tabular}{|c|c|c|c|}
\hline Project Name & Project Owner(s) & Investment & Financing Source \\
\hline $\begin{array}{l}\text { Gaobeidian Power Plant Carbon } \\
\text { Capture }\end{array}$ & Huaneng Group & CNY 30 million & China funds* \\
\hline Shanghai Shidongkou & Huaneng Group & $\begin{array}{l}\text { CNY } 150 \\
\text { million }\end{array}$ & China funds \\
\hline $\begin{array}{l}\text { Carbon Capture projects of } \\
\text { Chongqing Hechuan Shuanghai } \\
\text { Thermal Power Plant }\end{array}$ & $\begin{array}{l}\text { China Power Investment Corporation } \\
\text { (CPIC) }\end{array}$ & $\begin{array}{l}\text { CNY } 12.35 \\
\text { million }\end{array}$ & China funds \\
\hline Erdos CTL CCS demonstration & Shenhua Group & $\begin{array}{l}\text { CNY } 210 \\
\text { million }\end{array}$ & China funds \\
\hline Greengen Project (Tianjin) & $\begin{array}{l}\text { (1) Huaneng Group } \\
\text { (2) Datang Group } \\
\text { (3) Shenhua Group } \\
\text { (4) China Huadian Corporation } \\
\text { (5) CPIC } \\
\text { (6) Peabody Corporation (USA) } \\
\text { (7) China Guodian Corporation } \\
\text { (8) National Development and } \\
\text { Investment Corporation } \\
\text { (9)China National Coal Group } \\
\text { Corporation }\end{array}$ & $\begin{array}{l}\text { CNY } 7 \text { billion } \\
\text { (approximately) }\end{array}$ & $\begin{array}{l}\text { (1) China funds } \\
\text { (2) USD } 135 \\
\text { million, Asia } \\
\text { Development Bank } \\
\text { (3) USD } 1.25 \\
\text { million, ADB } \\
\text { technical grant }\end{array}$ \\
\hline $\begin{array}{l}\mathrm{CO}_{2} \text { capture and EOR } \\
\text { demonstration China SINOPEC } \\
\text { Shengli Oil Field }\end{array}$ & Sinopec Corp & Unclear & China funds \\
\hline $\begin{array}{l}\text { Deep coal seam injection of } \mathrm{CO}_{2} \\
\text { for enhancing } \mathrm{CBM} \text { recovery }\end{array}$ & $\begin{array}{l}\text { China United Coalbed Methane Co. } \\
\text { Ltd } \\
\text { An Alberta Canada Firm } \\
\text { Hong Kong Enviro Energy } \\
\text { International Holdings Ltd. }\end{array}$ & CNY 9.9 million & $\begin{array}{l}\text { (1) China funds } \\
\text { (2) CAD } 500000 \\
\text { Grant from } \\
\text { Canadian } \\
\text { Government }\end{array}$ \\
\hline $\begin{array}{l}\text { CNOOC Degradeable plastic } \\
\text { production from } \mathrm{CO}_{2}\end{array}$ & $\begin{array}{l}\text { China National Offshore Oil } \\
\text { Corporation }\end{array}$ & $\begin{array}{l}\text { CNY } 152 \\
\text { million }\end{array}$ & China funds \\
\hline
\end{tabular}

* Reference to funding that has been directed through the project owner, in most cases state-owned enterprises, however it is unclear whether domestic bank loans or additional public funds are provided.

Source: IEA research from Chinese news publications.

\section{International institutional financing}

There is intense interest within the international community in supporting China's efforts to reduce greenhouse-gas emissions through CCUS deployment. Moreover, China's government has 
strong potential to raise international funds. The Chinese government is also highly organised and effective at accessing multilateral development funds, making the country an attractive location for CCUS demonstration projects. Broadly speaking, potential international financing mechanisms fall into four categories: bilateral government funding; multilateral institutions; multilateral development banks; carbon finance.

\section{Bilateral government funding}

The European Union and several EU countries, Australia, Japan and the United States currently have bilateral activities with China on CCUS RD\&D which, in many cases include the broader portfolio of clean coal technologies. As noted previously, these activities have focused on studies, modelling, geologic storage assessments, test pilots etc. This is in large part because of funding limitations but also because of China's early stage of CCUS development. Now that China has established a foundation for CCS, it is prudent to advance large-scale demonstration activity and more substantial financing support. While current bilateral financing levels are too low for any meaningful large-scale projects, bilateral arrangements offer funding vehicles that could potentially be leveraged. Prominent examples of bilateral activities include:

China and the European Union: In September 2005, the EU-China Partnership on Climate Change was established to provide a high-level political framework for co-operation between the European Union and China. Several areas of CCS co-operation were launched under this framework including the China-UK Near Zero Emissions Coal Initiative (NZEC), Co-operation Action within CCS China-EU (COACH) and the Support to Regulatory Activities for Carbon Capture and Storage $\left(\mathrm{STRACO}_{2}\right)$. NZEC and $\mathrm{COACH}$ have both helped lay the foundation for large-scale CCUS demonstration. Funding is delivered through the European Union's Sixth Framework Programme. The overall budget for $\mathrm{COACH}$ is USD 3.7 million over three years.

China and the United States: Bilateral co-operation on CCUS between China and the United States is guided under two principal agreements: the US-China Fossil Energy Protocol (Shengli Consulting, 2010) and the Protocol for Cooperation on a Clean Energy Research Center. The Fossil Energy Protocol was established in 2000 between the US Department of Energy (US DOE) and MOST and includes six annexes under which joint projects are conducted (CCUS cuts across all of the annexes but is focused in Annex II: Clean Fuels and Annex IV: Energy and Environmental Control Technologies). In November 2009, the high-level US-China Clean Energy Research Center (CERC) was established with USD 150 million in equal joint funding that will support institutions and researchers in the two countries. CERC's Advanced Coal Technology Consortia (CERC-ACTC) have developed a five-year joint work plan that includes CCUS (US DOE, 2011).

China and Australia: Most bilateral CCUS activities take place under the Australia-China Joint Coordination Group on Clean Coal Technology, which was established in 2007. The China Australia Geological Storage of $\mathrm{CO}_{2}$ (CAGS) Project (2009-11) is supported through the Cleaner Fossil Energy Task Force of the Asia-Pacific Partnership on Clean Development and Climate (funded by the Australian Government) and jointly managed by Geoscience Australia and MOSTS's ACCA21 (Australian funding of AUD 4 million). Australia's Commonwealth Scientific and Industrial Research Organisation (CSIRO) was also involved in China's first post-combustion capture plant with Huaneng Group and has projects relating to geological storage assessments.

China and Japan: Co-operation between China and Japan is directed under China's NDRC and Japan's Ministry of Economy, Trade and Industry (METI). It currently focuses on a USD 300 million $\mathrm{CO}_{2}$ EOR project that plans to capture and utilise $3 \mathrm{Mt}$ to $4 \mathrm{Mt}$ of $\mathrm{CO}_{2}$ per year from two $600 \mathrm{MW}$ coal-fired power plants in China's north-east province of Heilongjiang. Lead partners include 
Japan's Research Institute of Innovative Technology for the Earth (RITE) and CNPC, Daqing Oil Field Ltd., Harbin Utilities Co. and Huadian of China. The project started in 2009.

\section{Multilateral Development Banks}

Support for CCS is available from multilateral development banks, but it is limited to small-grant financing for technical assistance, project preparation advisory services or long-term loans and guarantees. The banks can also play an important role in building conditions that enable investors and commercial financiers to plan CCS investments.

\section{Asian Development Bank (ADB)}

The ADB is active in CCS in a number of areas from technical assistance and capacity building to project loans. In June 2009, the ADB established a CCS Fund to accelerate CCS demonstrations with an initial contribution of AUS 21.5 million (USD 23 million) from the Global CCS Institute (GCCSI). The fund is structured to allow other financing partners to contribute and participate; however, there have been no additional partners to date. The ADB has proposed to build on this CCS fund concept with a larger, dedicated USD 5 billion CCS Demonstration Fund (still in the development stage) to stimulate and provide incentives for CCS demonstration in developing countries. The ADB also manages the Clean Energy Financing Partnership Facility (CEFPF) to support clean energy projects in developing countries through grants and loans, through which funds are available for CCS projects in China.

ADB is providing support to China's GreenGen project, an IGCC with plans to include CCS in later stages. ADB issued a construction loan of USD 135 million and a technical assistance grant of USD 1.25 million to help support IGCC scale-up and CCS (Phases II and III). GreenGen is expected to be eligible for carbon credits under the CDM and the ADB is providing technical support to help with the CDM registration process on the basis that the GreenGen facility will be more efficient than China's baseline power plants.

\section{European Investment Bank (EIB)}

The EIB maintains a China Climate Change Framework Loan of EUR 500 million that provides concessional loans to China for efforts to mitigate climate change. While there have been no projects directly related to CCS, it is a potential mechanism that should be explored further.

\section{The World Bank}

In 2010, the World Bank established a CCS trust fund with support from the Government of Norway (USD 6 million) and GCCSI (USD 2 million) focused on providing technical and capacity building support for CCS in developing countries. It presently does not have a China-specific focus. Another vehicle for CCS is the World Bank's Clean Investment Funds (CIF), a portfolio of new funding sources that provides support in the form of highly concessional loans, grants and risk-mitigation instruments to developing countries to support investments in low-carbon development plans. In order to access CIF funding, a Country Investment Plan is required, which could include CCS.

\section{Global Environmental Facility (GEF)}

GEF is an independent multilateral financial mechanism of the United Nations Framework Convention on Climate Change (UNFCCC). Jointly implemented by the World Bank, the United Nations Environment Programme (UNEP) and the United Nations Development Programme 
(UNDP), the GEF assists developing countries in meeting their commitments under the UNFCCC through policy implementation co-financing, technology pilots and demonstrations. So far, there has not been any financing for CCS in China from GEF. Based on an internal review in 2007, CCS was not eligible for GEF support (ADB Briefing, 2010). However, in response to the request of the Conference of the Parties to the UNFCCC (COP), the GEF is now re-examining its possible support of CCS, which could include capacity building, small technical assistance grants, and possibly large-scale demonstrations. The Special Climate Change Fund, administered by the GEF, has awarded a USD 2.65 million grant to finance a carbon capture project based on a sugar fermentation project in Brazil, but broader CCS support has not gained much traction under the Fund (GEF, STAP, 2007).

\section{Multilateral institutions}

Many of the bilateral partnerships with China described above are also linked with multilateral institutions and programmes (represented by countries and private organisations) that address capacity building, knowledge sharing, technical assistance related to CCS. Working groups from the Asia-Pacific Partnership (APP), Asia-Pacific Economic Cooperation (APEC), the Clean Energy Ministerial, the International Energy Agency, the Major Economies Forum on Energy and Climate (MEF), the World Energy Council (WEC), The GCCSI, the UN Industrial Development Organization (UNIDO), the Carbon Sequestration Leadership Forum (CSLF) and the G8/G20 processes have engaged on a discussion of CCS development.

In many cases and increasingly, these policy fora address CCS financing issues either through expert meetings or advancement of policy recommendations. China's participation in these groups is important to help advance CCS financing strategies, build domestic capacity, enhance networks and share project experience. However, none of these multilateral institutions currently have the capability or mandate to fund large-scale CCS demonstration projects in China. Only the GCCSI and APP have resources, albeit limited, to support some collaborative R\&D or pilot tests.

\section{Carbon finance}

Carbon finance is a generic term for revenue generated by projects from the sale of GHG emissions reduction or trade of carbon credits. The Kyoto Protocol to the UNFCCC brought carbon finance activities into play, but voluntary GHG reduction schemes also generate carbon finance revenue $(G E F, 2011)$. The two most significant legally binding carbon markets in operation today are the EU Emissions Trading Scheme (EU ETS) and the Clean Development Mechanism under the Kyoto Protocol to the UNFCCC. However, a number of other countries including Australia, Canada, China, Indonesia, Mexico, Thailand and the United States have nascent carbon markets under development.

From its inception in 2005 (the year the Kyoto Protocol came into force), the CDM system has generated USD 25 billion for developing countries (World Bank, 2011). Carbon finance can offer an important source of financial support for CCS, but the degree of its impact depends on its inclusion in various trading schemes and also on the market price for carbon credits. The international carbon market is now at its lowest point since it opened, generating only USD 1.5 billion in credits in 2010 (with 97\% coming from the EU). In part, low prices are a reflection of uncertainty over the future of the Kyoto protocol and extension to a second commitment period beyond 2012. 
It is important to emphasise that current carbon prices are inadequate to bridge the commercial gap for CCS projects and must be combined with other types of public assistance or financing mechanisms to enhance viability of project implementation. The EU ETS provides an example of a package of incentives for CCS. Under the EU ETS, regulated emitters may use CCS as a means to reduce their $\mathrm{CO}_{2}$ emissions to meet GHG emissions limits. With current low carbon prices, this mechanism has yet to provide a strong incentive to emitters to deploy CCS, which would be considerably more expensive than current technology. The European Union, however, has further harnessed carbon markets with plans to auction 300 million tonnes of emissions allowances held in the New Entrants Reserve (NER) of the EU ETS, the proceeds of which will fund seven to eight competitively selected large-scale CCS demonstration projects in the European Union. Given variations in the carbon market, it remains to be seen how much resources NER 300 will raise for CCS projects. However, if it is a successful use of carbon finance for CCS development, it could set an example for other carbon markets, including China.

The province of Guangdong has recently proposed a regional cap and trade system for carbon emissions, while other provinces have proposed the establishment of national trading platforms. In October 2010 the 17th Central Committee of the Communist Party of China (CPC) approved proposals to establish a carbon emissions trading market gradually over the next five years, with relevant targets included in the $12^{\text {th }}$ FYP and 2011 White Paper China's Policies and Actions for Addressing Climate Change 2011.

Box 3 China's domestic carbon trading pilot programs

China is assessing sector-specific and economy-wide carbon trading schemes through an examination of the experience of the EU and other regions, along with domestic pilot programs that are expected in three areas:

- Low carbon pilot regions (chosen from five nationally-recognized, low carbon provinces and eight low carbon cities, including Guangdong's proposed regional carbon-trading pilot in 11 cities)

- Energy-intensive industrial sectors (such as electric power, chemicals and oil)

- SOEs

Pilot regions are expected to take on caps on energy or emissions, however, details remain undisclosed and likely undecided. As this process will be introduced gradually over a number of years it is not likely to contribute to significant emissions reductions in the 12th FYP period.

Source: TCG, 2011

\section{Possible mechanisms for the future}

\section{CCS in the Clean Development Mechanism}

One approach to employing carbon finance to support CCS is through carbon-offset projects based on CCS technology. In carbon-offset projects under the Clean Development Mechanism, project proponents develop a project to reduce emissions in a developing country and then sell emissions credits (verified by a third party) to buyers from a developed country with GHG emission reduction targets. The buyers can then apply those credits against their emissions reduction commitment. 
During the UNFCCC negotiations in Cancun in December 2010, CCS was approved as an eligible activity under the CDM provided that technical details are resolved. At the subsequent COP 17/CMP 7 in Durban in December 2011, Modalities and Procedures for CCS in the CDM were officially adopted. This means that CCS projects can now be developed to reduce $\mathrm{CO}_{2}$ emissions in developing countries and generate $\mathrm{CO}_{2}$ emission reduction credits for sale to developed countries with GHG emission reduction commitments. This is a critical step in acceptance of the technology and in providing international incentives for its development. This decision would also create an international standard for addressing technical details of a CCS project.

The debate on whether or not to include CCS in the Clean Development Mechanism under the UNFCCC has been ongoing since 2005, when CCS eligibility in the CDM was first discussed at the COP/MOP in Montreal. These discussions have been protracted and hamstrung by two deeply entrenched positions both for and against its inclusion. Broadly, developed countries and a number of developing countries (including OPEC countries, the African Group, Pakistan, Indonesia and Papua New Guinea) have supported the inclusion of CCS in the CDM, while the opposition has come from a few influential developing countries, including Brazil and India, as well as some countries in the Alliance of Small Island States (AOSIS). The opposition to CCS in the CDM has been based on a range of objections related to technological, methodological/policy, legal, finance/market and other issues.

While CCS has received mixed support among developing countries, China has been cautiously interested and supportive. China, the leading beneficiary country in CDM projects, would clearly additionally benefit from CCS in the CDM. Based on cost data for CCS in China, carbon offsets could potentially bridge a much higher portion of the commercial cost gap in comparison to developed countries. However, China and many other CDM host countries still have questions and concerns related to long-term liability and stewardship of storage sites and associated financial liability. Modalities and Procedures for CCS projects under the CDM leave the decision on assigning long-term liability to the project participants and their respective governments. The rules specify that liability and responsibility for the project rest with the project participants during the project phase and until the liability is transferred to the host party (and to the Annex I party if the host party does not accept the obligation to address a net reversal of storage in case of physical seepage).

However, current weak $\mathrm{CO}_{2}$ emission reduction targets in Annex I countries and resulting low carbon prices as well as lengthy CDM project procedures mean that financing CCS through the CDM remains highly uncertain. It is likely to be several years before the first CCS CDM projects are able to raise capital through the sale of CDM certified emissions reduction credits. It is also plausible that CDM financing will need to be combined with other financing mechanisms to bridge the existing commercial gap of CCS projects.

\section{Green Climate Fund (GCF)}

The Green Climate Fund, adopted in 2010 at the UNFCCC COP 16 as part of the Cancun Agreements, and officially launched by COP 17 in Durban, intends to mobilise and distribute USD 100 billion annually by 2020 as climate finance to help developing countries meet GHG emissions reduction targets and adapt to the impacts of climate change. The GCF will cover full and incremental costs for mitigation, adaptation, technology transfer (including CCS) and capacity building through grants and concessional loans. 
The Green Climate Fund Board was created in Durban and charged with creating rules and procedures to make the GCF operational. The World Bank is currently serving as interim trustee, an arrangement that will be reviewed after three years of operation.

One of the key principles of the GCF is that it should support country-driven actions. For CCS it means that if a developing country views CCS as part of its mitigation strategy it could request assistance through the GCF for this technology development and deployment. Currently the agreement is to have mitigation and adaptation windows under the GCF. However, additional windows could be created, and some countries proposed creation of a CCS window or a window that could facilitate financing of long-term actions that are not cost-effective today. The fund is also supposed to provide resources for readiness, including for development of nationally appropriate mitigation actions (NAMAs) and strengthening of in-country institutions that also includes domestic financial institutions. Given the complexity of legal, institutional and financial arrangements that may be required for successful implementation of a CCS project, countries with interest in CCS may find it beneficial to request assistance for CCS-related capacity building. The Durban Decision on GCF also allows a private-sector facility to enable private-sector involvement. CCS projects that currently require both private and public sector funding could be good candidates for multi-source financing under the GCF.

The fund could be accessed through accredited UN agencies, multilateral development banks, international financial institutions and regional institutions. This provision leaves room for financing opportunities through the initiatives of regional banks and institutions. For example, a proposal from the Asia Development Bank to create a CCS Fund, if implemented, could potentially be a vehicle for accessing GCF resources for CCS development in the Asian region.

\section{Framework for nationally appropriate mitigation actions (NAMAs)}

The emerging post-2012 framework recognises that major developing countries will need to contribute to global emission reduction efforts through domestic action. It also recognises that a substantial proportion of costs that developing countries incur in reducing their emissions may be met by developed countries. Some of this may be achieved through nationally appropriate mitigation actions, which will outline the costs, emissions reductions and time frame associated with these actions.

A registry of NAMAs and available support was officially created at the COP 17 in Durban. Now developing countries will be able to submit their NAMAs seeking support while developed countries will submit information on resources available to support NAMAs. The registry will match NAMAs and support. The idea is that some NAMAs will be unilateral actions by developing countries and will be registered in the NAMA Registry for the purposes of recognition. While other NAMAs may seek international support for their implementation and will be submitted to the Registry to be matched with offers of support made available by developed countries. These offers of support could cover both capital and operating costs. In addition, NAMA support can take the form of building capacity, overcoming financing barriers, reducing the costs of implementing policies (e.g. feed-in tariffs), and developing and demonstrating advanced technologies that are not cost-effective today.

The NAMA framework will significantly differ from the Clean Development Mechanism. First, supported NAMAs will produce GHG emissions reductions that are developing-country contributions to the global effort to control climate change; they will not deliver offsets for developed countries. Second, in most cases, support for NAMAs will begin after developing countries achieve a certain level of emissions reduction from business as usual (BAU) with their 
own resources - so-called unilateral actions (Centre for Clean Air Policy, 2009). Depending on the growth pattern of the developing country, supported NAMAs (e.g. policies and programmes) may produce a net reduction in emissions or they may reduce the amount of growth in emissions that would otherwise occur in these countries.

The NAMA framework could be used by developing countries to request financial support for development and demonstration of CCS technologies. There may be interest and political drivers for developed countries to offer support for CCS NAMAs.

Box 4 Potential benefits to NAMAs supported CCS projects

Developed countries may benefit and choose to support developing-country mitigation efforts through funding for CCS projects in such ways as:

- Short-term operational and technology learning obtained, regardless of project location;

- A wider variety of CCS projects that enhance global experience across applications;

- Cumulative mitigation actions that benefit the global community, no matter where $\mathrm{CO}_{2}$ is stored.

Developed countries with long-term interest in CCS technology (due to energy security, climate mitigation and economic competitiveness) may be interested in supporting CCS projects in the developing world, if this facilitates adoption of CCS.

\section{Technology Mechanism}

At COP 16 in Cancun in 2010, a decision was adopted to create a Technology Mechanism, comprising a Technology Executive Committee (TEC) and a Climate Technology Centre and Network, with the objective of enhancing action on technology development and transfer to support action on mitigation and adaptation. The 2011 Durban Decision on Modalities and Procedures of the TEC adopted rules that would guide the work of the TEC and make it operational in the near future.

Box 5 Focus of TEC's future work

The rules stipulate that the TEC will work on the following six elements:

- Analysis and synthesis;

- Policy recommendations;

- Facilitation and catalysing (including sharing experience in developing and implementing technology roadmaps);

- Linkage with other institutional arrangements;

- Engagement of stakeholders;

- Information and knowledge sharing.

It is clear that CCS could be one of the technologies that could benefit from a targeted and co-ordinated international effort focused on its development and deployment through policy recommendations, knowledge sharing, international networks and partnerships. 


\section{Stakeholder Perceptions of CCS Options in China}

\section{Introduction and views on role of CCS}

Page | 44 In co-ordination with the IEA, the China Coal Information Institute (CCII) ${ }^{5}$ and The Climate Group China, jointly conducted a survey to identify stakeholder perceptions of aspects of CCS technology development in China. The 49 stakeholders surveyed included representatives from government (8), industry (12), research institutions (25), and international organizations (4), with expertise in CCS-related energy policy, technical programmes and industries. This section discusses the survey results and provides an indication of stakeholder perspectives on a range of CCS technology development trends in China. The responses reflect personal opinions of respondents and do not represent the positions of the agencies involved. They should be viewed as providing insight and background to the current debate and discussion of CCS activities and their direction in China.

\section{Role of CCS in China}

The survey suggests that approximately $80 \%$ of stakeholders consulted consider CCS a necessary technology to deal with climate change, though the role, scale and the sectors most impacted vary according to economic drivers, pace of technical development and the learning curve. The findings also suggest that Chinese government agencies have adopted a positive but cautious view of CCS development, noting that critical economic and technical issues remain to be resolved. $75 \%$ percent of government stakeholders responded that CCS may be an important means to reduce China's GHG emissions in the future, with industry stakeholders taking a somewhat lower though still positive attitude.

Among the mitigation options currently available, many stakeholders suggest that priority should be given to:

- (1) developing energy efficiency measures,

- (2) renewable energy deployment,

- (3)nuclear energy technologies, and

- (4) CCS, as it is identified as the lowest priority of the four options.

Respondents from key research institutes and government agencies expressed that the energy penalty and co-ordination required across multiple industry sectors for large-scale deployment of CCS are barriers that limit long-term sustainability of the technology, given unclear cost requirements to make CCS a reality. There was scepticism from some stakeholders, who felt that it would be challenging to develop scalable applications in industry at reasonable cost and for large-scale application of CCS across varying sectors and projects of varying scale. Nonetheless, increased focus on carbon capture and $\mathrm{CO}_{2}$ utilisation in China, using recycled $\mathrm{CO}_{2}$ in production processes, may be a choice to transition to the deployment of CCS for reduction of GHG emissions.

\footnotetext{
${ }^{5}$ The China Coal Information Institute is a research institute under China's State Administration of Work Safety.
} 


\section{Survey key findings}

Survey Finding (Figure 13): Demonstrating economic feasibility and developing a clear industry policy are top priorities. Survey results point to the key focus and challenge of further demonstrating economic feasibility and clarifying industrial and support policies to address cost concerns if CCS pilot projects and further demonstration will be deployed (Figure 13). Additionally, the survey identified low stakeholder prioritization for the issues of public awareness, which may reflect low expectations for public engagement necessary to get projects developed in China, as well as low awareness of technology at the current stage of development.

Figure 13 Stakeholder ranking* of key factors for CCS development in China

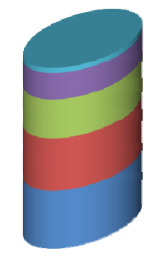

3\% Public awareness

15\% Framework convention

- $22 \%$ Technical feasibility

$28 \%$ Industrial policy

-32\% Economic feasibility

\footnotetext{
*As a percentage of total participant rankings. The prioritisation ranking was determined by asking each stakeholder surveyed to select three important areas, among options listed. Rankings were then represented as a percentage of the total for each priority to demonstrate relative importance for Figures 13, 14,15,17.

Source: CCII Survey
}

In 2009, the China Coal Information Institute (CCII) completed a survey of CCS initiatives in China, prepared for the UK Department of Energy and Climate Change. Results of this survey also indicate strong interest in continued technical and cost research to disseminate best practice and information on CCS activities in China and CCS RD\&D. No further policy or regulation beyond R\&D initiatives has been planned or, to date, publicly announced, but the results from this analysis reinforce the indication of continued interest and involvement from stakeholders in China in ongoing investment in CCS R\&D and demonstration projects.

\section{Technology priorities}

Survey Finding (Figure 14): Post Combustion R\&D viewed as near term priority. Among government, industry and researchers, over $80 \%$ of respondents indicated that post-combustion capture should be the short-term priority, while those from international institutions highlighted the importance of pre-combustion capture (Figure 14). Survey responses suggest that precombustion RD\&D may play an increasingly important role after 2020. 
Figure 14 Stakeholder ranking* on priorities for capture technology

arecombustion $\square$ Post combustion Oxyfuel $\square$ Other

Page | 46

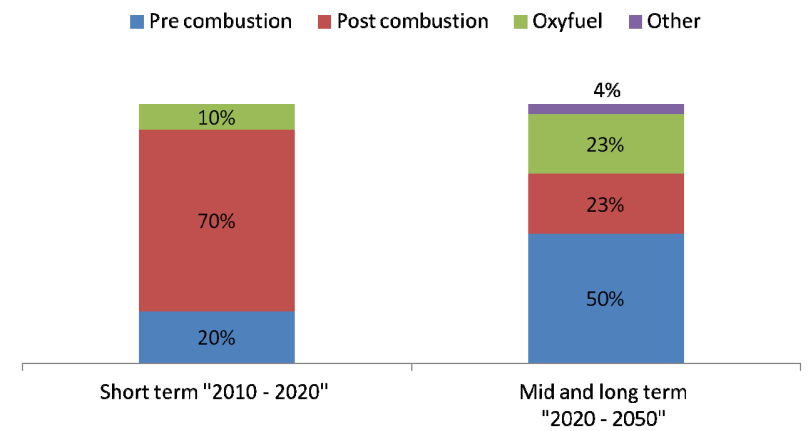

Source: CCII Survey.

According to stakeholder views, post-combustion capture technology should be prioritised. However, pre-combustion capture will likely become the dominant technology in the long term. Current R\&D projects in China focus on post-combustion capture and IGCC with initial plans for future storage. These projects tend to explore utilisation applications. Stakeholders indicate that, until 2020, project demonstration will likely be limited to those projects that provide a reference for government decision-making on future CCUS policy emphasising aspects of utilisation.

Stakeholders suggest that IGCC is not likely to play a significant role in the power industry in the near term, given the pace of existing and planned demonstration plants. As a result, precombustion capture will likely not be a first priority for early development in China, though continued R\&D and demonstration are likely. Furthermore, IGCC relies on complex technologies such as high-temperature purification, oxygen generation and advances in the power, chemicals and heavy machinery sectors, which, when coupled with issues of technology transfer (China's gas turbines, compressors and high purification technology rely on imports), mean that IGCC may not be a strategic or mainstream technology for the power sector in the short-term.

Stakeholders commented current economic feasibility studies of post-combustion capture favour cost structures for post-combustion rather than IGCC and other pre-combustion technologies in China. However, China's comparatively low labour and construction costs suggest that it may be better suited for early commercial demonstration across technologies which may favour more intensive joint international programmes in advanced technologies that can be deployed in OECD countries.

Survey results also suggested a strong interest in further clarifying costs and key economic drivers for CCS in China as a primary step. ${ }^{6}$ Stakeholders suggested there are limited or no publicly available China-specific cost models for $\mathrm{CO}_{2}$ pipeline transportation, and related transportation and site-specific costs are very unclear.

Over $75 \%$ of respondents suggested that China lags far behind in terms of storage technology capability. At present, CCS research is focusing on CCUS pathways (including in the beverage industry) or for EOR/ECBM. The Shenhua Erdos CTL project is currently the only one with plans for storage, with $100000 \mathrm{t} / \mathrm{CO}_{2}$ to be stored annually in a saline aquifer. Potential plans for

6 At present, China is pursuing early demonstrations of pre-combustion and post-combustion capture technologies. However, several discussions with stakeholders, including funding institutions, indicated a lack of clarity in related cost assessments for both technologies in the Chinese context. Results from demonstration projects by Huaneng Group and other state-owned companies are expected to provide important reference for related CCS and domestic climate policy making in China. Meanwhile, wider availability of economic data from pre-feasibility and technical studies of global CCS projects in commercial operation may provide impetus for the Chinese government, industry and researchers to clarify a strategic direction towards CCS development and deployment. 
storage in the GreenGen project post 2015 have been discussed, but lack detailed planning at this point. Information on storage capacity, site selection standards, and site investigation and injection safety were seen as lagging far behind international developments in these areas.

Figure 15 Stakeholder ranking* on $\mathrm{CO}_{2}$ storage priorities and options to 2050

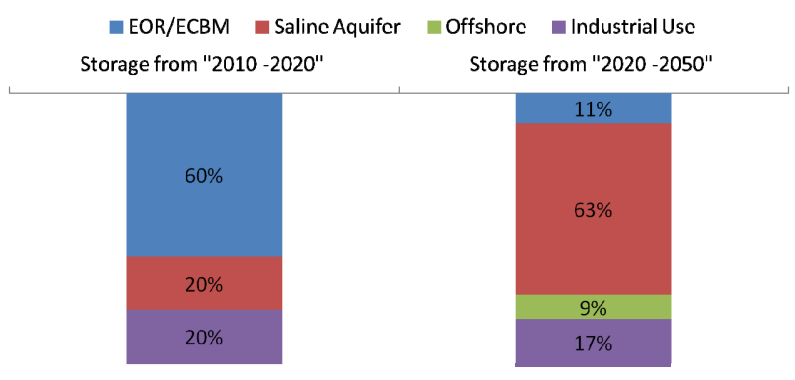

Source: CCII Survey.

Survey Finding (Figure 15): EOR and ECBM seen as key initial drivers for CCUS, though with limited long-term role. Experience in geologic storage of $\mathrm{CO}_{2}$ in China has been closely linked to EOR, which is increasingly discussed for pilot CCS projects, along with ECBM. Given China's focus on CCUS, activities are likely to begin with $\mathrm{CO}_{2}$ resource recycling, including usage in EOR, ECBM and Enhanced Gas Recovery (EGR) and in the chemical and food industries. Many respondents felt that EOR/ECBM/EGR will be a major focus of R\&D and deployment policies between 2010 and 2020 along with new technologies and methods for industrialising $\mathrm{CO}_{2}$ utilisation, however, technical issues and $\mathrm{CO}_{2}$ leakage concerns still remain.

Many stakeholders suggested that, in China, although EOR and ECBM utilisation may be a priority out to 2020, the volume of $\mathrm{CO}_{2}$ utilisation through EOR, ECBM and EGR is rather limited relative to $\mathrm{CO}_{2}$ storage required to meet climate change imperatives (Figure 15). Therefore, storage in saline aquifers was seen as a priority from 2020 to 2050. Stakeholders also suggested that China's offshore storage sites were inadequate for the medium and long term (2020-50), with issues of cost and oceanic impacts. Note, that the views on distribution of storage potential displayed here do not necessarily reflect actual storage capacity in China.

\section{China's industry readiness and leadership in CCS}

Just under $45 \%$ of stakeholders indicated that the overall level of Chinese CCS technology lags behind an advanced international standard (Figure 16). However, almost $37 \%$ felt that China's technical development was on par with an international level, and just over $6 \%$ were of the opinion that China currently surpasses other international technology leaders. Views differ from international organisations and local stakeholders on whether China has the components to develop an industry ecosystem for CCS. Given the increasing development of technical projects and international collaborations on advanced research, it is likely that these views reflect China's existing and growing leadership in the global industry. 
Figure 16 Stakeholder views on industry readiness for CCS in China

Page | 48

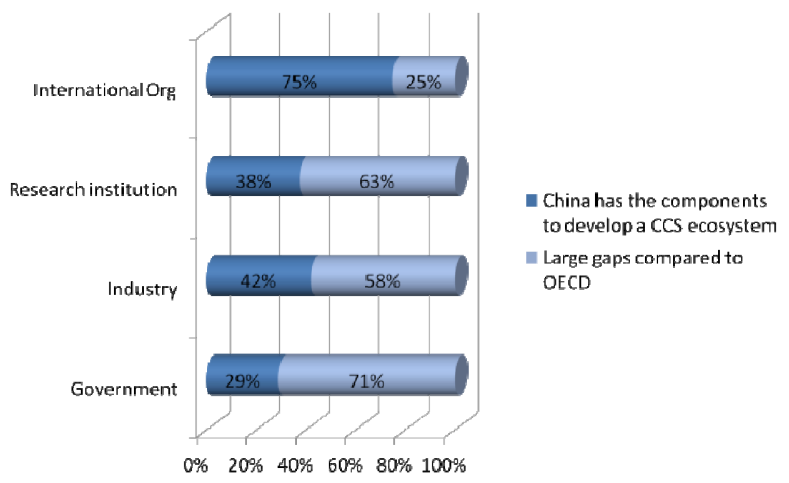

Source: CCII Survey.

Survey Finding (Figure 16): Views differ on China's CCS leadership. Local stakeholders suggested that China's leadership in CCS technology would likely be developed post 2020, citing a late start in R\&D and a lack of funds and policy support. Almost $90 \%$ agreed that China would not be a global leader in CCS technology development until 2020. However, $80 \%$ expressed confidence that China would inevitably become a leader in the long run, with increased Chinese government investment in R\&D and drivers such as international competitiveness of CCS technology and China's status as the largest potential CCS market. These differing views may also reflect lack of a clear global policy direction or agreement both from a policy and technical perspective on a standardised path to CCS development.

Moving forward, stakeholders suggested, China's future CCS projects should prioritise capture technology R\&D (Figure 17), as CCS project feasibility from a cost perspective depends heavily on economic viability of the capture process, with capture efficiency a key priority and closely linked to an acceleration of demonstration projects. Development of policy and planning was seen as a lower priority at this point.

Survey Finding (Figure 17): $\mathrm{CO}_{2}$ storage issues remain dominant concern. Addressing knowledge and technical gaps related to storage issues in China seemed a significant priority for future development overall, with storage-related issues accounting for over $55 \%$ of the total issues to be prioritised and addressed. Similar past studies reflect the importance of clarifying key questions of China's storage capacity.

Figure 17 Stakeholder ranking* on China's near-term CCS technical development priorities

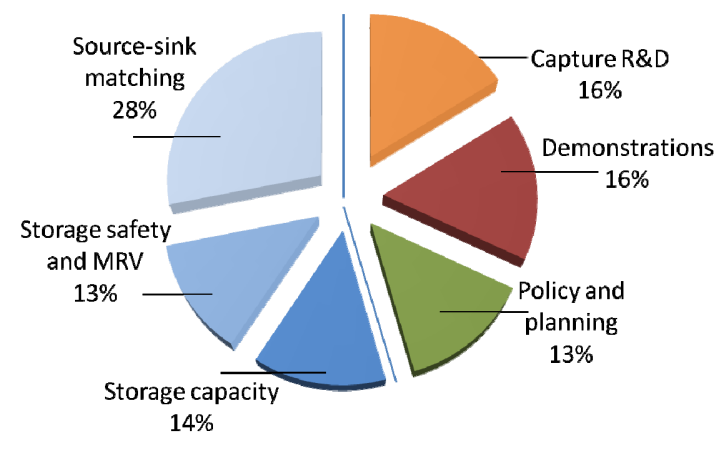

Source: CCII Survey. 


\section{A policy framework relevant to China}

Survey Finding (Figure 18): Policies to drive CCS driven by global and national developments. In their ranking of policy options to promote CCS, $54 \%$ of stakeholders stressed the requirement to establish an international climate change policy to facilitate international financing for CCS demonstration and deployment. Just over $51 \%$ cited the need for a taxation policy to provide related incentives such as a carbon tax, income tax or value-added tax exemptions. To date, carbon taxes have been adopted in several countries to provide enhanced economic feasibility for CCS projects and increase motivation for deployment CCS projects. Stakeholders generally felt that similar policies would be required in China, and smaller groups favoured an industrial development policy mandating related CCS industry development and local municipal or regional policy action. In China, related programmes may be driven or initiated in pilot phases at the local, provincial or regional level, and it will be important to note how these structures may differ or lead the way in providing incentives for low-carbon projects in these areas, initially for potential replication or inclusion into a national mechanism or incentives framework.

Figure 18 Stakeholder ranking on CCS policy priorities

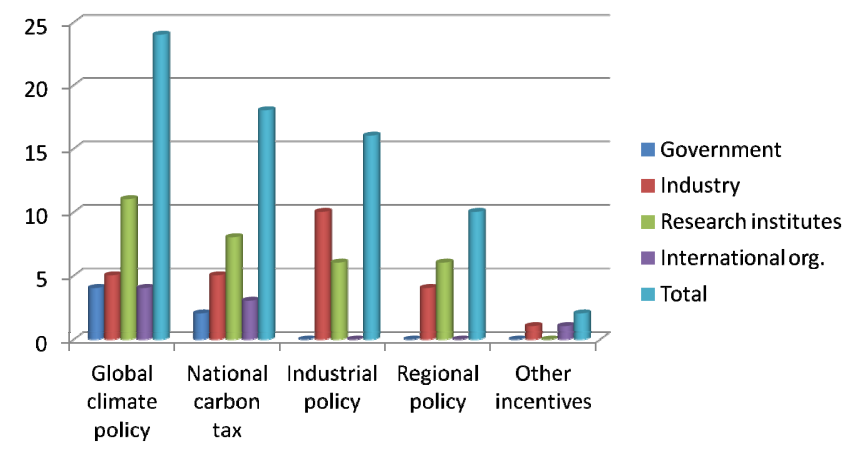

Source: CCII Survey.

Survey Finding (Figure 19): Lack of market and policy mechanisms most significant barrier to new project development. Stakeholders state the lack of policies and incomplete market mechanisms to be largest barriers to CCS deployment. High project risks and unclear project boundaries are also listed as potential main barriers. Such result is well in line with the current general perception that policy and incentive development has not been at the core of China's CCS activity so far, and will in all likelihood require more emphasis in the future if CCS is to develop.

Figure 19 Stakeholder views on barriers to cross-sector co-operation

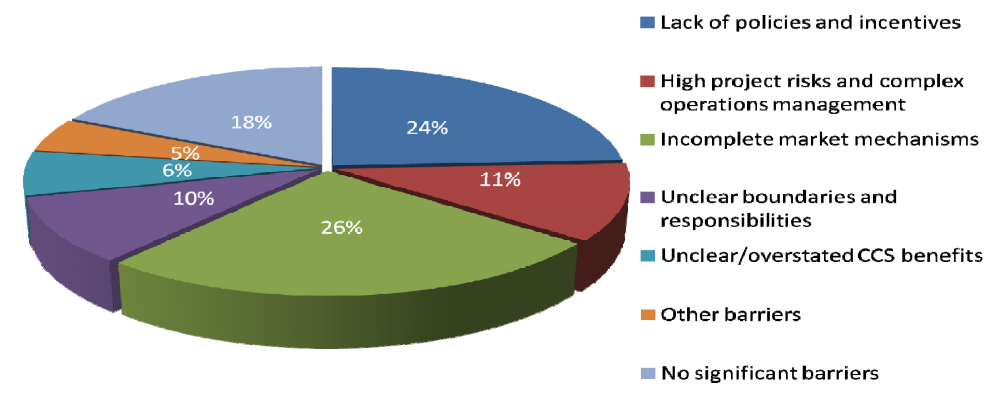

Source: CCII Survey. 


\section{Conclusions and Implications for the Future}

Unless sustained progress is made towards development and deployment of clean and efficient technologies, including CCS, China's continued rapid industrialisation and heavy reliance on coal and other fossil fuels in power generation over the next few decades can lead to substantial increases in greenhouse gas emissions.

The next decade will be critical in reversing the global path of GHG emissions. In all IEA scenarios of energy sector development globally over the next 40 years, CCS plays an important role in the GHG mitigation path and will be required in both a high-renewable and a high-nuclear case for power production. CCS is especially important in industrial applications in which fossil fuels are essential and where there are not so many options for decarbonisation, and GHG emissions reduction targets could only be achieved through efficiency improvements and CCS. Given China's growing share of world energy demand and increasing carbon emissions, the pace of CCS development in China will have a major impact on the overall potential of CCS to play its role in mitigating carbon emissions globally.

The rate of development and the role that CCS will play in China by 2050 will be subject to national policies that consider national energy strategies, technology development goals, sitespecific costs of CCS projects, $\mathrm{CO}_{2}$ storage capacity at a regional level and incentive mechanisms. As China currently commands $48 \%$ of total global coal consumption, options to reduce emissions from coal use will require greater efficiencies across the coal development chain and rapid advances in cleaner coal technologies and CCS. Coupled with other mitigation measures such as, bio-energy combined with CCS (BECCS), with potential for negative emissions, a mix of strategies for cleaner fossil fuels will need to be considered.

\section{China's current strategy and drivers for CCS}

Facilitation and clarification of the links, roles and responsibilities across economic sectors are critical for success on CCS. In China, the following sectors and related policies would need to be engaged in cross-sector co-ordination: $\mathrm{CO}_{2}$ capture, transportation and storage, power projects, chemical (coal chemical) industry, oil, natural gas, coal extraction and geological services. These sectors may experience differing strategic industrial development drivers and will need to balance common and competing interests as they engage in developing CCS or CCUS projects across resource extraction, power generation, transport, industrial utilisation and storage and monitoring processes.

\section{Energy security as a primary driver}

China's primary energy structure is based on abundant proven coal reserves, with limited domestic oil and gas reserves. National and regional economic development and environmental objectives, including a reliance on domestic resources in western provinces, will drive cleaner coal and related CCS technology considerations over the next several decades. China's existing coal-fired power plants and related technical competencies and competitive technical advantages in these areas further support the development of cleaner coal technologies, including CCS.

China continues to focus on CCUS dialogue amid near-term realities that require development of increasingly efficient coal technologies while meeting surging energy demand and energy security priorities. With the majority of China's coal fleet deployed in the past 15 years, China is also likely 
to have considerable potential for retrofitting of CCS onto existing plants and on those being built today. This would however depend on criteria not limited to proximity to storage, physical space at plant, and plant efficiency. This should be considered when setting policy and technical priorities for this and the coming decades.

\section{Technology and industrial development}

China has accumulated a significant level of knowledge on CCS technologies and continues to promote CCS-related R\&D. The priority areas of current R\&D efforts are reduction of costs for CCS technologies (and specifically capture technologies) and reduction of energy consumption during the capture phase across all capture technologies.

China has considerable domestic resources to support the development of the CCS industry. In addition to R\&D efforts, China could deploy policies to support domestic demand for CCS technologies and to position its companies to export technology and/or generate $\mathrm{CO}_{2}$ emissions reduction through CCS projects for the international carbon market. China's policies to promote new technologies typically include: providing capital and other incentives for technology adoption; forcing industry to upgrade power and industrial facilities; and entering into voluntary agreements with industry to adopt technology. In addition, China's lower cost structure and short timelines for project approvals and construction provide the rationale for a positive outlook on CCS in China compared to other parts of the world. However, as mentioned, costs, viability of storage and scale of capacity, along with creating markets and financing channels, are key challenges that need to be addressed for CCS to be feasible in China in the long term.

\section{Considering the environment}

A potential scale of development of CCS in China would require significant use of coal resources to offset the energy penalty for CCS, creating additional pressures on an already high demand for coal. Additional external costs would need to be considered across the coal development chain from extraction to generation, creating heightened environmental stresses and demand for water and other resources necessary for extraction, processing, transportation and utilisation of coal. In China, these resources are already stretched and will require significant added investment in infrastructure to provide for further development, such as water transport to coalrich areas in the traditional dry climates and arid north and northwest coal regions. Any advances in R\&D on minimisation of the energy penalty during carbon capture will have significant impact on resource efficiency, CCS cost and CCS development in China.

\section{Climate policy considerations}

China's actions on CCS are also partly driven by important global climate policy considerations, although except for a recently adopted decision to authorise CCS under the CDM, no other direct international CCS-related policy drivers are yet in place. Facing rapidly rising GHG emissions, China's government is one of the most pro-active in using incentives to stimulate adoption of clean energy technology, and has proven itself a global leader in deploying renewable energy technologies, such as hydroelectric, wind and solar thermal applications. In these efforts, China commonly relies on policy tools such as direct subsidies to project developers, tax credits and special power tariffs. Introduction of carbon taxes and various types of emissions-trading pilot programmes is also under consideration in China as a possible prelude to a domestic carbon market, both of which would establish a Chinese price for carbon. 
Enacting a domestic carbon tax or trading system may provide the fiscal and tax subsidies for power plants equipped with CCS devices. However, current international carbon prices are inadequate to bridge the commercial gap for CCS projects and would have to be combined with other types of public assistance or financing mechanisms to enhance viability of CCS implementation.

\section{Available funding options}

Today CCS activities in China are financed through governmental funding, contributions from state-owned enterprises, loans from state-owned banks, and capacity-building resources from bilateral and multilateral programmes. The energy sector is a strategic priority in China, and the government invests more generously in clean energy technologies than any other government in the world. China's state-owned banking system has demonstrated willingness to lend to CCUS projects. This is significant as few banks globally have been willing to lend to CCS-related projects to date. In addition, provincial and local governments work to create favourable conditions for the uptake of new and efficient technologies. CCS benefits from these conditions but not to the extent possible and desirable due to the lack of targeted governmental programmes on deployment of the technology. There is also intense interest within the international community in supporting China's efforts to reduce GHG emissions through CCS deployment, and China's government has strong potential to raise international funds.

\section{Challenges for the future}

\section{Improving understanding of costs}

Clarification on cost estimates and comparative capture routes relevant to China's case as well as approaches to cleaner coal pathways (including efficiency improvements, retrofits and plant upgrades) will help to clarify strategic priorities towards CCS RD\&D, in both the short and long term.

Based on findings from several studies and perceptions among government and industry, Chinese stakeholders remain consistent in their view that, in the near-term, costs of CCS may be prohibitive to accelerate the types of CCS projects required to meet the IEA BLUE Map Scenario. Estimates that CCS demonstration today would require a carbon price of USD 70 to USD 80 per tonne are also prohibitive. NZEC and other estimates put the cost in China at roughly USD 40 per tonne, but these costs for various technology paths and in a site-specific context need to be further clarified.

\section{Enhancing technology demonstration}

For China, the development and progress of cleaner coal technologies, and subsequent application of coal-to-liquids, coal-to-chemicals and IGCC, as well as the use of $\mathrm{CO}_{2}$ for enhanced oil, and gas and coalbed methane recovery in the next 10 to 20 years, will be important in determining policy direction for related CCS applications. Many of China's initially announced IGCC projects have not proceeded or received necessary government approvals, and challenges remain for the development of coal-to-chemicals and coal-to-liquids technologies, including safety, security and environmental impact across the coal development chain and long-term demand impact on domestic resources (such as water and broader commodities markets). 
Engagement with the private sector for successful demonstration is fundamental for CCS to be deployed. China's investments, as well as other national CCS projects in CCS RD\&D should be optimised by involving and leveraging private sector resources across the industrial and resource development chain to ensure the success of demonstration projects. The explicit design of Chinese programmes to encourage or even require private sector resources, led by state-owned institutions, such as in the case the GreenGen project, is an important step in leveraging private resources. Policy mandates and clear guidelines to industry are necessary.

\section{Storage capacity}

Large uncertainties remain pertaining to viability of long-term storage of $\mathrm{CO}_{2}$ in China's geological structures. Geological storage conditions in relation to site-specific cost analysis need to be addressed to further clarify China's storage capacity and China's overall potential CCS contribution to total global emissions reduction. International co-operation programmes are currently working to develop information and data to facilitate storage estimates, but access to detailed and reliable data in these areas is still an obstacle. One of the arguments for EOR and ECBM development in China may be that this could help to clarify storage information and resource capacity estimates. Related learning and availability of data will be key to any CCUS approach that China pursues, in order to ensure that long-term storage is prioritised, rather than pursued as an end to fossil fuel extraction and promotion of energy security itself.

\section{International co-operation and knowledge sharing}

China provides a low-cost venue for conducting research and development that has already attracted foreign investors and joint ventures in technology development and research. These programmes are continuing and are likely to expand at national, provincial, and industry levels. Strengthening laws to protect intellectual property (IP), jointly developed by foreign and Chinese ventures, would further enhance China's potential to attract foreign investment in research collaboration in related fields. Programmes such as the US-China Clean Energy Research Center have provided clear outlines of how future projects will be developed to maximise the exchange of information from these public-private and international partnerships. Several international co-operative initiatives, development banks and international institutions have sought to develop capacity-building and knowledge-sharing initiatives, including networks, fora, workshops, joint research programmes and collaborative technology-development programmes. The CERC, NZEC and related research programmes have made significant inroads in clarifying and developing best practices in these areas, and future multilateral and bilateral projects should consider the importance of these agreements from the outset.

\section{Future options for financing CCS}

Given inadequate economic incentives for CCS projects in China, additional mechanisms would be required for deployment of CCS. Carbon trading through an emissions trading system will likely constitute a major financing platform for GHG emissions reduction. In 2013, China is planning to launch a domestic carbon market to help meet its carbon intensity targets of $40 \%$ to $-45 \%$ by 2020 compared with 2005 levels and a 17\% reduction over the 2011-15 period. This could provide incentives and generate revenues for CCS technology deployment. New international instruments recently adopted by the UNFCCC decisions in Durban (such as CCS in the CDM, the NAMA framework and the Green Climate Fund created to support mitigation actions in developing countries) along with adaptation and technology transfer as well as the 
Technology Mechanism, would provide new opportunities for financing and incentives for CCS in China.

\section{The Durban Decision: a new window of opportunity for CCS}

Given the CCS potential in China and the technical work that has been done to date, China would clearly benefit from international mechanisms facilitating CCS development such as the CDM, the NAMA framework, the Green Climate Fund, and the Technology Mechanism. Based on cost data for CCS in China, carbon offsets (either through the CDM or NAMAs) could potentially bridge a much higher portion of the commercial cost gap in comparison to developed countries. Differing from a CDM framework, NAMA support may take the form of building capacity, overcoming financing barriers, reducing costs of implementing policies (e.g. feed-in tariffs) and developing and demonstrating advanced technologies like CCS that are not cost-effective today. The Green Climate Fund and the Technology Mechanism would support implementation of NAMAs and will be critical in facilitating CCS development and deployment in China as well as other emerging economies.

\section{Will CCUS projects meet the objectives of CCS?}

There is significant and expanding activity in the area of R\&D into CCUS activities, with a growing number of pilot projects currently underway to provide technical knowledge, training and further research. Existing technical skills and experience with transport, EOR and other CCS-related industries give China a significant competitive advantage in developing demonstration projects.

China's move towards CCUS is underpinned by some early experience with EOR and ECBM projects; however, safety, storage permanence and long-term monitoring will be critical from the start, and doubts remain whether all such utilisation projects are going to meet the inherent objectives of CCS as a climate-change mitigation tool.

Determining the most efficient path for CCS technology development, while evaluating China's context, and understanding the importance of timely action to meet rapidly accelerating carbon emissions is a near-term priority.

\section{Next steps}

CCS development in China is critical for global GHG mitigation based on current scenarios. China is already engaged in an ambitious effort on CCS research, development and demonstration. It has the right conditions and political will to enhance these efforts provided that international support and global climate policy also expand.

Box 6 Next Steps for R\&D

Building on existing work, China may benefit further from directing resources to priority R\&D areas such as:

- Reducing efficiency penalty during capture;

- Assessing storage capacity;

- Assessing opportunities for CCS in industrial applications;

- Testing co-benefits and costs of CCS-EOR and CCS-ECBM; and

- Implementing related pilot projects. 
This would allow China to speed up technological development, position itself as a technology leader and achieve ultimate objectives of reducing costs of CCS.

A focus on policy development conducive to CCS would be a way for China to explore domestic and international incentive mechanisms, facilitating the commercialisation and deployment of this technology. China could start with further evaluating the costs; reviewing fiscal and financial instruments, as well as legal and regulatory frameworks that would need to be adjusted and/or created for CCS. It could also explore how an emerging domestic carbon market could be structured to benefit CCS and other low-carbon technologies. There are also several international mechanisms that could assist China in CCS policy development and implementation. The NAMA framework could be a vehicle for setting national CCS-related GHG targets and receiving support through the mechanisms like the Green Climate Fund and private financing for achieving and over-achieving them.

CCS should not be considered in isolation: local and regional environmental, resources and economic considerations are also important in China. Additional analytical work, potentially done with international experts, could help clarify risks, costs and benefits further and suggest ways for addressing risks and challenges. Continued knowledge sharing, technical exchange and capacity building will be an important part of engagement on CCS in China. 


\section{Abbreviations, acronyms and units of measure}

\section{Abbreviations and acronyms}

Page | 56

ACCA21

ADB

AOSIS

APEC

APP

BAU

BP

btce

btoe

CAGS

CBM

CCAP

CCS

CCUS

CDM

CCII

CDB

CDM

CEFPF

CERC

CERC-ACTC

CIF

CLSF

$\mathrm{CO}$

$\mathrm{CO}_{2}$

$\mathrm{CO}_{2}$-ECBMR

$\mathrm{CO}_{2}$-EOR

$\mathrm{COACH}$

CNOOC

CNPC

COP

CPI

CSLF

CSIRO

CTL

DECC

ECBM

ECUST

EGR

EIB

EOR

ERI

EU ETS

G8
Administrative Centre for China's Agenda for the $21^{\text {st }}$ Century

Asia Development Bank

Alliance of Small Island States

Asia-Pacific Economic Cooperation

Asia-Pacific Partnership

business as usual

British Petroleum

billion tonnes of coal equivalent

billion tonnes of oil equivalent

China Australia Geological Storage of $\mathrm{CO}_{2}$ Project

coalbed methane

Center for Clean Air Policy

carbon capture and storage

carbon capture, utilisation and storage

Clean Development Mechanism

China Coal Information Institute

China Development Bank

Clean Development Mechanism

Clean Energy Financing Partnership Facility

US-China Clean Energy Research Center

CERC's Advanced Coal Technology Consortia

Clean Investment Funds (World Bank)

Carbon Sequestration Leadership Forum

carbon monoxide

carbon dioxide

$\mathrm{CO}_{2}$ for enhanced coalbed methane recovery

$\mathrm{CO}_{2}$ for enhanced oil recovery

Co-operation Action within CCS China-EU

China National Offshore Oil Corporation

China National Petroleum Company

Conference of the Parties (to the UNFCCC)

China Power Investment Corporation

Carbon Sequestration Leadership Forum

Commonwealth Scientific and Industrial Research Organisation (Australia)

coal-to-liquids

Department of Energy and Climate Change (United Kingdom)

enhanced coalbed methane

East China University of Science and Technology

Enhanced Gas Recovery

European Investment Bank

enhanced oil recovery

Energy Research Institute

EU Emissions Trading Scheme

Group of Eight 


\begin{tabular}{|c|c|}
\hline GCF & Green Climate Fund \\
\hline GDP & gross domestic product \\
\hline GEF & Global Environmental Facility \\
\hline GHG & greenhouse-gas \\
\hline GCCSI & Global CCS Institute \\
\hline $\mathrm{Gt} / \mathrm{yr}$ & gigatonnes per year \\
\hline HUST & Huazhong University of Science and Technology \\
\hline IEF & International Energy Forum \\
\hline IGCC & integrated gasification combined cycle \\
\hline IP & intellectual property \\
\hline IPCC & Intergovernmental Panel on Climate Change \\
\hline LBNL & Lawrence Berkeley National Laboratory \\
\hline MEF & Major Economies Forum on Energy and Climate \\
\hline METI & Ministry of Economy, Trade and Industry (Japan) \\
\hline MIT & Massachusetts Institute of Technology \\
\hline MOP & Meeting of the Parties (COP) \\
\hline MOST & Ministry of Science and Technology (China) \\
\hline $\mathrm{MtCO}_{2} / \mathrm{yr}$ & Megatonne of $\mathrm{CO}_{2}$ per year \\
\hline Mtoe & million tonnes of oil equivalent \\
\hline NAMA & nationally appropriate mitigation actions \\
\hline NDRC & National Development and Reform Commission \\
\hline NER & New Entrants Reserve (of the EU ETS) \\
\hline NSFC & National Science Foundation of China \\
\hline NZEC & UK-China Near Zero Emissions Coal initiative \\
\hline OPEC & Organization of the Petroleum Exporting Countries \\
\hline PPP & public-private partnerships \\
\hline$R \& D$ & research and development \\
\hline RD\&D & research, development and demonstration \\
\hline RITE & Research Institute of Innovative Technology for the Earth (Japan) \\
\hline SAWS & State Administration of Work Safety (China) \\
\hline SERC & State Electricity Regulatory Commission of China \\
\hline SINOPEC & China Petroleum and Chemical Corporation \\
\hline SOE & state-owned enterprise \\
\hline $\mathrm{STRACO}_{2}$ & Support to Regulatory Activities for Carbon Capture and Storage \\
\hline TEC & Technology Executive Committee \\
\hline TPRI & Thermal Power Research Institute \\
\hline$t / y r$ & tonne(s) per year \\
\hline UNFCCC & United Nations Framework Convention on Climate Change \\
\hline UNDP & United Nations Development Programme \\
\hline UNEP & United Nations Environment Programme \\
\hline UNIDO & UN Industrial Development Organization \\
\hline US DOE & US Department of Energy \\
\hline WEC & World Energy Council (WEC) \\
\hline WEO & World Energy Outlook \\
\hline
\end{tabular}




\section{Units of measure}

GJ

Gt

$\mathrm{Km}$

Page | 58

$\mathrm{kWh}$

$\mathrm{m}$

Mt

MW

ppm gigajoule

gigatonne

kilometre

kilowatt hour

metre

megatonne

megawatt

parts per million 


\section{References}

ADB (Asia Development Bank) (2009), People's Republic of China: Carbon dioxide capture and storage demonstration, strategic analysis and capacity strengthening, ADB Technical Assistance Program 7286, Asia Development Bank, Manila, the Philippines.

ADB (2010), Tianjin Integrated Gasification Combined Cycle Power Plant Project, Project Administration Memorandum, Asia Development Bank, Tianjin, People's Republic of China.

The Administrative Centre for China's Agenda 21, MOST, (2011) Technology Roadmap Study on Carbon Capture, Utilization and Storage in China, Beijing, September 2011.

Asia Society (2009), A Roadmap for U.S.-China Collaboration on Carbon Capture and Sequestration; www.asiasociety.org/policy-politics/environment/roadmap-us-china-collaboration-carbon-captureand-sequestration.

Brookings (2010), Carbon Capture and Sequestration, Briefing Paper, Doha Carbon and Energy Forum, Energy Security Initiative, The Brookings Institution.

CAGS (China Australia Geological Storage of $\mathrm{CO}_{2}$ Project) (2011), "Proceedings and Presentations from the $2^{\text {nd }}$ CCS Summer School", The China-Australia Geological Storage of $\mathrm{CO}_{2}$, www.cagsinfo.net/

Campbell, Richard (2010), China and the United States-A Comparison of Green Energy Programs and Policies, www.fas.org/sgp/crs/row/R41287.pdf

CCAP (Center for Clean Air Policy) (2009), Nationally Appropriate Mitigation Actions by Developing Countries: Architecture and Key Issues, Center for Clean Air Policy, Washington D.C.

CERC (US-China Clean Energy Research Center) (2011), Joint Work Plan for Research on Clean Coal Including Carbon Capture and Storage, U.S.-China Clean Energy Research Center, www.us-chinacerc.org/pdfs/US/CERC-Coal_JWP_english_OCR_18_Jan_2011.pdf

Chen, W. and R. Xu (2010), "Clean coal technology development in China", Energy Policy, 38(5): 2123-2130

The Climate Group China (2011), Delivering Low Carbon Growth: A Guide to China's $12^{\text {th }}$ Five Year Plan, March 2011, Beijing

The Climate Group China (2010), CCS: Towards Market Transformation in China, Briefing Paper, www.theclimategroup.org/_assets/files/China-CCS-briefing_2.pdf

China Climate Change Info-Net website, (2010), "Promising opportunities for the promotion of Carbon Capture and Storage Technologies," July 22, 2010, www.ccchina.gov.cn/cn/NewsInfo.asp?Newsld=24806

China Coal Industry.Net, (2011) "Shenhua CCS Demonstration Project successfully produced high purity $\mathrm{CO}_{2}$ liquid," January 5, 2011, www.coalchina.org.cn/page/info.jsp?id=44268

China Energy Net (2009), "CCS Knowledge - An Introduction to CCS Technology," 6 November 2009 www.china5e.com/show.php?contentid=55063.

China State Council (2008), China's policies and actions on climate change, White Paper, State Council Information Office, www.china.org.cn/government/news/2008-10/29/content_16681689.htmg

COACH, (Co-operation Action within CCS China-EU) (2009), EU-China Cooperative action on CCS, Cooperation Action within CCS China-EU, www.co2-coach.com

CSLF, (2011) Carbon Sequestration Leadership Forum Conference Proceedings, Beijing, http://www.cslforum.org/meetings/beijing2011/index.html

DECC (Department of Energy and Climate Change) (2011), “Chinese advanced power plant carbon capture options", Department of Energy and Climate Change, United Kingdom, www.decc.gov.uk 
Downs, E. (2011), Inside China, Inc: China Development Bank's Cross-Border Energy Deals, The Brookings Institution, www.brookings.edu/papers/2011/0321_china_energy_downs.aspx

Duke Energy News (2011), "Duke Energy and ENN Group Sign EcoPartnership at U.S. State Department", 10 May 2011, www.duke-energy.com/news/releases/2011051001.asp

ERI (2009), “China's Low Carbon Development Pathway by 2050: Scenario Analysis of Energy Demand and Carbon Emissions", Energy Research Institute, Beijing, People's Republic of China.

ERI (2011d), China Wind Energy Development Roadmap 2050, (Oct, 2011) Beijing, Paris, http://www.iea.org/papers/roadmaps/china_wind.pdf

Finkenrath, M. (2011), "Cost and Performance of Carbon Dioxide Capture from Power Generation", IEA/OECD Working Paper, International Energy Agency, Paris.

Fletcher, J. and Sun Qingyun (2004), Shenhua Investment in Direct Coal Liquefaction, Twenty-first Annual International Pittsburgh Coal Conference, 13-17 September 2004, Osaka, Japan

Forbes, S. and S. Hanson (2009), Governments Investing in CCS Demonstrations, World Resources Institute, Washington D.C.

GEF (Global Environmental Facility) (2008), Carbon Dioxide Capture and Storage: Conclusions and Recommendations from a STAP Brainstorming Meeting, Scientific and Technical Advisory Panel, 17-18 October 2007, GEF/C.33/Inf.14, Global Environmental Facility www.thegef.org/gef/sites/thegef.org/files/documents/GEF.C.33\%20Inf.14.pdf

GEF (2011), Renewable $\mathrm{CO}_{2}$ CCS Project in San Paulo State, Global Environmental Facility, www.adaptationlearning.net/project/tt-pilot-gef-4-renewable-co2-capture-and-storage-sugarfermentation-industry-sao-paulo-state

Hart, C. and H. Liu (2010), “Advancing carbon capture and sequestration in China: a global learning laboratory", China Environment Series, Issue 11

Harvey, F. (2011), "World Bank warns of 'failing' international carbon market”, The Guardian, 1 June 2011.

IEA (International Energy Agency) (2009a), Cleaner Coal in China, International Energy Agency, Paris.

IEA (2009b), Technology Roadmap: Carbon Capture and Storage, International Energy Agency, Paris.

IEA (2010a), Coal and Oil Data, International Energy Agency, Paris.

IEA (2010b), Energy Technology Perspectives, International Energy Agency, Paris.

IEA (2010c), Carbon Capture and Storage: Full Scale Demonstration Progress Update, International Energy Agency, Paris.

IEA (2010d), Carbon Capture and Storage: Progress and Next Steps, IEA/CSLF Report to the Muskoka 2010 G8 Summit, International Energy Agency, Paris.

IEA (2011a), World Energy Outlook, International Energy Agency, Paris.

IEA (2011b), IEA Coal Information, International Energy Agency, Paris.

IEA (2011c), Medium Term Market Report, International Energy Agency, Paris

IEF (International Energy Forum) (2009), GreenGen Project: Update and Outlook, International Energy Forum.

IPCC (Intergovernmental Panel on Climate Change) (2005), Special Report on Carbon Dioxide Capture and Storage, Intergovernmental Panel on Climate Change, Cambridge University Press, New York, USA.

LBNL (Lawrence Berkeley National Laboratory ) (2011), China's energy and carbon emissions: outlook to 2050, Lawrence Berkeley National Laboratory, http://china/lbl.gov/publications/2050 -outlook 
Liu, Hengwei and K.S. Gallagher (2010), "Preparing to Ramp up Large-scale CCS Demonstrations: An Engineering-economic Assessment of $\mathrm{CO}_{2}$ Pipeline Transportation in China", International Journal of Greenhouse Gas Control.

Liu Zhenyu et al. (2010), Coal liquefaction technologies: Development in China and challenges in chemical reaction engineering, Chemical Engineering Science 65.

McKinsey (2008), Carbon Capture and Storage: Assessing the Economics, McKinsey \& Co., Page |61 ww1.mckinsey.com/clientservice/sustainability/pdf/CCS_Assessing_the_Economics.pdf

MEF (Major Economies Forum on Energy and Climate) (2009), Technology Action Plan: Carbon Capture, Use, and Storage, Major Economies Forum on Energy and Climate, www.majoreconomiesforum.org/images/stories/documents/MEF\%20CCUS\%20TAP\%2011Dec2009.pdf

Michener, A. (2011), CCS Challenges and Opportunities for China, Clean Coal Centre, United Kingdom

MIT (Massachusetts Institute of Technology) (2007), The Future of Coal: Options for a Carbon Constrained World, Massachusetts Institute of Technology, Cambridge, Massachusetts, USA.

Morse, R. et al. (2009), The Real Drivers of Carbon Capture and Storage in China and Implications for Climate Policy, Program on Energy and Sustainable Development, Working Paper \#88, Stanford University, USA.

MOST, Ministry of Science and Technology, (2011) Carbon Capture, Utilization and Storage, Technology Development in China, Beijing, September, 2011

MOST, (2007) China's Scientific \& Technological Actions on Climate Change, Ministry of Science and Technology, People's Republic of China www.ccchina.gov.cn/WebSite/CCChina/UpFile/File199.pdf

MOST (2008), Notice on Application Guide on CCS Key Projects, Resource and Environment Office, 863 program, Ministry of Science and Technology, People's Republic of China, 22 February 2008.

NDRC (National Development and Reform Commission) (2007), China's National Climate Change Programme, National Development and Reform Commission, People's Republic of China, www.china.org.cn/english/environment/213624.htm

NRDC (2009), Identifying Near-Term Opportunities for Carbon Capture and Sequestration (CCS) in China, National Development and Reform Commission, People's Republic of China.

Peng, Sizhen (2011), The Administrative Centre for China's Agenda 21, MOST, Presentation at CSLF Technical Meeting; 19 May 2011, Edmonton, Canada.

People's Government of Hainan Province Net, (2009), "CNOOC's production of carbon dioxide degradable plastic items" February 5, 2009, www.hainan.gov.cn/data/news/2009/02/69754/

Pew Charitable Trusts (2010), Who's Winning the Clean Energy Race? Growth, Competition and Opportunity in the World's Largest Economies, G-20 Clean Energy Factbook.

Reed, M.E. (2007), National Energy Technology Laboratory, 2007 Gasification Technology Conference, October 17, 2007

Ren Xiangkun et al. (2009), " $\mathrm{CO}_{2}$ Emissions in the Process of Coal Chemical Industry and Analysis of the Research Status of CCS Technology", Shenhua Science and Technology, 7(2),Shenhua Ningxia Coal Industry Group, Yinchuan City, China.

Riahi, K. et al. (2004), "Technological learning for carbon capture and sequestration technologies", Energy Economics 26, pp. 539-564, Elsevier B.V.

Shen Guoliang et al. (2009), Use of Carbon Dioxide in Chemical Industry, Proceedings of Workshop on Emissions Reduction and Utilization as Resources, Qingdao City, China.

Sina.Net, 2010, "China Power Investment Corporation invested 10 Million RMB in Carbon Capture Project," January 22, 2010, Sina Net, http://finance.sina.com.cn/roll/20100122/03017289497.shtml 
Sino-Italy Cooperation on Clean Coal Technologies (2011), Proceedings of the $1^{\text {st }}$ Meeting on Research and Development Activities on Carbon Capture and Storage, Beijing, People's Republic of China.

Stanford University's Global Climate \& Energy Project International Workshop (2005): Exploring the Opportunities to Integrate Advanced Coal Technologies with Carbon Capture and Storage in China, Beijing, August 22, 2005

Page | 62 Stanway, D. (2011), China's carbon market plans, Thomson Reuters.

State Council Information Office (2008), China's Policies and Actions for Addressing Climate Change, http://www.china.org.cn/government/news/2008-10/29/content_16681689_6.htm

Stern, N. (2006), Stern Review on the Economics of Climate Change, London.

Sun, Q. (2008), CTL Development in China, Washington Coal Club Briefing, U.S.-China Energy Center, West Viriginia University.

US DOE (U.S. Department of Energy) (2010), US China Clean Energy Research Center Cooperation Progress Report http://fossil.energy.gov/international/International_Partners/China.html

WRI (2010), CCS in China: Toward an Environmental, Health and Safety Regulatory Framework, World Resources Institute, Washington D.C.

Wu Xiuzhang (2010), "Shenhua Direct Coal Liquefaction Project: From R\&D to Commercial Demonstration", JPEC Presentation from Conference Proceedings, May 26, 2010.

Xie Zhenhua (2011), Opening Statement, NDRC-Asia Development Bank International Conference on CCUS, Beijing, People's Republic of China.

Xu Shisen and Gao Shiwang, (2006), Near Zero Emission Coal Based Power Generation in China: GreenGen Project, JCoal.org, Japan

Yan Jiabao et al. (2005), "Recovery Technique and Application Prospects of $\mathrm{CO}_{2}$ ", Applied Chemical Industry, 34(2), Shaanxi Research Design Institute of Petroleum and Chemical Industry, Xi'an City, People's Republic of China.

Ye Jianping et al. (2007), "Micro-pilot test for enhanced coalbed methane recovery by injecting carbon dioxide in south part of Qinshui Basin", Acta Petrolei Sinica, 20(4), Chinese Petreleum Society, Beijing, People's Republic of China.

Yingying, Ai (2010), Research on Efficient Adsorbents for Low Concentration $\mathrm{CO}_{2}$ Capture, Dissertation for Master Degree, Dalian University of Technology, Dalian City, People's Republic of China.

Zhang, J. (2010), Overview of CCUS Activities in China, Proceedings from CAGS Workshop II, ACCA21, Beijing, People's Republic of China. http://www.cagsinfo.net/pdfs/workshop2/Session-1/OverviewCCUS-Activities-China.pdf

Zhang Weidong, Zhang Dong and Tian Kezhong (2009), Carbon Capture and Sequestration Technology, Sina-Global Energy, 14(11), China Energy Research Society.

Zhao Lifeng et al. (2009), Reoprt on Joint Workshop on Promoting the Development and Deployment of IGCC/Co-Production/CCS Technologies in China and the United States, Cambridge, Mass.

Zhu, Lei, Fan, Ying, (2011), A real options-based CCS investment evaluation model: Case study of China's power generation sector, Applied Energy, Elsevier. 


\section{iea}

\section{International Energy Agency}
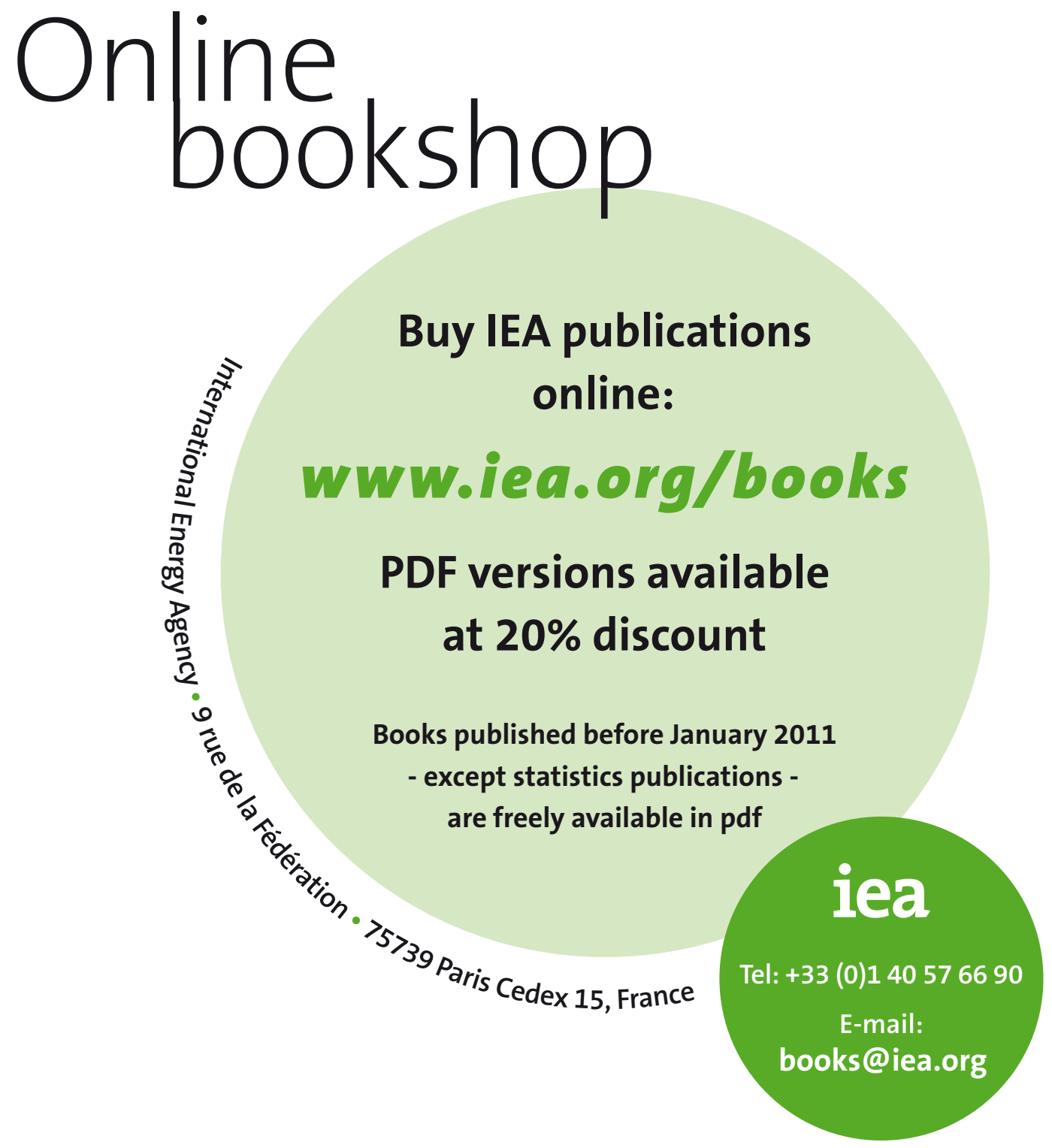